\title{
Status Report on Efforts to Enhance Instrumentation to Support Advanced Test Reactor Irradiations
}

\author{
J. L. Rempe \\ D. L. Knudson \\ J. E. Daw \\ K. G. Condie
}

March 2011

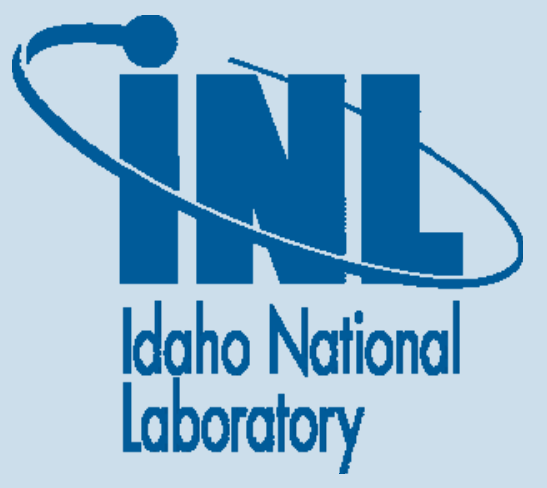




\title{
Status Report on Efforts to Enhance Instrumentation to Support Advanced Test Reactor Irradiations
}

\author{
J. L. Rempe, D. L. Knudson, J. E. Daw, and K. G. Condie
}

March 2011

Idaho National Laboratory

Idaho Falls, Idaho 83415

Prepared for the

U.S. Department of Energy

Office of Nuclear Energy

Under DOE Idaho Operations Office

Contract DE-AC07-05ID14517 



\begin{abstract}
The Department of Energy (DOE) designated the Advanced Test Reactor (ATR) as a National Scientific User Facility (NSUF) in April 2007 to support U.S. leadership in nuclear science and technology. By attracting new research users - universities, laboratories, and industry - the ATR NSUF facilitates basic and applied nuclear research and development, further advancing the nation's energy security needs. A key component of the ATR NSUF effort is to prove new in-pile instrumentation techniques that are capable of providing real-time measurements of key parameters during irradiation. To address this need, an assessment of instrumentation available and under-development at other test reactors was completed. Based on this review, recommendations were made with respect to what instrumentation is needed at the ATR; and a strategy was developed for obtaining these sensors. In 2009, a report was issued documenting this program's strategy and initial progress toward accomplishing program objectives. In 2009, a report was issued documenting this instrumentation development strategy and initial progress toward accomplishing instrumentation development program objectives. This document reports progress toward implementing this strategy in 2010.
\end{abstract}


INL/EXT-11-21231 


\section{CONTENTS}

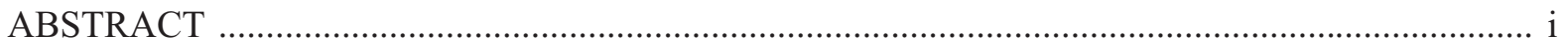

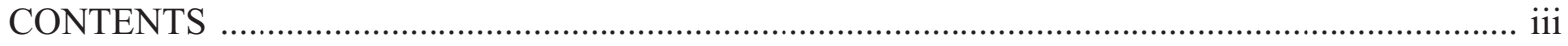

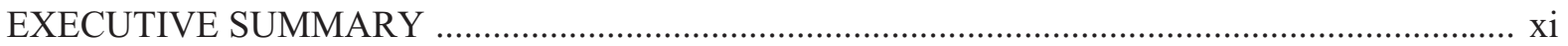

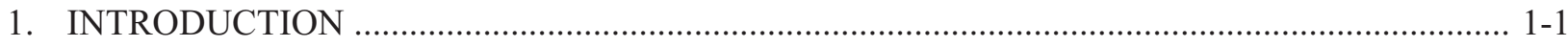

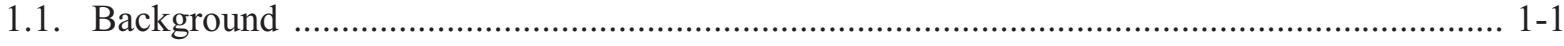

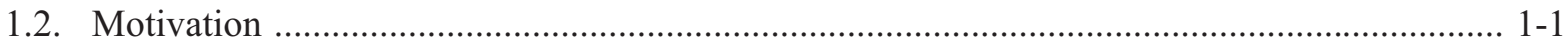

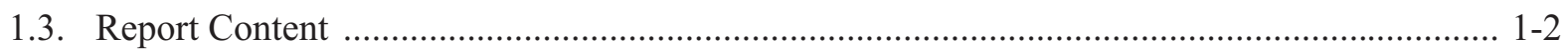

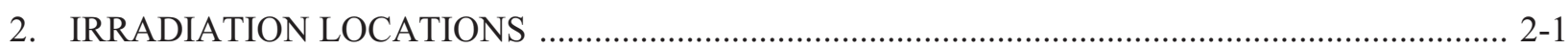

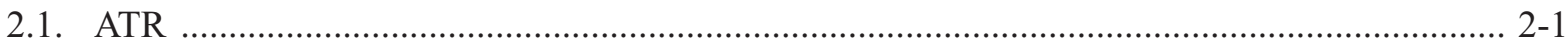

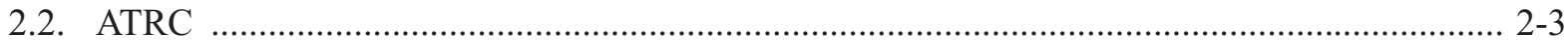

3. INTERNATIONAL DEVELOPMENT EFFORTS ….......................................................... 3-1

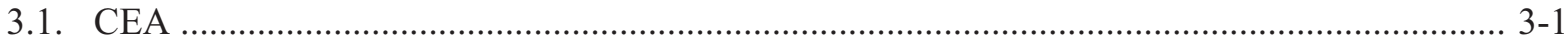

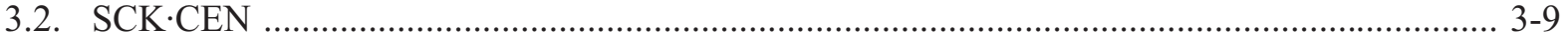

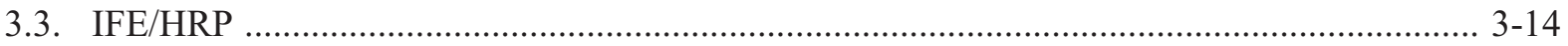

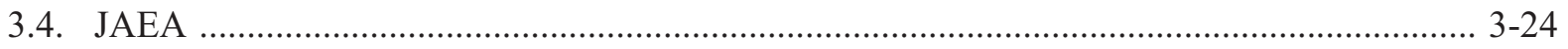

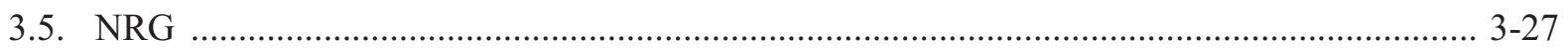

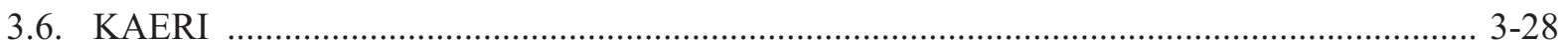

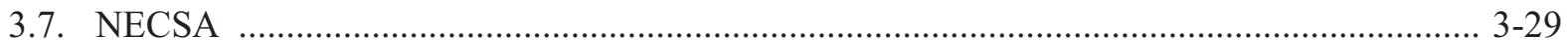

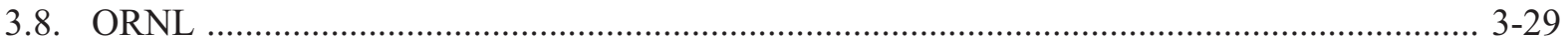

4. PATH FORWARD FOR ENHANCED ATR INSTRUMENTATION ....................................... 4-1

4.1. Motivation/Justification for Investment …......................................................................... 4-2

4.2. Currently Available ATR Instrumentation ........................................................................ 4-3

4.3. Current Prioritization for Instrumentation Development ...................................................... 4-5

5. DEVELOPMENT - IDAHO NATIONAL LABORATORY ….................................................... 5-1

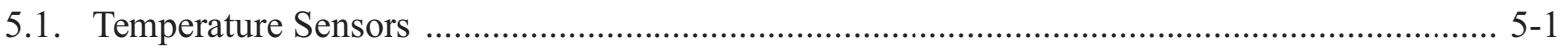

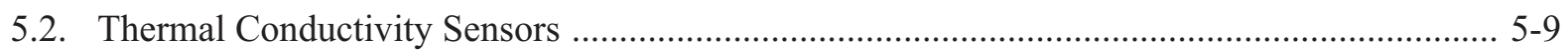

5.3. Elongation/Deformation/Creep/Swelling ……................................................................. 5-12

5.4. Direct Current Potential Drop (DCPD) .............................................................................. 5-20

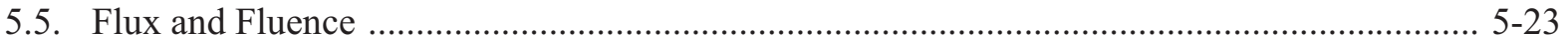

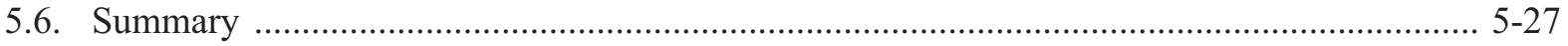

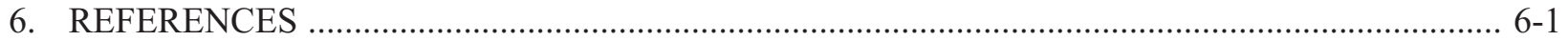


INL/EXT-11-21231 


\section{FIGURES}

ES-1. Current schedule for ATR NSUF advanced instrumentation research and development. .............xiv

ES-2. Quartz tube containing four melt wires in separated compartments. ........................................... xvii

ES-3. HTTL setup to anneal and measure electrical resistivity of SiC temperature monitors. ................xvii

ES-4. HTTL setup for evaluating new LVDTs jointly developed with IFE/HRP. ...............................xvii

ES-5. Creep test rig positioned in autoclave for testing ........................................................................

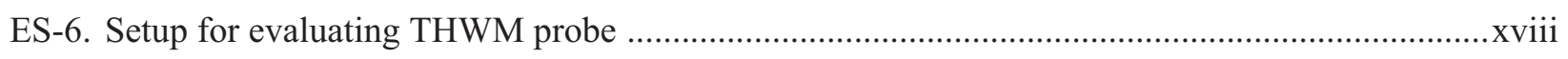

ES-7. Specialized fixturing for flux detector evaluation installed at ATRC . ........................................ xix

2-2. Schematic diagrams illustrating ATR irradiation locations. ................................................... 2-2

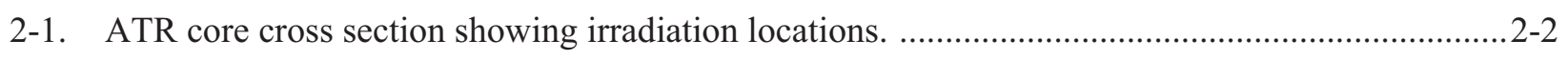

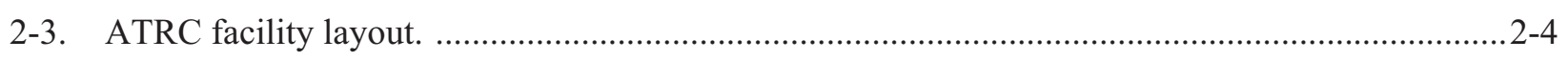

2-4. Sample /sensor positioning equipment and insertion locations at ATRC. .................................2-5

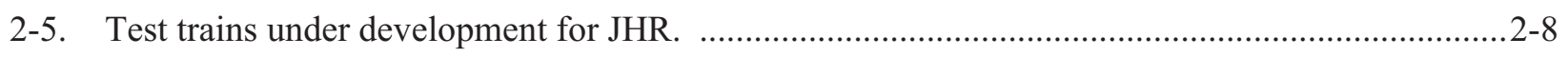

3-1. In-pile instrumentation needs for future irradiation experiments. ............................................. $3-1$

3-2. Current INSNU in-pile instrumentation research .............................................................. $3-2$

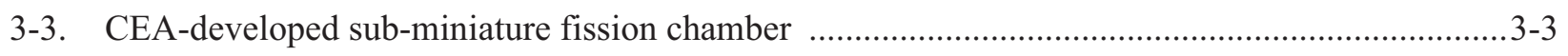

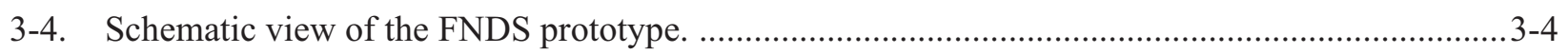

3-5. THERMEX experiment device: stainless steel capsule (1), graphite barrel (3) filled with pure copper (2), additional electric heating elements (4), thermocouples (5). ............................ 3-6

3-6. Wiring schematic for LVDTs using the five-wire method. .................................................... 3-7

3-8. CEA counter-pressure sensor for detecting fission gas release amount. .................................... 3-8

3-7. Proposed sensor for detecting elongation and diameter changes in OSIRIS testing. ..................... 3-8

3-9. CEA fission gas release pressure and composition detection (a) sensor and (b) system

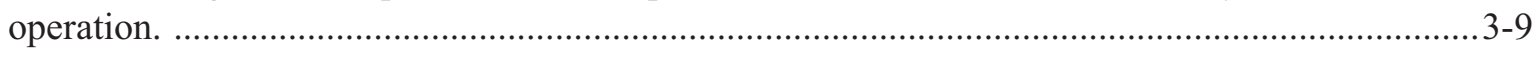

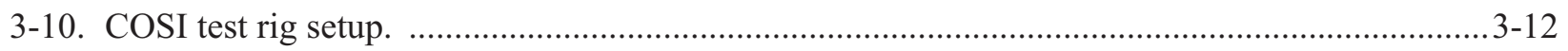

3-11. Representative results from COSI-Change in loss for the STU2 fiber (22 days corresponds

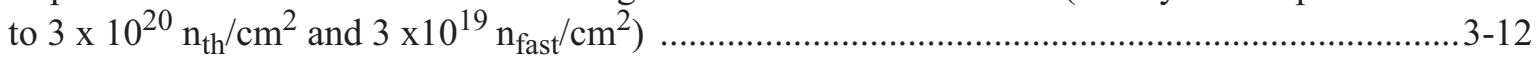

3-12. Optical fiber based elongation detection sensor developed by CEA and SCK-CEN. .................3-13

3-13. Schematic of tensile test module: (1) gas line, (2) pneumatic loading unit, (3) firm specimen fixing point, (4) specimen, (5) movable specimen fixing point, (6) LVDT plunger and (7) LVDT holder.

3-14. Tensile test rig for BR-2 irradiations: (a) simplified layout and operational features including necessary instrumentation; and (b) final assembly of test module prior to installation in the test rig.

3-15. High temperature calibration device of the pneumatic loading unit. 
3-17. Fuel thermal conductivity derived from fuel centerline temperature measurements.

3-18. Thermal expansion thermometer.

3-19. Fuel stack elongation detector.

3-20. Pressure gauge

3-21. HRP fuel pellet cladding interaction/crud deposition test rig (a) with diameter gauge (b).

3-22. Fuel rod diameter traces showing cladding creep down and crud deposition.

3-23. Crack growth test rig

3-24. I-I type irradiation unit with weight loading equipment $3-26$

3-25. Signals obtained with optical fiber detector and $\mathrm{Au}$ foil activation methods.

3-26. Electrical resistivity technique applied over a range of irradiation temperatures.

4-1. Current schedule for ATR NSUF advanced instrumentation research and development.

5-1. Quartz tube containing four melt wires in separated compartments.

5-2. Setup to anneal and measure electrical resistivity of $\mathrm{SiC}$ temperature monitors.

5-3. Electrical resistivity measurement comparison on $\mathrm{SiC}$ monitors irradiated at $300^{\circ} \mathrm{C}$.

5-4. Representative thermocouple response in INL $1200^{\circ} \mathrm{C}$ tests.

5-5. HTIR-TCs installed in AGR-1 test capsule and representative HTIR-TC and Type N data during ATR irradiation.

5-6. A typical multi-sensor pulse/echo ultrasonic thermometry system and 'notched' sensor.

5-7. Photonic bandgap fiber.

5-8. In-pile thermal conductivity methods under evaluation (see text for variable definitions).

5-9. Setup for evaluating the two thermocouple method.

5-10. Setup for evaluating transient hot wire needle probe.

5-11. Comparison of THWM needle probe results obtained at various power levels for (a) fused silica and (b) Inconel 625.

5-12. LVDT components (a) and operation (b).

5-13. LVDT response during long duration (1000 hour) test at $500{ }^{\circ} \mathrm{C}$ : (a) LVDTs originally provided by nuclear grade vendors (LVDTs designated with an "A" were provided by IFE/ HRP; and (b) developmental LVDTs provided IFE/HRP.

5-14. Tensile test module irradiated in the BR-2 ( $a$ and $b$ ) with schematic of tensile test module (c) that includes: (1) gas line, (2) pneumatic loading unit, (3) firm specimen fixing point, (4) specimen, (5) movable specimen fixing point, (6) LVDT plunger and (7) LVDT holder.

5-15. Creep test rig positioned in autoclave for testing. $5-16$

5-16. Typical setup for detecting sample length changes with an ultrasonic transducer. $5-17$

5-17. Candidate magnetostrictive sleeve designs investigated. 
5-18. UT testing equipment evaluating specimen attached to acoustic horn and $30 \mathrm{ft}$ wave guide.

5-19. Comparison of waveforms from 4 and 6 inch specimens heated at $525^{\circ} \mathrm{F}\left(302^{\circ} \mathrm{C}\right)$.

5-20. Diagram of autoclave setup for ultrasonic evaluations.

5-21. New autoclave system installed at HTTL for ultrasonics evaluations.

5-22. Crack growth test rig.

5-23. Cutaway 3-D rendering of an in-core contains two. Note that this design is for the MITR, but it is anticipated that a similar concept would easily fit within an ATR PWR loop.

5-24. Isometric and dimensioned drawing of proposed crack growth specimen.

5-25. Representative activation foils and wires.

5-26. Representative real-time flux sensors evaluated at ATRC.

5-27. Positioning of activation detector apparatus in the ATRC NW IPT Test Train (the inset photo shows the entire test train assembly).

5-28. Specialized fixturing for flux detector evaluation in the NW LIPT (left) and EGTs for evaluations in six N-16 positions (right) 
INL/EXT-11-21231 


\section{TABLES}

ES-1 Instrumentation available at ATR and proposed advanced technologies................................ii

ES-2 Status of ATR NSUF sensor development and evaluation efforts. ........................................

2-1 Comparison of design parameters in selected operating test reactors. ${ }^{8}$.............................. 2-6

3-1 Single mode and multimode optical fibers tested in OSIRIS COSI test............................. $3-11$

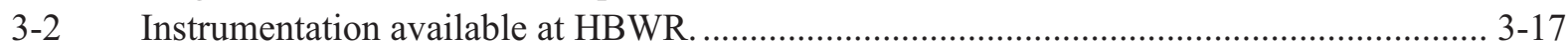

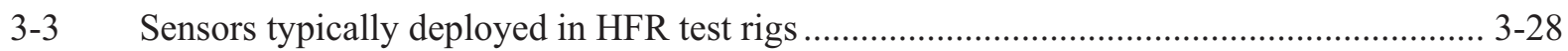

4-1 Funding sources and potential collaborators for INL instrumentation elements................. 4-3

4-2 Instrumentation available at ATR and proposed advanced technologies............................. 4-4

4-3 Status of ATR NSUF sensor development and evaluation efforts. ..................................... 4-6 
INL/EXT-11-21231 


\section{EXECUTIVE SUMMARY}

The Department of Energy (DOE) designated the Advanced Test Reactor (ATR) at the Idaho National Laboratory (INL) as a National Scientific User Facility (NSUF) in April 2007 to support the growth of nuclear science and technology in the United States (US). By attracting new research users - universities, laboratories, and industry - the ATR NSUF facilitates basic and applied nuclear research and development, further advancing the nation's energy security needs. A key component of the ATR NSUF effort is development of new in-pile instrumentation to support irradiation testing. In addition to ATR NSUF needs, it is recognized that new in-pile instrumentation enhances the ATR's ability to attract new customers from the commercial power, defense, and manufacturing sectors. In 2008, a strategy was developed for obtaining these sensors. In 2009, a report was issued documenting this instrumentation development strategy and initial progress toward accomplishing instrumentation development program objectives. This document is an updated version reporting progress toward implementing this strategy. It is anticipated that this report will continue to be updated in future years.

As noted within this document, the ATR is unique with respect to irradiation testing capabilities. The test volumes and flux levels in each of its irradiation locations [Static Capsules, Hydraulic Shuttle Irradiation System (HSIS), Instrumented Lead Tests, and Pressurized Water Reactor (PWR) loops] are unsurpassed by few, if any, test reactors in the world. Despite its long history for developing highly specialized instrumentation to meet demands of customers conducting unique tests in one-of-a-kind test facilities, INL instrumentation research funding decreased significantly in the 1980s when large nuclear test facility programs ended.

In 2008, the ATR NSUF initiated an effort that allowed INL to develop unique instrumentation required for ATR irradiations. As part of this effort, a review was first completed to identify instrumentation available to users at other materials and test reactors (MTRs) located in the US and abroad. Table ES-1 summarizes results from this review. The column labeled "Technology Available at ATR" indicates the types of sensors currently available to ATR users. The column "Proposed Advanced Technology" includes two categories: "Available at Other Reactors," which identifies several technologies employed at other test reactors that could be adapted to enhance ATR instrumentation capabilities; and "Developmental," which lists developmental or nonnuclear technologies that could be used in ATR irradiation tests. Technologies listed in this column are considered to be less "ready" for implementation. Blue text denotes the instrumentation currently being pursued as part of instrumentation research activities, and red text denotes new or enhanced instrumentation recently developed and deployed by INL in the ATR. It should be noted that many of these instrumentation development efforts are in collaboration with other organizations. 
Table ES-1. Instrumentation available at ATR and proposed advanced technologies.

\begin{tabular}{|c|c|c|c|c|c|c|}
\hline \multirow[b]{2}{*}{ Parameter } & \multicolumn{3}{|c|}{ Location } & \multirow[b]{2}{*}{$\begin{array}{c}\text { Available Technology } \\
\text { at ATR }\end{array}$} & \multicolumn{2}{|c|}{ Proposed Advanced Technology } \\
\hline & $\begin{array}{c}\text { Static } \\
\text { Capsule/ } \\
\text { Shuttle }\end{array}$ & $\begin{array}{l}\text { Instr. } \\
\text { Lead }\end{array}$ & $\begin{array}{l}\text { PWR } \\
\text { Loop }\end{array}$ & & Available at Other MTRs & Developmental \\
\hline \multirow[t]{2}{*}{ Temperature } & $\checkmark$ & $\checkmark$ & $\checkmark$ & $\begin{array}{l}\text {-Melt wires (peak) } \\
\text {-SiC temperature } \\
\text { monitors (range) }\end{array}$ & -Paint spots (peak) & -Wireless $^{b}$ \\
\hline & & $\checkmark$ & $\checkmark$ & $\begin{array}{l}\text {-Thermocouples (Type } \\
\text { N, K, C } \text {, and HTIR- } \\
\text { TCs) }\end{array}$ & -Expansion thermometer & $\begin{array}{l}\text { - Fiber optics } \\
\text {-Noise thermometry } \\
\text {-Ultrasonic thermometers }\end{array}$ \\
\hline $\begin{array}{l}\text { Thermal } \\
\text { Conductivity }\end{array}$ & & $\checkmark$ & $\checkmark$ & $\begin{array}{l}\text {-Out-of-pile } \\
\text { examinations }\end{array}$ & $\begin{array}{l}\text {-Degradation using signal } \\
\text { changes in thermocouples }\end{array}$ & -Hot wire techniques \\
\hline \multirow{2}{*}{$\begin{array}{l}\text { Flux/Fluence } \\
\text { (neutron) }\end{array}$} & $\checkmark$ & $\checkmark$ & $\checkmark$ & -Flux wires and foils & -Activating foil dosimeters & \\
\hline & & $\checkmark$ & $\checkmark$ & & $\begin{array}{l}\text {-Self-Powered Neutron } \\
\text { Detectors (SPNDs) } \\
\text {-Subminiature / miniature } \\
\text { fission chambers }\end{array}$ & \\
\hline $\begin{array}{l}\text { Gamma } \\
\text { Heating }\end{array}$ & & $\checkmark$ & $\checkmark$ & & $\begin{array}{l}\text {-Calorimeters } \\
\text {-Gamma thermometers }\end{array}$ & \\
\hline \multirow{2}{*}{$\begin{array}{l}\text { Dimensional } \\
\text { (stressed and } \\
\text { unstressed } \\
\text { samples) }\end{array}$} & $\checkmark$ & $\checkmark$ & $\checkmark$ & $\begin{array}{l}\text {-Out-of-pile } \\
\text { examinations }\end{array}$ & & \\
\hline & & $\checkmark$ & $\checkmark$ & & $\begin{array}{l}\text {-LVDT-based elongation } \\
\text { (stressed and unstressed) } \\
\text {-Diameter gauge } \\
\text {-Hyper-frequency resonant } \\
\text { cavities }\end{array}$ & $\begin{array}{l}\text {-Ultrasonic transducers } \\
\text {-Fiber optics }\end{array}$ \\
\hline $\begin{array}{l}\text { Fission Gas } \\
\text { (Amount, } \\
\text { Composition) }\end{array}$ & & $\checkmark$ & $\checkmark$ & $\begin{array}{l}\text { Sampling ('near' real- } \\
\text { time) and evaluation } \\
\text { using detectors } \\
\text {-Chromatography } \\
\text {-Pressure sensor }\end{array}$ & $\begin{array}{l}\text {-LVDT-based pressure } \\
\text { monitors } \\
\text {-Counter-pressure monitor }\end{array}$ & $\begin{array}{l}\text {-Acoustic measurements } \\
\text { with high-frequency } \\
\text { echography }\end{array}$ \\
\hline Loop Pressure & & & $\checkmark$ & $\begin{array}{l}\text {-Differential pressure } \\
\text { transmitters } \\
\text {-Pressure gauges with } \\
\text { impulse lines }\end{array}$ & & \\
\hline Loop Flowrate & & & $\checkmark$ & $\begin{array}{l}\text {-Flow venturis } \\
\text {-Orifice plates }\end{array}$ & & \\
\hline $\begin{array}{l}\text { Loop Water } \\
\text { Chemistry }\end{array}$ & & & $\checkmark$ & $\begin{array}{l}\text {-Off-line sampling / } \\
\text { analysis }\end{array}$ & $\begin{array}{l}\text {-Electrical chemical potential } \\
\text { probes }\end{array}$ & \\
\hline $\begin{array}{l}\text { Crud } \\
\text { Deposition }\end{array}$ & & & $\checkmark$ & $\begin{array}{l}\text {-Out-of-pile } \\
\text { examinations }\end{array}$ & $\begin{array}{l}\text {-Diameter gauge with } \\
\text { neutron detectors and } \\
\text { thermocouples }\end{array}$ & \\
\hline $\begin{array}{l}\text { Crack Growth } \\
\text { Rate }\end{array}$ & & & $\checkmark$ & $\begin{array}{l}\text {-Out-of-pile } \\
\text { examinations }\end{array}$ & $\begin{array}{l}\text {-Direct Current Potential } \\
\text { Drop (DCPD) technique }\end{array}$ & -Ultrasonic transducers \\
\hline
\end{tabular}

a. Although melt wires have been used at ATR, recent efforts have expanded the types offered to our users, allowing more accurate estimates of peak temperature, and enhanced encapsulation methods.

b. Although listed under temperature, wireless technologies could be pursued for many parameters.

c. Type $\mathrm{C}$ thermocouple use requires a "correction factor" to correct for decalibration during irradiation.

The instrumentation currently being evaluated for the ATR was selected based on anticipated user needs and "technology readiness" (providing ATR users needed instrumentation in the nearterm). For example, other MTRs have sensors available for real-time detection of parameters such 
as neutron flux (thermal and fast) and geometry changes (length and diameter). As indicated by the blue text in Table ES-1, efforts are underway to explore using these technologies at the ATR. However, as discussed in Section 2, adapting instrumentation used at other test reactors often requires demonstrations because of ATR-specific irradiation conditions (e.g., higher neutron fluxes, higher temperatures, etc.) and test capsule geometries.

As indicated by the red text in Table ES-1, three new or enhanced sensors are now available to ATR users as a result of this instrumentation development effort. The ultimate goal of this effort is to provide ATR users sensors for detecting all of the parameters listed in Table ES-1.

Section 3 provides detailed information about instrumentation available and under development at other test reactors. As reported within Section 3, several test reactor programs in Europe and Asia, such as the Institute for Energy Technology at the Halden Reactor Program (IFE/HRP) have maintained their instrumentation development and evaluation research capability. The Japan Atomic Energy Agency and Studiecentrum voor Kernenergie • Centre d'Étude de l'énergie Nucléaire $(\mathrm{SCK} \cdot \mathrm{CEN})$ also offer a suite of instrumentation to users performing irradiations in their test reactors. Finally, the French Atomic Energy Commission (CEA), which supports the existing OSIRIS test reactor and the new Jules Horowitz Reactor, not only offer users a suite of instrumentation, but are rapidly trying to increasing their capabilities. If the ATR is to remain competitive, enhanced instrumentation must be made available to its users.

An instrumentation research and development plan was developed in 2008 by INL so that ATR users have access to enhanced real-time in-pile sensors, comparable to (and, in some cases, superior to) that available at other MTRs, by 2015. Figure ES-1 presents an updated schedule for developing and demonstrating this instrumentation. There are two major activities identified: "Nearer-Term Instrumentation Development" and "Developmental Technologies". Qualitative judgments with respect to ATR capabilities compared to other test reactors are shown at the bottom of this figure. As indicated in this figure, it is planned to have comparable instrumentation by the end of Fiscal Year 2012 (FY12) for many parameters and "world class" (e.g., comparable, and in some cases, superior) irradiation capabilities by FY15. As noted in Section 4, sensor development activities have been prioritized based on user need and technology readiness.

Note that the ATR NSUF-funded instrumentation development effort began in FY09. Prior to that time, new ATR instrumentation was primarily developed using a limited amount of INL Laboratory Research and Development (LDRD) funding. Sensors were developed that addressed needs identified by current and potential customers. Then, programmatic funding covered the costs required for qualifying the instrumentation for ATR irradiations. Although such an approach did allow a limited amount of instrumentation to be developed, the limited amount of LDRD funding devoted to this effort were inadequate for the ATR NSUF to have instrumentation comparable to that in other test reactors by 2015. Evaluations indicate that a sustained effort of at least $\$ 1.5 \mathrm{M}$ per year is needed to support this effort. With this level of funding, all 'Nearer Term' technologies can be adapted and demonstrated for ATR applications (at least demonstrated to the point that direct programmatic funding can be obtained for additional instrument qualifications). Note that this requested level of funding will also provide for selected research of 'Developmental 


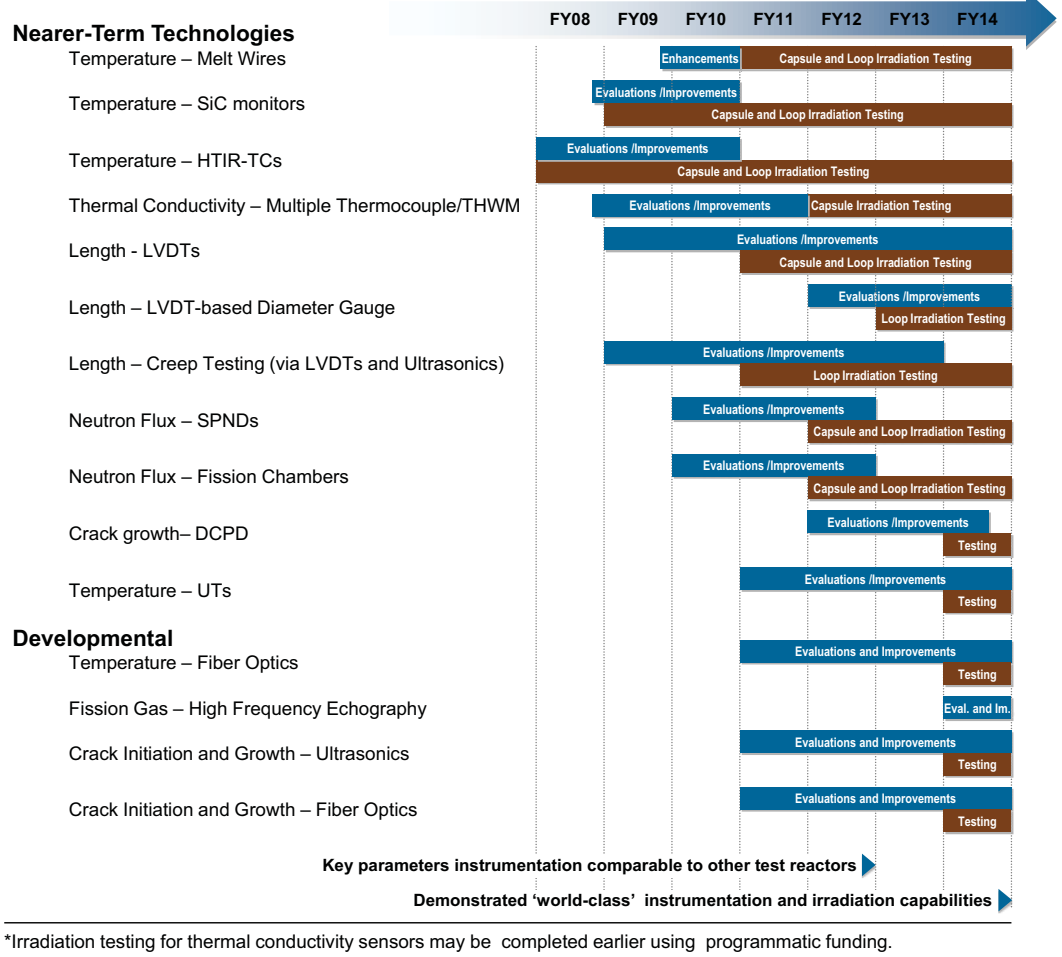

Figure ES-1. Current schedule for ATR NSUF advanced instrumentation research and development.

Technologies.' However, the selected priority for "Developmental Technologies" research is based on customer and reactor staff prioritization recommendations at the time that funding becomes available. ATR NSUF funding (or other programmatic funding) is expected to cover costs required to develop and deploy test trains to demonstrate instrumentation performance in inert gas and PWR loop conditions.

When the ATR NSUF instrumentation strategic plan was originally developed, estimates for the required funding to obtain a world-class instrumentation capability for ATR were identified. Although ATR NSUF funding provided in FY10 was close to the estimated value, FY11 funding was significantly lower (and preliminary information from DOE suggests that funding will be even more limited in FY12). However, as anticipated in the original version of this report, the instrumentation capability developed with ATR NSUF funds has been sufficient for this effort to attract funding from other sources. Hence, all of the FY10 instrumentation development activities were completed as planned. In FY11, the DOE-NE Fuel Cycle Research and Development (FCRD) program and the ATR Life Extension Project (LEP) have funded selected instrumentation development activities. In addition, selected programs are supported by INL's LDRD program. It should be emphasized that the schedule shown in Figure ES-1 will only be fulfilled if this instrumentation development program can continue to attract multiple fund sources. Because it is key for US MTRs to be competitive, efforts continue to request funds from several direct programs, such as DOE's Nuclear Energy Enabling Technology (NEET) 
instrumentation and control initiative and the ATR NSUF initiative, work-for-others customers, such as Naval Reactors, the US Nuclear Regulatory Commission, NASA, and DOD organizations, and internal INL LDRD funds.

Table ES-2 summarizes the status of on-going sensor development and evaluation efforts at INL shown in Figure ES-1. As indicated in Table ES-2, considerable progress has been made in this program during the last 3 years. Several new sensors are available to users; and as indicated in Section 5, several new sensors should be fully qualified within FY11. It is encouraging to see that some level of research has been initiated on most of the sensor technologies identified in this table. As discussed in Section 5, sensor development and evaluation activities rely heavily on collaborations with other research organizations, such as IFE/HRP and CEA, to maximize the benefit from research expenditures. In addition, collaborations have also been initiated with universities possessing specialized capabilities in sensor development and evaluation areas, such as the Massachusetts Institute of Technology (MIT), Idaho State University (ISU), Utah State University (USU), and the Pennsylvania State University (PSU). Many of these sensor development efforts are conducted in INL's High Temperature Test Laboratory (HTTL), which has specialized equipment and trained staff for sensor fabrication and evaluation.

Table ES-2. Status of ATR NSUF sensor development and evaluation efforts.

\begin{tabular}{|c|c|c|}
\hline Parameter & Sensor & Status \\
\hline \multirow[t]{5}{*}{ Temperature } & Melt Wires & $\begin{array}{l}\text { Procedures completed for DSC testing of melt wires; numerous melt } \\
\text { wires evaluated; Developing reference document for interpreting } \\
\text { results. }\end{array}$ \\
\hline & SiC Temperature Monitors & $\begin{array}{l}\text { Initial in-pile irradiations underway. Development and evaluation of } \\
\text { post-irradiation measurement capability completed (including com- } \\
\text { parison evaluations with ORNL); Evaluation of SiC monitors irradi- } \\
\text { ated in ATR expected in FY11. }\end{array}$ \\
\hline & $\begin{array}{l}\text { High Temperature Irradia- } \\
\text { tion Resistant Thermo- } \\
\text { couples (HTIR-TCs) }\end{array}$ & $\begin{array}{l}\text { Initial out-of-pile testing completed. In-pile testing (in the AGR-1 gas } \\
\text { reactor fuel irradiation test) and sensor enhancement evaluations } \\
\text { completed; HTIR-TCs provided to MIT in FY10 and preparations for } \\
\text { HTIR-TC testing by IFE/HRP initiated. }\end{array}$ \\
\hline & Fiber-Optics & Evaluation as a FCRD effort initiated in FY11. \\
\hline & Ultrasonic Thermometers & $\begin{array}{l}\text { Successfully developed and deployed to support high temperature } \\
\text { fuel testing several decades ago. Enabling technology information } \\
\text { documented; preparations initiated for developing a prototype for } \\
\text { FCRD evaluations in FY11. }\end{array}$ \\
\hline \multirow[t]{2}{*}{$\begin{array}{l}\text { Thermal } \\
\text { Conductivity }\end{array}$} & Multiple thermocouples & $\begin{array}{l}\text { Initial laboratory testing completed. Anticipate that inclusion of } \\
\text { HTIR-TCs could allow detection at higher temperatures than current } \\
\text { methods used by IFE/HRP. }\end{array}$ \\
\hline & Hot-wire method & $\begin{array}{l}\text { Prototype design developed and initial laboratory testing completed. } \\
\text { Anticipated that inclusion of HTIR-TCs could allow detection at } \\
\text { higher temperatures. Prototype THWM probe shipped to MIT for } \\
\text { inclusion in hydride fuel test. }\end{array}$ \\
\hline
\end{tabular}


Table ES-2. Status of ATR NSUF sensor development and evaluation efforts.

\begin{tabular}{|c|c|c|}
\hline Parameter & Sensor & Status \\
\hline \multirow[t]{3}{*}{$\begin{array}{l}\text { Elongation, Crud } \\
\text { deposition, Corro- } \\
\text { sion }\end{array}$} & LVDTs & $\begin{array}{l}\text { Out-of-pile testing completed on developmental LVDT that resists } \\
\text { high temperature degradation and eliminates Curie temperature } \\
\text { effects. }\end{array}$ \\
\hline & Diameter gauge & $\begin{array}{l}\text { Currently used in HBWR for detecting swelling, corrosion, and crud } \\
\text { buildup. Investigations delayed due to funding limitations. }\end{array}$ \\
\hline & $\begin{array}{l}\text { Ultrasonic Transducers } \\
\text { (UTs) }\end{array}$ & $\begin{array}{l}\text { Scoping tests completed on prototype; additional prototype out-of- } \\
\text { pile testing needed. }\end{array}$ \\
\hline $\begin{array}{l}\text { In-pile Creep Test } \\
\text { Rig }\end{array}$ & $\begin{array}{l}\text { LVDT-based rig with bel- } \\
\text { lows }\end{array}$ & $\begin{array}{l}\text { Design developed. Prototype evaluated at PWR conditions in a lab- } \\
\text { oratory autoclave. Follow-on work should develop design with } \\
\text { variable load capability }\end{array}$ \\
\hline Neutron Flux & $\begin{array}{l}\text { SPNDs and Fission } \\
\text { Chambers }\end{array}$ & $\begin{array}{l}\text { Initiated evaluations of candidate specially-developed fixturing } \\
\text { installed at ATRC. In FY11, additional evaluations of detectors will } \\
\text { be performed and new fixturing, for simultaneous placement of } \\
\text { detectors in the NW LIPT, will be developed. }\end{array}$ \\
\hline Gamma Heating & Gamma thermometers & $\begin{array}{l}\text { Currently used at HBWR; Investigations delayed due to funding } \\
\text { limitations. }\end{array}$ \\
\hline \multirow[t]{3}{*}{ Crack propagation } & $\begin{array}{l}\text { DCPD method with CT } \\
\text { specimens }\end{array}$ & $\begin{array}{l}\text { Preliminary design (based on HRP method) developed by MIT in } \\
\text { FY09; funding constraints limited progress in FY10. }\end{array}$ \\
\hline & Ultrasonic techniques & Efforts initiated under FCRD program in FY11 \\
\hline & Fiber optics techniques & Efforts initiated under FCRD program in FY11 \\
\hline
\end{tabular}

Significant accomplishments during FY10 include: enhanced melt wire options and encapsulation methods (Figure ES-2); validated SiC temperature monitor evaluation methods (Figure ES-3); a new LVDT design based on HTTL evaluations (Figure ES-4); a creep test rig design based on autoclave testing (Figure ES-5); and a inpile thermal conductivity probe based on Hot Wire Transient Method (THWM) techniques that is being sent to the MIT reactor for irradiation testing (Figure ES-6). In addition, a new capability was established at the ATR Critical (ATRC) that allows inpile evaluation of flux sensors (see Figure ES-7). Details about each of these achievements are reported in Section 5. In addition to providing ATR customers the instrumentation required for their irradiation tests, this program has clearly added to the prestige and capabilities of the ATR NSUF, INL, and to the DOE. As noted previously, international collaborations have been established with leaders in the world of inpile testing, such as IFE/HRP and CEA. Partnerships with universities have not only helped students successfully complete their graduate level research, but have led to new INL employees. Over 12 peer-reviewed conference papers and 20 archival journal papers have been produced, and several patents have been awarded or are pending from this research. Finally, the specialized fixtures and software developed and installed at the ATRC for evaluating flux detectors expands the capability of this facility. It is anticipated that this new capability will be used in future years to develop and evaluate new, improved sensors for measuring flux and other parameters. 


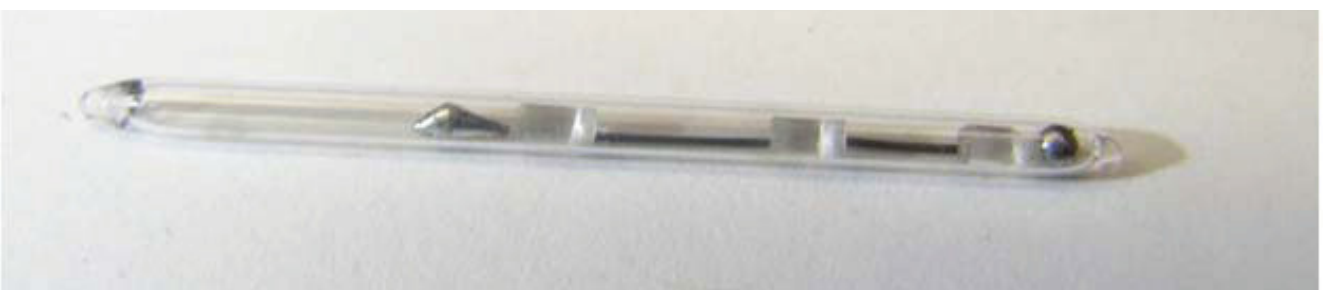

Figure ES-2. Quartz tube containing four melt wires in separated compartments.

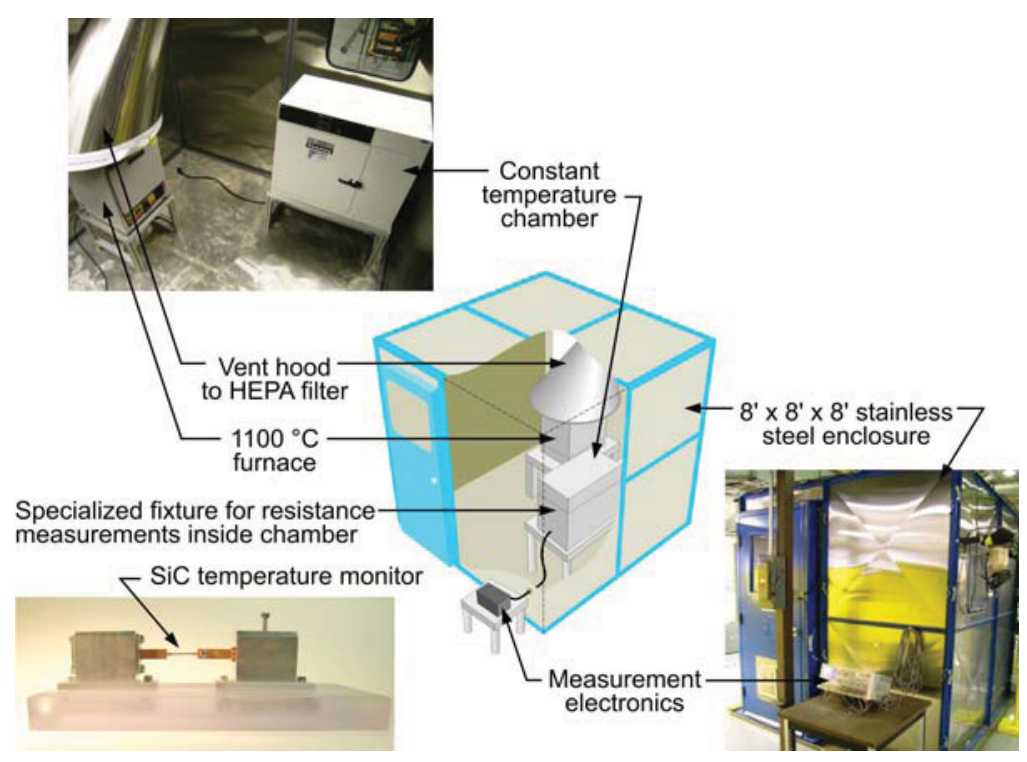

Figure ES-3. HTTL setup to anneal and measure electrical resistivity of SiC temperature monitors.

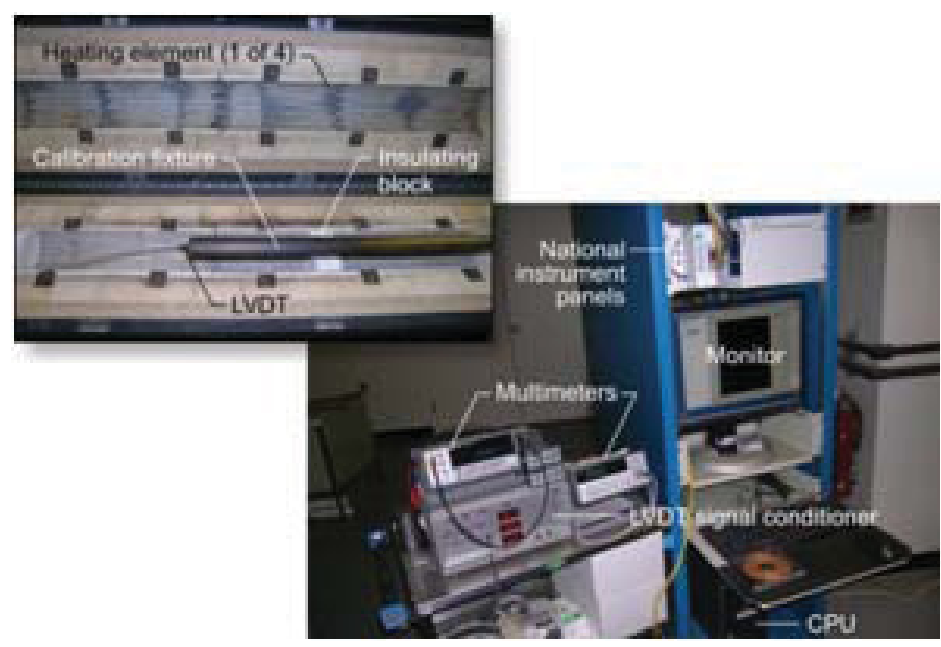

Figure ES-4. HTTL setup for evaluating new LVDTs jointly developed with IFE/HRP. 

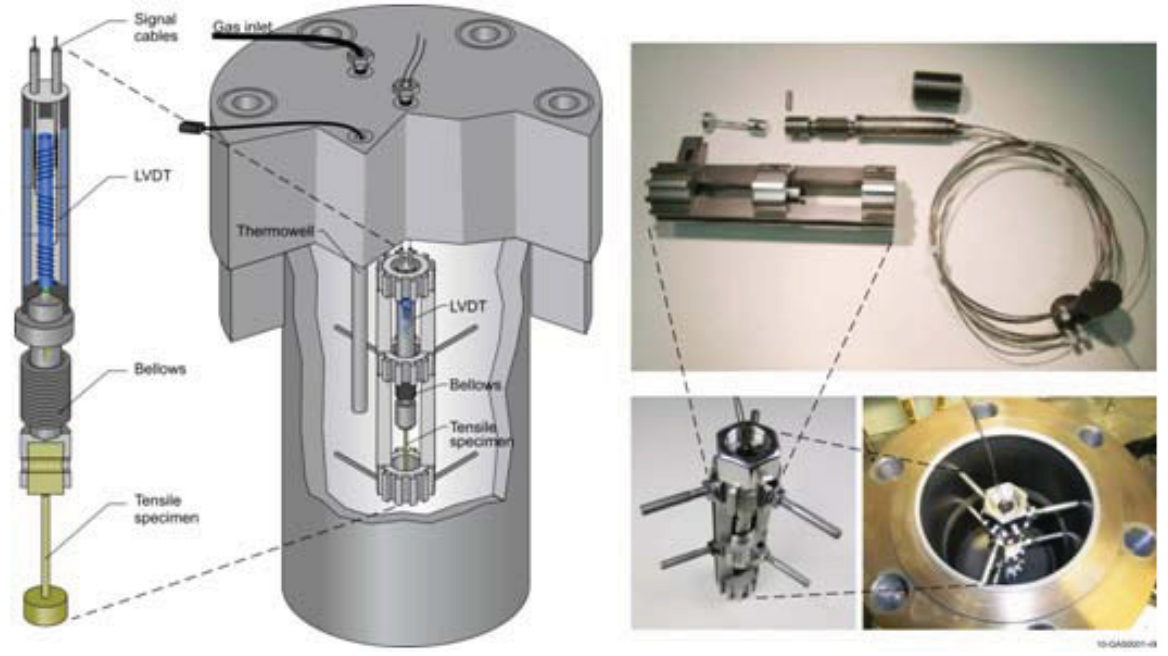

Figure ES-5. Creep test rig positioned in autoclave for testing

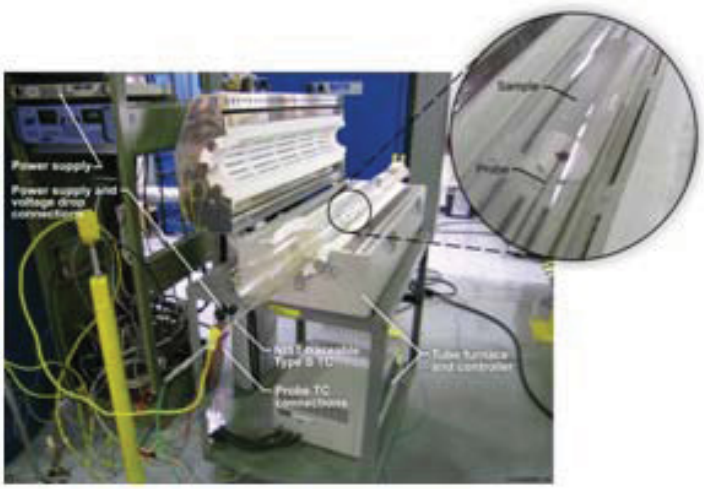

(a)

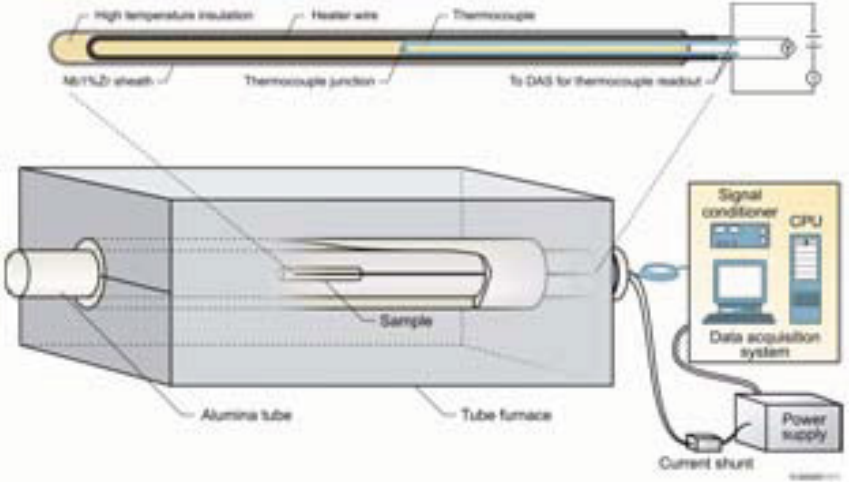

(b)

Figure ES-6. Setup for evaluating THWM probe 


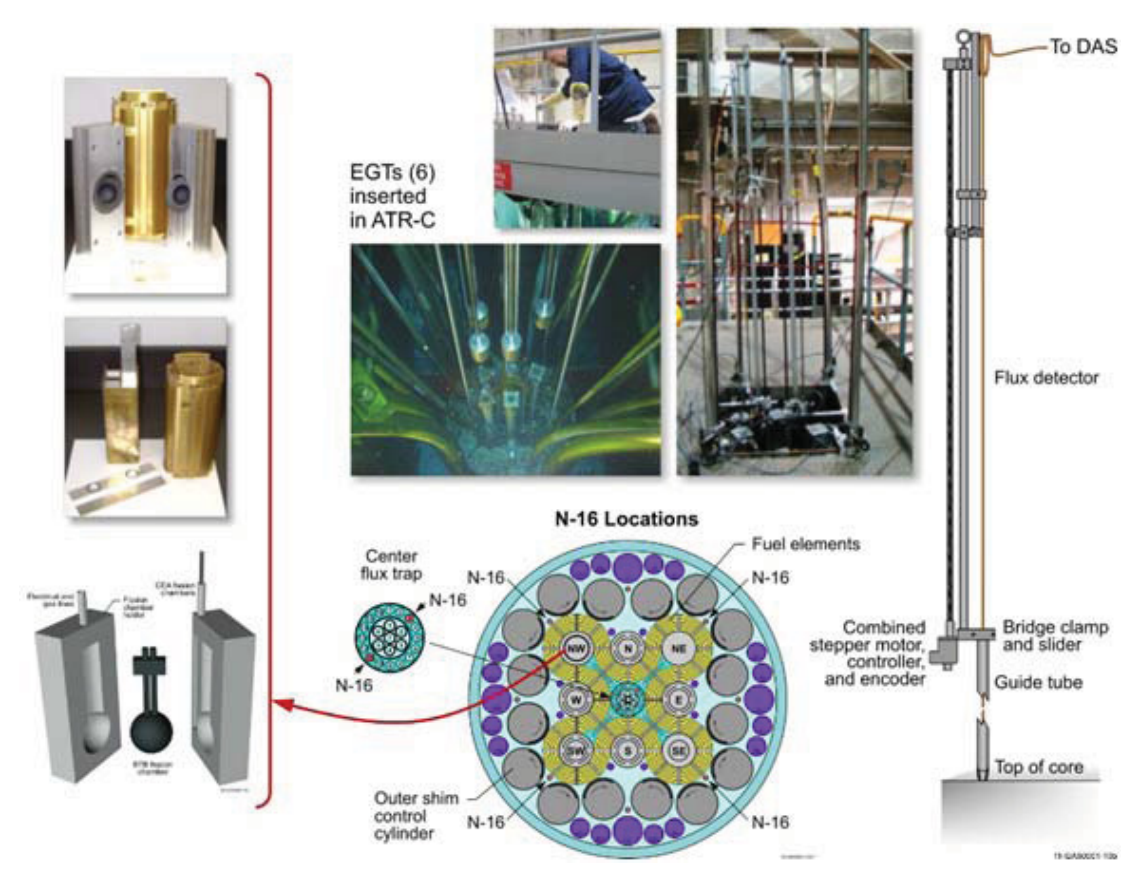

Figure ES-7. Specialized fixturing for flux detector evaluation installed at ATRC. 
INL/EXT-11-21231 


\section{INTRODUCTION}

The Department of Energy (DOE) designated the Advanced Test Reactor (ATR) as a National Scientific User Facility (NSUF) in April 2007 to support U.S. leadership in nuclear science and technology. By attracting new research users - universities, laboratories, and industry - the ATR NSUF facilitates basic and applied nuclear research and development, further advancing the nation's energy security needs. A key component of the ATR NSUF effort is to provide new in-pile instrumentation techniques that are capable of providing real-time measurements of key parameters during irradiation. To address this need, an assessment of instrumentation available and under-development at other test reactors was completed. Based on this review, recommendations were made with respect to what instrumentation is needed at the ATR; and a strategy was developed for obtaining these sensors. In 2009, a report was issued documenting this instrumentation development strategy and initial progress toward

accomplishing instrumentation development program objectives. ${ }^{1}$ This document reports progress toward implementing this strategy in 2010.

\subsection{Background}

The ATR is a pressurized, light-water moderated, beryllium-reflected research reactor located at the Idaho National Laboratory (INL) Reactor Technology Complex (RTC). Its ability to produce an extremely high neutron flux makes it possible to subject materials to the equivalent of years of radiation exposure, as would take place in a commercial nuclear reactor, in a matter of weeks or months. The ATR core design allows many experiments to run concurrently, with each experiment receiving a different and carefully controlled level of neutron irradiation. Originally commissioned in 1967 to evaluate fuels and materials performance for the Navy Nuclear Propulsion Program, the ATR is expected to continue operating until at least 2050.

As noted above, DOE's decision to designate the ATR as a NSUF is increasing the ATR's customer base, although it is anticipated that irradiations will still primarily support nuclear science and technology programs. In fact, as discussed in this document, ATR-related instrumentation development efforts are now attracting funding from several DOE-sponsored nuclear research and development programs, such as the Next Generation Nuclear Plant, the Fuel Cycle Research and Development, and the Nuclear Energy Enabling Technologies efforts. New in-pile instrumentation will further enhance the ATR's ability to attract new customers from the commercial power, defense, and manufacturing sectors.

\subsection{Motivation}

As noted above, it is recognized that new instrumentation techniques are needed to support ATR in-pile irradiations. For decades, irradiation tests at material test reactors (MTRs) have used in-pile instrumentation to measure parameters, such as temperature, dimensional changes, fission 
gas release, neutron fluence, and gamma heating. However, most in-pile instrumentation was developed decades ago, and efforts to enhance in-pile instrumentation were reduced in the 1980s. Furthermore, in several cases, ATR instrumentation for in-pile testing lags behind instrumentation available at other materials test reactors. Hence, a key component of the ATR NSUF is to develop, fabricate, and demonstrate the performance of new real-time sensor technologies required to measure key parameters for irradiation testing.

As discussed in this report, INL's existing High Temperature Test Laboratory (HTTL) is a unique facility for developing, fabricating, and performing laboratory demonstrations of proposed new instrumentation. This facility already features specialized sensor fabrication and evaluation equipment and trained staff with an established reputation for fabricating unique sensors. The HTTL is playing a key role in helping the ATR obtain the instrumentation needed to become a 'world class' NSUF.

\subsection{Report Content}

As a first step in this effort, a review was completed to document what in-pile instrumentation is currently available at the ATR and other material test reactors and what instrumentation could be developed or transferred from other applications to enhance in-pile irradiation testing. This report documents results from this review. Section 2 provides an overview of irradiation locations available in the ATR and the ATR Critical (ATRC), what materials are typically irradiated for various experimental configurations, and what instrumentation is typically available for each configuration. Section 2 also highlights irradiation capabilities of other test reactors in the U.S. and abroad. Section 3 summarizes instrumentation currently used to support test reactor programs and on-going efforts to enhance this instrumentation at non-INL locations. Section 4 outlines a program for obtaining all of the higher priority instrumentation, based on customer input, required for near-term and long term irradiations at ATR and other test reactors. Where possible, potential collaborators are identified for obtaining this instrumentation. Section 5 summarizes INL progress on accomplishing objectives in the plan presented in Section 4, identifying new in-pile instrumentation researched by INL to support ATR irradiations and reporting on the status of each research effort. References for this document are listed in Section 6. 


\section{IRRADIATION LOCATIONS}

This section provides an overview of irradiation locations available in the ATR and ATRC, what materials are typically irradiated in representative experimental configurations, and what instrumentation is typically available for each configuration. A brief overview of other MTRs is also provided for comparison.

\subsection{ATR}

The ATR is a unique facility for scientific investigation of nuclear fuel and materials. ${ }^{2-6}$ Designed to allow simulation of long neutron radiation exposures in a short time period, the ATR has a maximum power rating of $250 \mathrm{MW}_{\text {th }}$ with a maximum unperturbed thermal neutron flux of $1 \times 10^{15} \mathrm{n} / \mathrm{cm}^{2}$-s and a maximum fast neutron flux of $5 \times 10^{14} \mathrm{n} / \mathrm{cm}^{2}$-s. The ATR is cooled by pressurized (2.5 MPa/360 psig) water that enters the reactor vessel bottom at an average temperature of $52{ }^{\circ} \mathrm{C}\left(126^{\circ} \mathrm{F}\right)$, flows up outside cylindrical tanks that support and contain the core, passes through concentric thermal shields into the open part of the vessel, then flows down through the core to a flow distribution tank below the core. When the reactor is operating at full power, the primary coolant exits the vessel at $71^{\circ} \mathrm{C}\left(160^{\circ} \mathrm{F}\right)$.

\subsubsection{Reactor Design and Characteristics}

As shown in Figure 2-1, the ATR core consists of 40 curved plate fuel elements in a serpentine arrangement around a 3 x 3 array of primary testing locations, or nine large highintensity neutron flux traps. The unique ATR control device design permits large power variations among its nine flux traps using a combination of control cylinders (drums) and neck shim rods. The beryllium control cylinders contain hafnium plates that can be rotated toward and away from the core. Hafnium shim rods, which withdraw vertically, are inserted or withdrawn for minor power adjustments. Within bounds, the power level in each corner lobe of the reactor can be controlled independently to allow for different power and flux levels in the four corner lobes during the same operating cycle. The ratio of fast to thermal flux can be varied from 0.1 to 1.0 . In addition to the nine large volume (up to 48" long and up to 5.0" diameter) high-intensity neutron flux traps, there are 66 irradiation positions inside the reactor core reflector tank, and there are two capsule irradiation tanks outside the core with 34 low-flux irradiation positions. A Hydraulic Shuttle Irradiation System (HSIS), more commonly referred to as the "Rabbit", was also recently installed in the ATR to restore the reactor's capability to perform irradiations of small capsules in the B-7 position of the reactor for materials research, rapid activations, and isotope production. ${ }^{7}$

\subsubsection{Test Configurations and Conditions}

Irradiated samples are enclosed in test capsules that are then typically placed in a basket to facilitate positioning within the reactor. This section provides summary information about the 


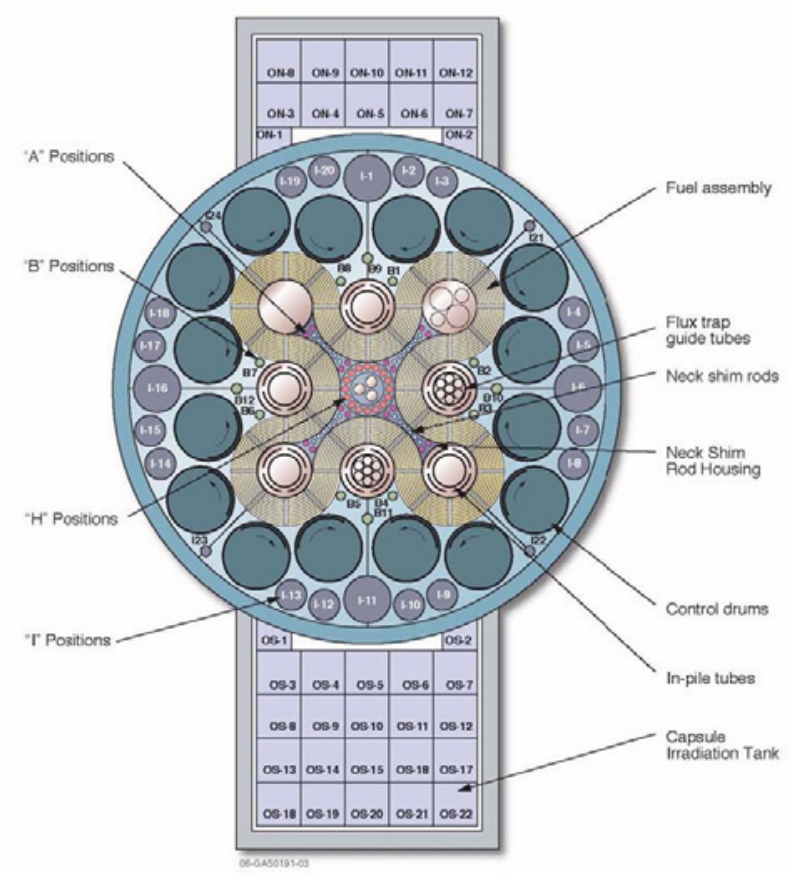

Figure 2-1. ATR core cross section showing irradiation locations.

three ATR primary test configurations, which are conceptually shown in Figure 2-2, and the HSIS. More detailed information can be found in References 2 and 7.
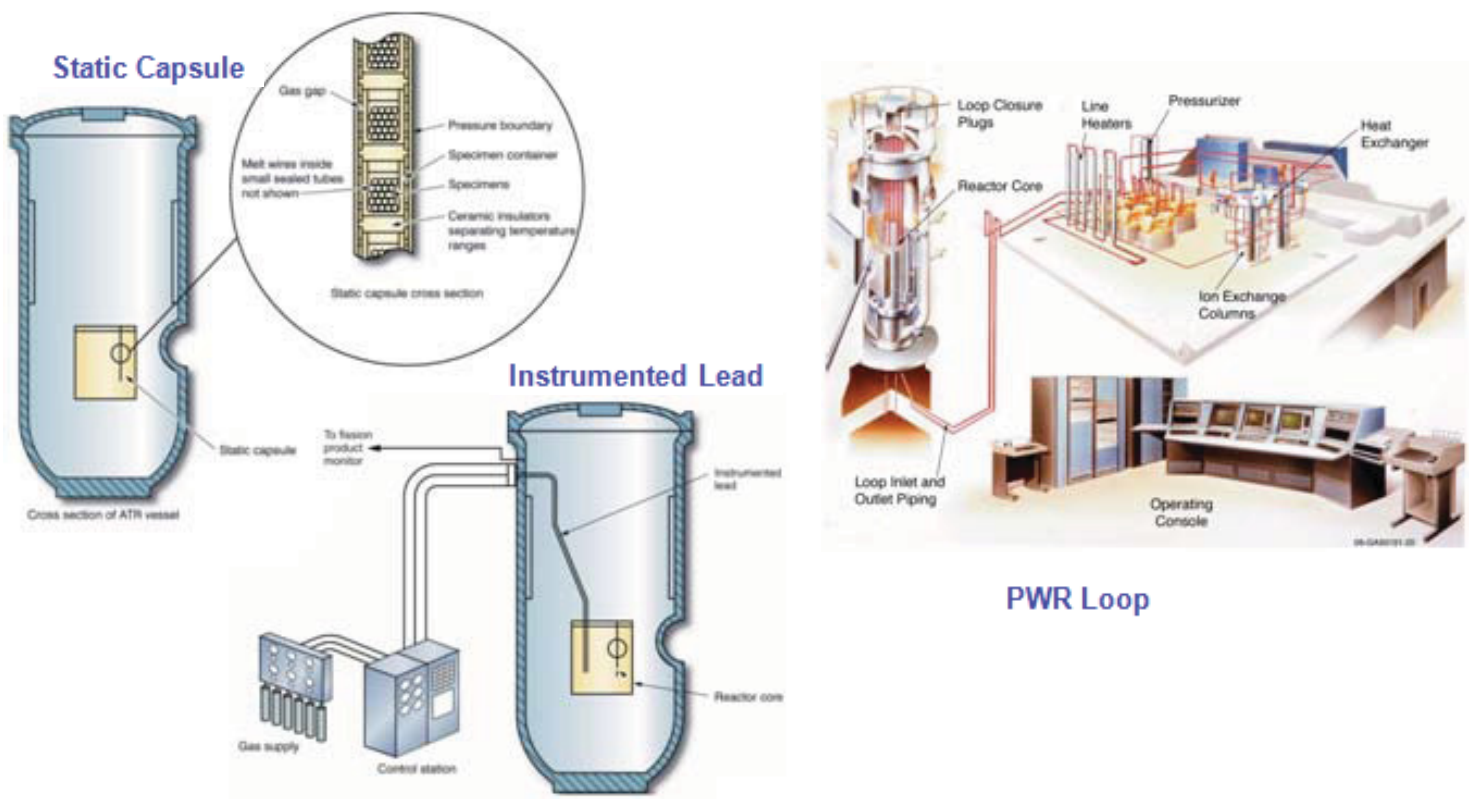

Figure 2-2. Schematic diagrams illustrating ATR irradiation locations. 
- Static Capsule Experiments - These capsules may contain a number of small samples or engineered components. Static capsule experiments may be sealed or may contain material that can be in contact with the ATR primary coolant (such capsules are in an open configuration without being sealed). Capsules may be any length, up to $122 \mathrm{~cm}$ (48 in.) and may be irradiated in any core position, including the flux traps. Irradiation temperature may be selected, within limits, by including a gas gap in the capsule with a known thermal conductance. Peak temperatures may be measured using a series of melt wires, temperature-sensitive paint spots, or silicon carbide temperature monitors. Accumulated neutron fluences may be verified using flux wires.

- Instrumented Lead Experiments - Active control of experiments and data from test capsules during irradiation is achieved using core positions with instrumentation cables and temperature control gases in ATR instrumented lead experiments. Such experiments can have instrumentation, such as thermocouples, connected to individual capsules or single specimens. This instrumentation can be used to control and monitor conditions within the capsule. For example, temperature control in individual zones is performed by varying the gas mixture (typically helium and neon) in the gas gap that thermally links the capsule to the water-cooled reactor structure. In addition to temperature, instrumented lead experiments can be configured to monitor the gas around the test specimen. In a fueled experiment, the presence of fission gases due to fuel failures or oxidation can be detected via gas chromatography. Instrument leads allow real time display of experimental parameters in the control room.

- Pressurized Water Loop Experiments - Five of the nine ATR flux traps used for materials and fuels testing are equipped with pressurized water loops (at the NW, N, SE, SW, and W locations). A sixth loop will be operational in 2011. Each of the water loops can be operated at different temperatures, pressures, flow rates, or water chemistry requirements. These loops can operate above the standard temperatures and pressure of a commercial PWR power plant. The great advantage of loop tests is the ease with which a variety of samples can be subjected to conditions specified for any PWR design. Each ATR pressurized loop is instrumented to measure and control coolant flows (both inert gas and water), temperatures, pressures and sample test data.

- Rabbit Tests - The HSIS, or "rabbit", enables insertion and removal of experiment specimens during ATR during operational cycles. The HSIS is installed in the B-7 reflector position, which is one of the higher flux positions in the reactor with typical thermal and fast $(>1 \mathrm{MeV})$ fluxes of $2.8 \mathrm{E}+14 \mathrm{n} / \mathrm{cm}^{2} / \mathrm{sec}$ and $1.9 \mathrm{E}+14 \mathrm{n} / \mathrm{cm}^{2} / \mathrm{sec}$, respectively. The titanium experiment capsules, or shuttles, are approximately $16 \mathrm{~mm}$ in diameter $\mathrm{x} 57 \mathrm{~mm}$ in length with interior usable dimensions of $14 \mathrm{~mm}$ in diameter $\mathrm{x} 50 \mathrm{~mm}$ long. Up to 14 capsules can be used for irradiations simultaneously, although one does not need to fill all 14 capsules for a test. The maximum allowable weight of each shuttle contents is 27.0 grams.

\subsection{ATRC}

Located at the INL, the ATRC facility is a full-size nuclear mock-up of the ATR core that allows researchers to characterize in advance, with precision and accuracy, the expected changes in ATR core reactivity due to a proposed test. This facility generally operates at a thermal power of less than $5 \mathrm{~kW}$ (with associated peak thermal fluxes of around $10^{10} \mathrm{n} / \mathrm{cm}^{2}$-s and a maximum fast neutron flux of around $10^{9} \mathrm{n} / \mathrm{cm}^{2}-\mathrm{s}$ ). 


\subsubsection{Reactor Design and Characteristics}

The primary difference between the ATRC and ATR is that the highly-enriched uranium fuel in the ATRC is uniformly loaded with boron while the ATR fuel is not. A second difference of note is that the ATRC uses five cadmium-plated safety rods while the ATR uses six hafnium-plated safety rods. During operation, this difference is insignificant. ATRC criticality is normally attained at a power greater than $0.25 \mathrm{~mW}$. However, this pool-type reactor (Figure 2-3) usually operates at a power level of about $600 \mathrm{~W}$ and provides useful physics data for evaluating:

- worth and calibration of control elements,

- excess reactivities and charge lifetimes,

- thermal and fast neutron distributions,

- gamma heat generation rates,

- fuel loading requirements,

- effects of inserting and removing experiments and experiment void reactivities, and temperature and void reactivity coefficients.

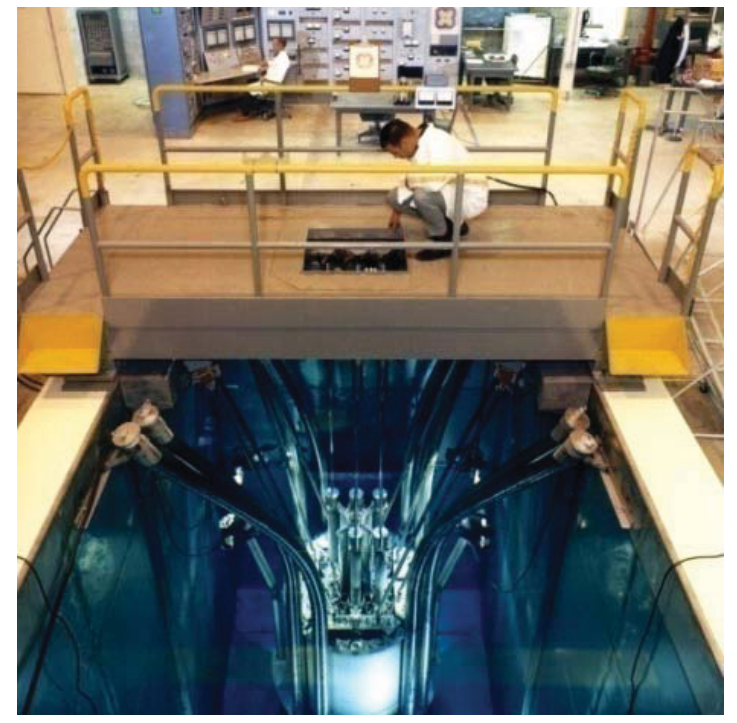

Figure 2-3. ATRC facility layout.

\subsubsection{Test Configurations and Conditions}

As part of the ATR NSUF, specialized instrument positioning hardware and associated software have been developed and installed by INL to evaluate and calibrate real-time flux sensors. Initial ATRC tests (see Figure 2-4), which began in 2010, are comparing the response and accuracy of specially-developed real-time flux detectors using experimental guide tubes (EGTs) that can position the detectors at up to six of the N-16 positions (with widths or diameters of approximately 0.625 inches) and specialized fixtures that can position detectors in the NorthWest Flux Trap (with a diameter of 5.25 inches). Software has been developed to process data obtained 
from these detectors, with the ultimate objective of providing a real-time three-dimensional ATRC flux map. Data are benchmarked with activation wire and foil measurements and modeled with reactor physics codes. The fixtures and software developed for this effort provide irradiation locations to test candidate in-pile sensors, fuels, and materials. Additional information about this effort is provided in Section 5.5. However, it should also be noted that the ATRC's pool type design offers users enhanced flexibility for testing in lower flux conditions. For example, gas lines and heaters are more easily included in ATRC test configurations.

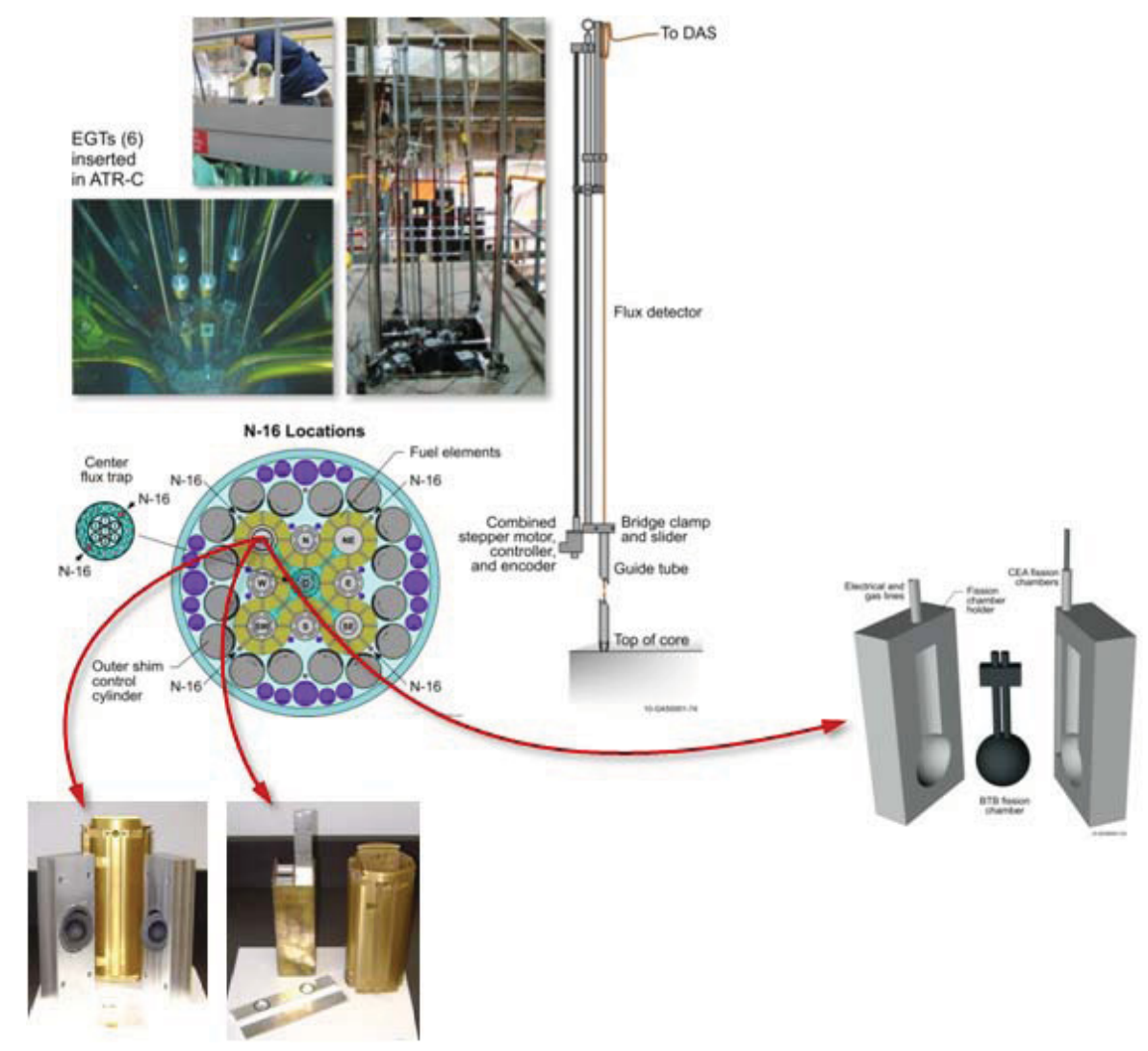

Figure 2-4. Sample/sensor positioning equipment and insertion locations at ATRC.

\subsubsection{Other MTRs}

Table 2-1 compares operating parameters for selected test and prototype reactors used (or under construction) throughout the world. Information in this table was primarily obtained from the IAEA Nuclear Research Reactor Database, ${ }^{8}$ which contains information from nearly 280 research reactors (operating, shutdown, and proposed). Although these reactors range in power levels from 0 to several hundred MWt, nearly 200 of them have power levels below $5 \mathrm{MWt}$. Most of the reactors listed in Table 2-1 achieved criticality in the 1960s (or earlier). Among the operating reactors, there are two exceptions: the HANARO reactor in South Korea, which went critical in 1995 and the prototype High Temperature Test Reactor (HTTR) in Japan, which went critical in 1998. 


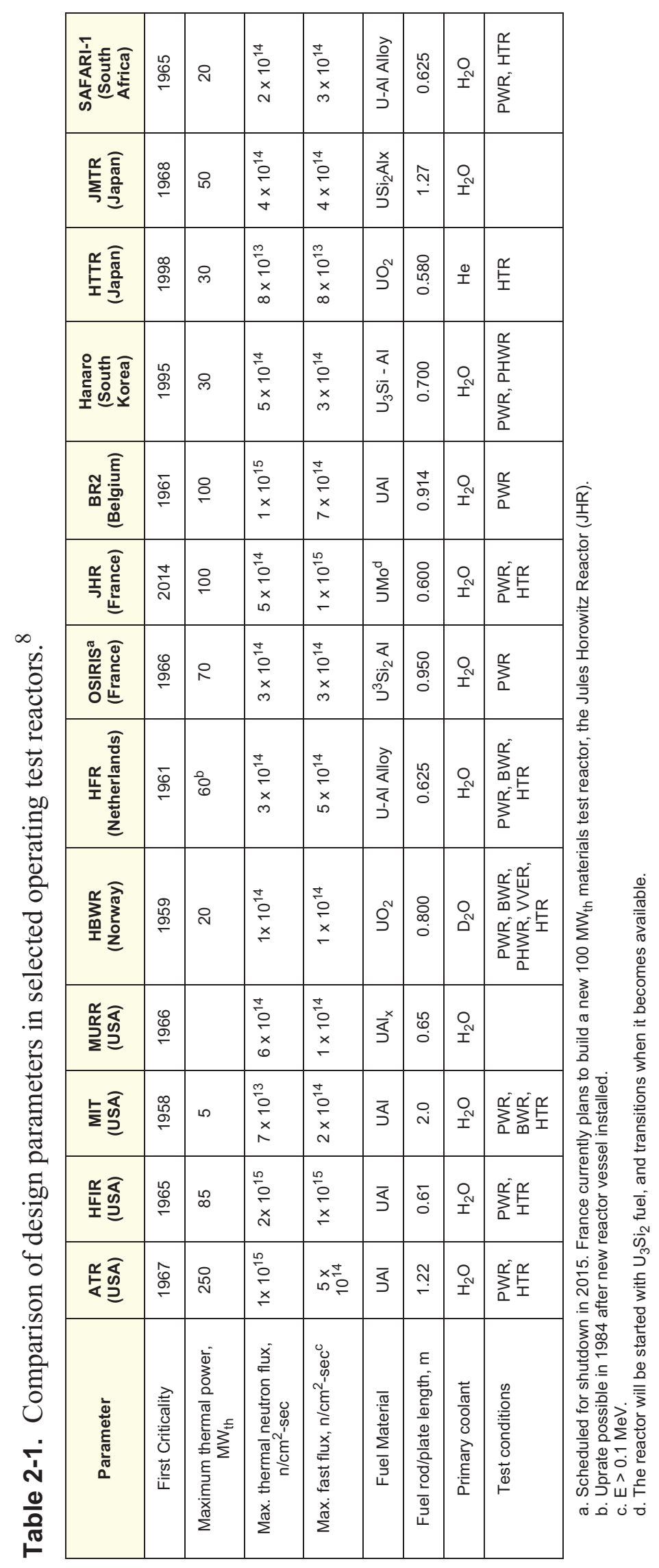


The Jules Horowitz Reactor (JHR), ${ }^{9}$ which is scheduled to go critical in 2014, is another exception with respect to initial date for achieving criticality. The JHR is being built to replace materials irradiation capabilities of older reactors in Europe as they are retired from service. This $100 \mathrm{MWt}$ reactor is designed to include static capsules, instrumented capsules, and in-pile loops. To support irradiation programs anticipated for the JHR, CEA is developing four standard types of test trains for experiments in loops at nominal and off-normal LWR conditions, of capsules at LWR accident conditions, and loops at sodium potassium loop conditions with high dpa and low thermal gradients (see Figure 2-5):

- MADISON - A test train in an in-core loop for fuel testing under nominal LWR (PWR or BWR) conditions.

- CALIPSO - A test train in an in-core sodium potassium loop for material testing under high $(\sim 15)$ dpa and limited thermal gradients $\left(<8^{\circ} \mathrm{C}\right)$

- ADELINE - A test train in an in-pile loop for fuel testing under LWR (BWR or PWR) offnormal conditions (e.g. power ramps) with fission product measurement

- LORELEI - A test capsule for fuel testing under LWR (PWR or BWR) accident (LOCA) conditions to observe phenomena such as clad ballooning or rupture, corrosion, and quench behavior and investigate fission product release.

The above trains are currently in the design and component verification stages. However, all are scheduled to be available when the JHR achieves criticality in 2014. In addition to these test trains, CEA has initiated an effort to enhance instrumentation for its users. This effort, which is known as the INSNU (see Section 3.1), was initially launched to improve instrumentation available to all European research reactors. In 2009, the INSNU effort was relocated from Saclay to Cadarache so that it can be better coordinated with the JHR.

It is also worth highlighting the Halden Boiling Water Reactor (HBWR). Although this reactor is older and its maximum power level $(20 \mathrm{MWt})$ is over an order of magnitude smaller than the ATR, its testing flexibility and the expertise of its staff for instrumenting its tests make this facility unique. For decades, organizations within the international community (including the US Nuclear Regulatory Commission, vendors such as General Electric and AREVA, and the US naval reactor program) have utilized this facility for in-pile irradiation needs. Approximately $40 \%$ of HBWR testing is devoted to Organization for Economic Cooperation and Development (OECD) programs with the remainder sponsored by bilateral agreements between Norway and customers from other countries. ${ }^{10}$ Most of these bilateral agreements allow the HBWR to perform tests for utility customers to address issues related to fuel thermal performance, fuel pellet/clad interactions, fuel fission gas release, reactor vessel embrittlement, structural materials degradation (e.g., corrosion, creep, etc.). As noted in Table 2-1, this reactor has developed loops for simulating BWR, PWR, Pressurized Heavy Water Reactor (CANDU), and VVER conditions.

Successful development and deployment of advanced reactors depends to a large extent on demonstration of "enabling" technologies. For example, the high temperature irradiation performance of new fuels and structural materials must be demonstrated with instrumented tests in prototypical environments. In addition, MTRs also support a wide range of non-nuclear programs 


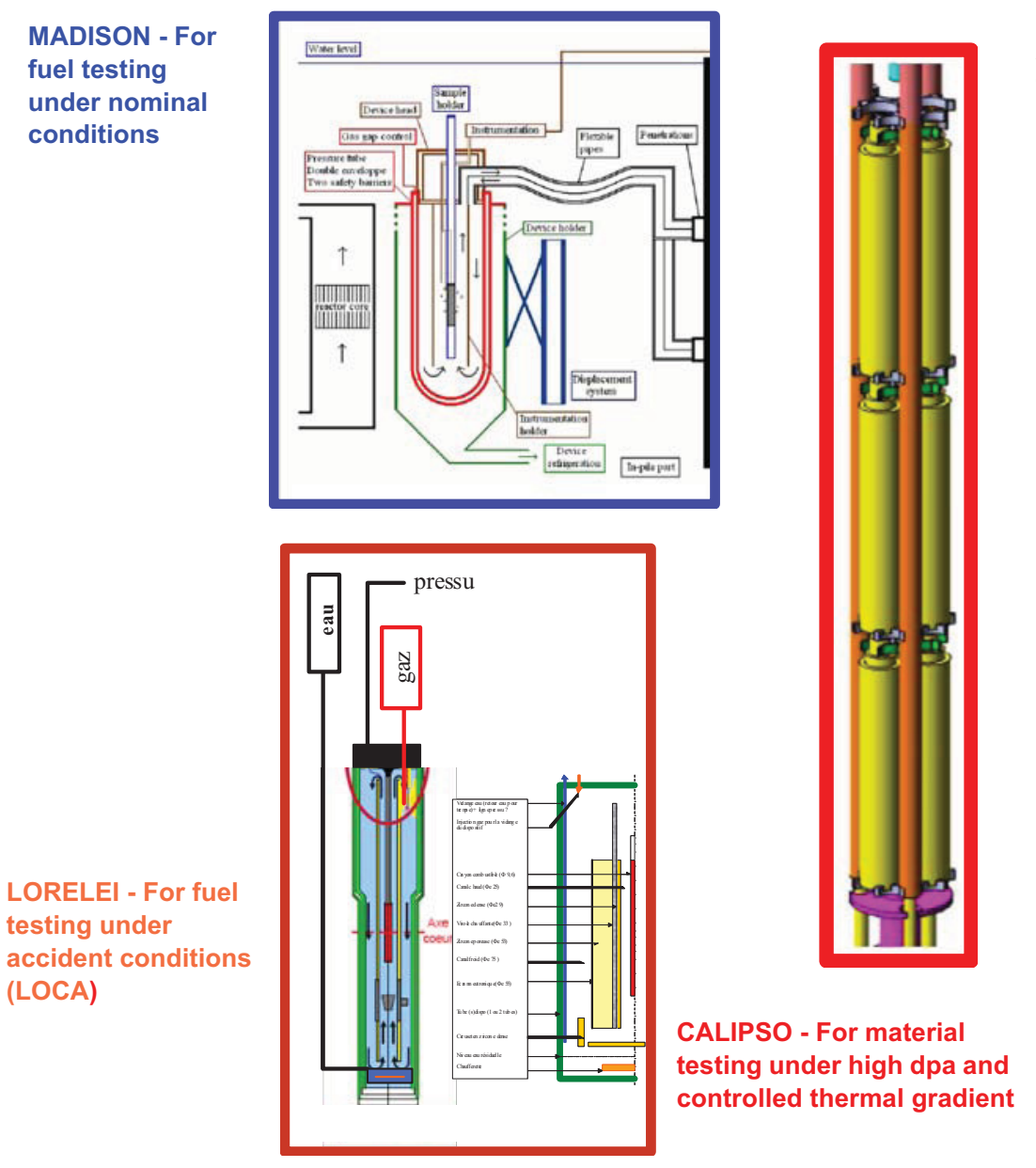

ADELINE - For fuel

testing under off-

normal conditions and

FP online

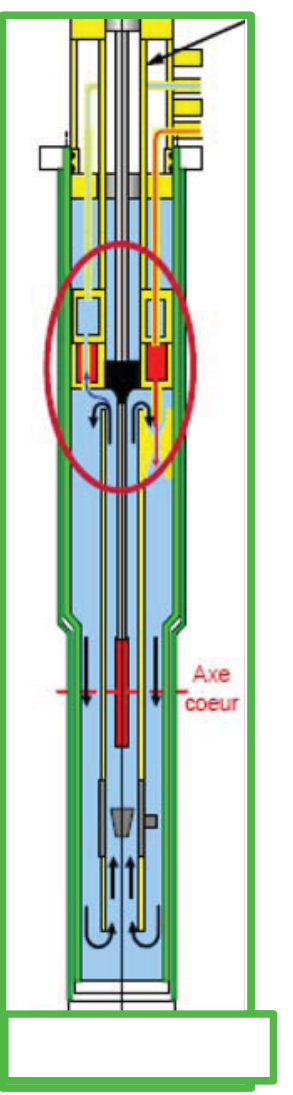

Figure 2-5. Test trains under development for JHR.

including medical isotope production research, and semiconductor industry production (neutron transmutation doping of semiconductors).

Although other test reactors, such as the HBWR, may currently have superior instrumentation capabilities and more flexible test trains, the ATR can be made competitive by adding additional capabilities required for research programs being performed at other research reactors. Many materials and fuels irradiations support research programs for existing LWRs (e.g., PWRs and BWRS) and advanced reactors (e.g, gas-cooled reactors, sodium fast reactors, and fusion reactors). Improved instrumentation for such tests offer the potential to obtain higher fidelity data, reduce irradiation costs, increase isotope production, and improve doping processes. Although research funding to advance instrumentation required to support MTR irradiations was significantly reduced in the 1980s, several organizations (as discussed in Section 3), are now promoting research programs to advance in-pile instrumentation at their MTRs. 


\section{INTERNATIONAL DEVELOPMENT EFFORTS}

As noted in Section 1.2, new instrumentation techniques are needed to support in-pile irradiation tests. Most in-pile instrumentation was developed over 20 years ago, and efforts to advance in-pile instrumentation were reduced in the 1980s. In recent years, several organizations have either initiated or enhanced their research instrumentation development programs. This section summarizes key international in-pile instrumentation efforts.

\subsection{CEA}

The "INSNU" program was initiated by the French CEA (Commissariat à l'Energie Atomique) with the aim of developing innovative in-pile instrumentation to meet the needs of emerging nuclear programs, such as GEN IV, fusion, and GNEP. ${ }^{13}-16$ The scope of these studies includes:

- radiation measurements (e.g., neutron flux and gamma heating)

- measurements of physical parameters inside the irradiation rigs (e.g., temperature, sample dimensions, and fission gas release)

The orange boxes in Figure 3-1 identify instrumentation areas studied within this CEA program. These areas were selected to address current and prospective needs identified by research reactor operators and irradiation experiment customers.

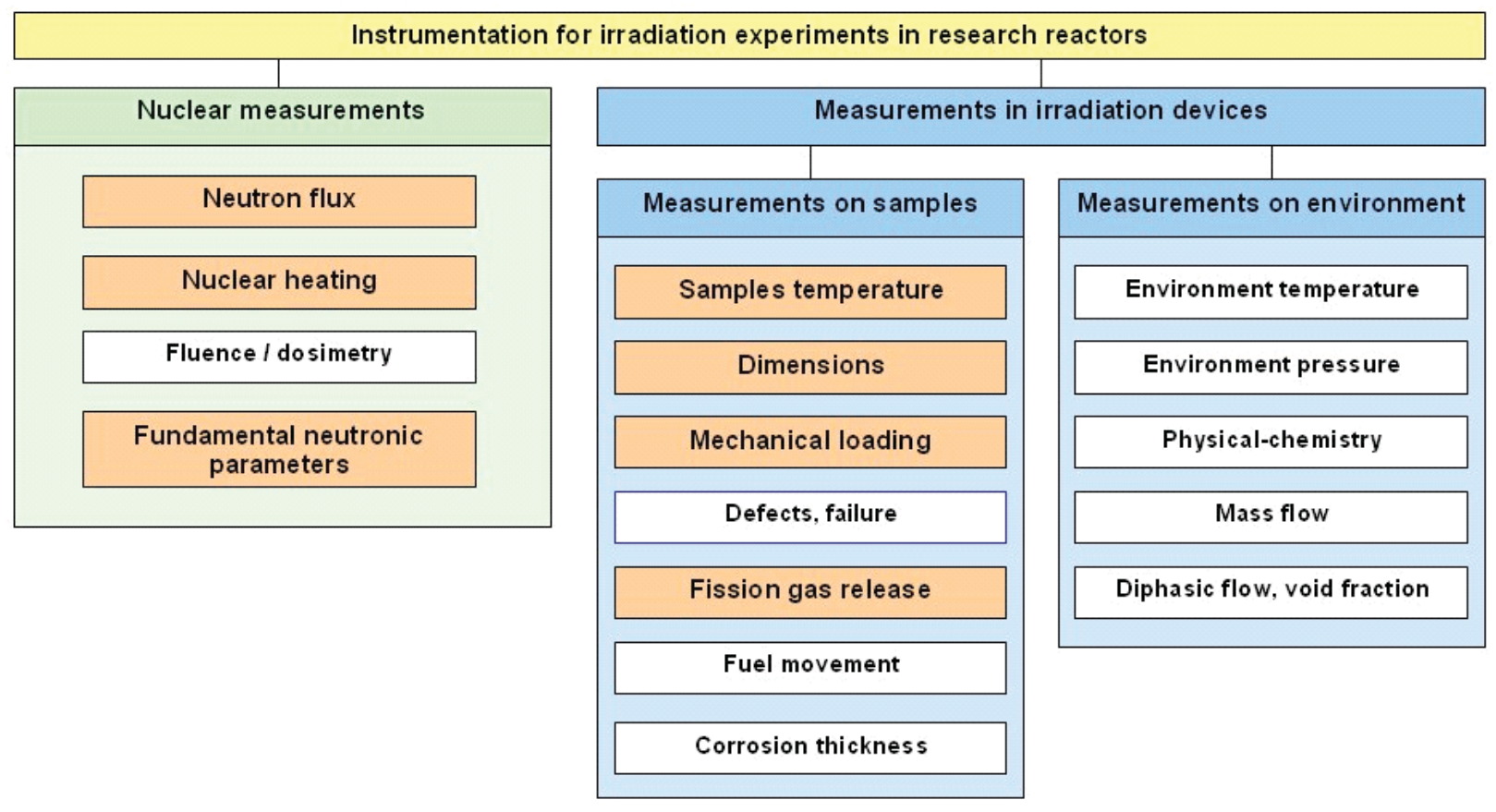

Figure 3-1. In-pile instrumentation needs for future irradiation experiments. 
Originally, INSNU was a combined CEA-Saclay (DEN/DRSN) and SCK·CEN (Belgian Nuclear Research Centre) effort to improve instrumentation in the OSIRIS reactor in Saclay, France, and the BR2 in Mol, Belgium. However, in preparation for the future Jules Horowitz Reactor that will go critical in Cadarache, France in 2014, the CEA instrumentation effort was moved to Cadarache and increased to include a larger number of organizations and sensor development activities (see Figure 3-2).

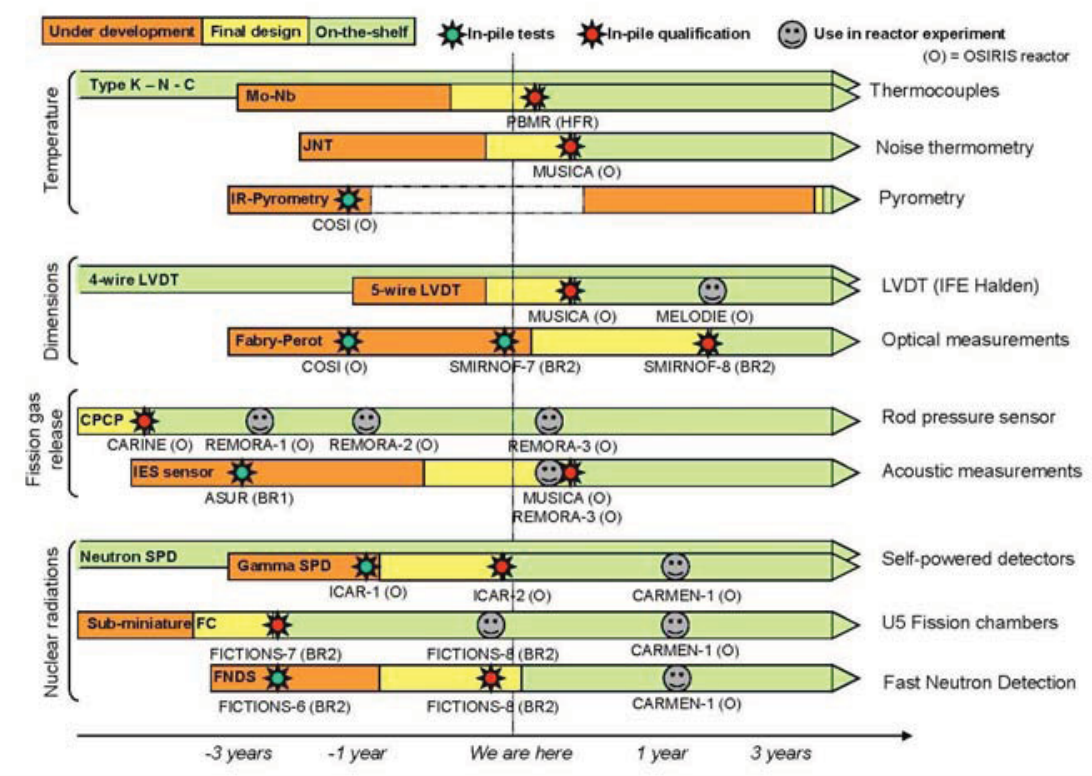

Figure 3-2. Current INSNU in-pile instrumentation research

As discussed in References 14 and 15, INSNU objectives focus upon developing innovative instrumentation for materials and test reactor irradiations that have possible fission and fusion reactor applications. Decisions for instrumentation development are based on users-needs, and development efforts include in-pile qualification. As indicated in Figure 3-2, instrumentation development efforts are often a collaborative effort between government research laboratories (CEA, PSI, HRP, etc.) and industry (e.g., Photonis, Thermocoax, etc.). By including industry partners, developers ensure its availability from a commercial supplier.

General characteristics of instrumentation developed within INSNU include:

- Reliable (because it is impossible or difficult to perform maintenance on irradiated objects)

- Accurate (sensors must meet testing requirements; e.g., $\mu \mathrm{m}$ dimensional measurements and within $5^{\circ} \mathrm{C}$ temperature measurements)

- Miniature (irradiation volumes are limited with narrow dimensions: few mm available)

- High temperature resistant $\left(>300^{\circ} \mathrm{C}\right.$, up to $\left.1600^{\circ} \mathrm{C}\right)$

- Corrosion resistant (in pressurized water, high temperature gas, and liquid metals)

- Neutron / $\gamma$ "resistant" (dose > 1GGy/day and > $10 \mathrm{dpa} /$ year in MTRs) 
As noted in References 15 and 17, in-pile instrumentation must be developed that doesn't pose a threat to the safety or economic operation of the test reactor (e.g., "simpler" is smarter). Selected examples of CEA in-pile instrumentation development are discussed below. The reader may find other examples, such as their collaboration with SCK $\cdot \mathrm{CEN}$ to explore the use of fiber optics in Section 3.2.3 or their collaboration with Forschungzentrum Jülich to demonstrate the viability of Johnson Noise Power Thermometry (JNPT) in References 14 and 15.

\subsubsection{Subminiature Fission Chambers}

For decades, in-pile neutron flux measurements were obtained using Self Powered Neutron Detectors (SPNDs), and signals were generally correlated with post-irradiation analysis of activation foil dosimeters. The development of CEA's sub-miniature fission chambers for in-pile measurements of high thermal neutron fluxes (up to $4 \times 10^{14} \mathrm{n} / \mathrm{cm}^{2}$-s) represents a significant improvement. These $1.5 \mathrm{~mm}$ external diameter sensors, containing a $\mathrm{U}^{235}$ fissile deposit, were qualified in the BR2 reactor in the CALLISTO loop between 2001 and 2004, although additional studies are needed to verify sensor robustness. These sensors are now manufactured by the PHOTONIS Company under the name "CFUZ53” (see Reference 18).

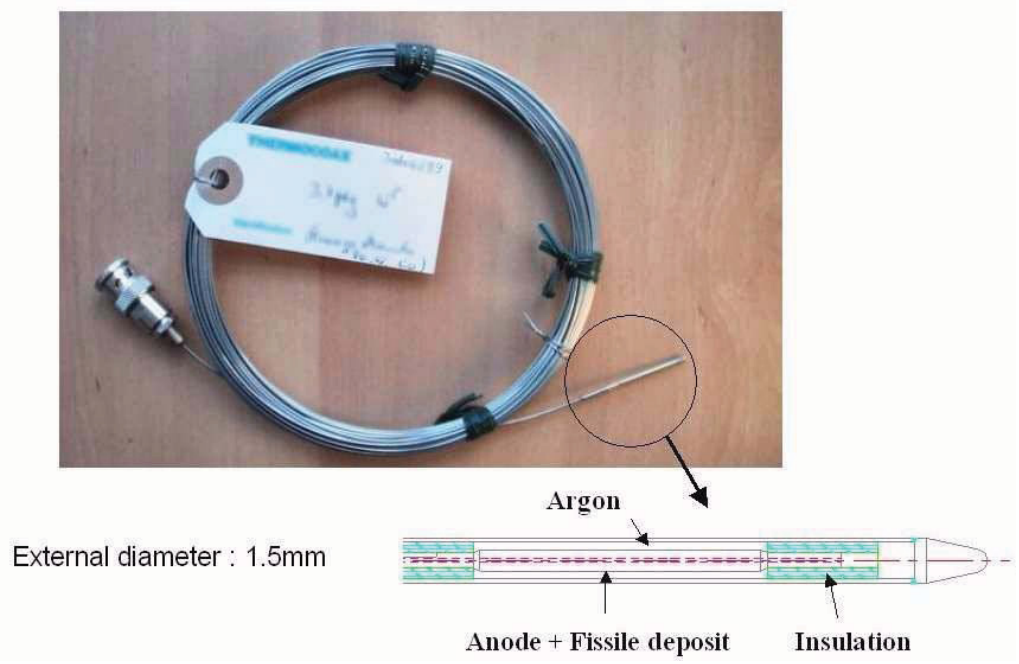

Figure 3-3. CEA-developed sub-miniature fission chamber

In addition, CEA, in collaboration with SCK-CEN, are developing and qualifying an improved sub-miniature fission chamber system, also known as the Fast Neutron Detection System (FNDS) for measuring fast neutron fluxes $(\mathrm{E}>1.0 \mathrm{MeV})$. At this time, no other sensor can provide online measurement of fast neutron flux. The FNDS is based on a patented miniature fission chamber with a special fissile deposit sensitive to fast flux with a low thermal contribution, operated in Campbelling mode for a high gamma rejection. A particular data processing software also calculates online the evolution of the signal given by the system. Major components of the FNDS are shown in Figure 3-4. 


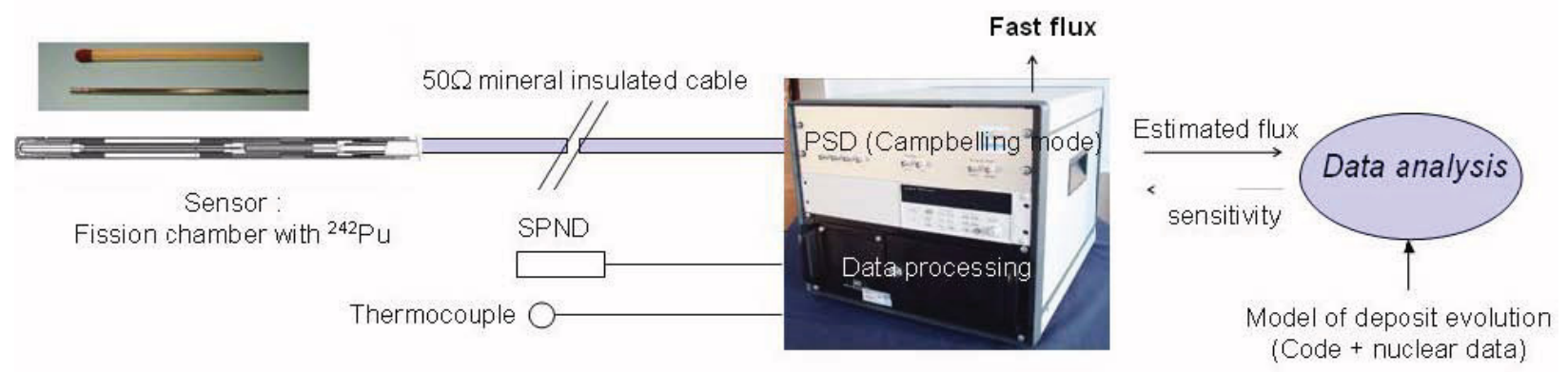

Figure 3-4. Schematic view of the FNDS prototype.

Selection of the fissile deposit in the fast fission chamber was motivated by two major factors:

- The fission cross-section is usually much larger for thermal neutrons than for fast neutrons. Moreover, even for the few isotopes presenting an energy threshold near $1 \mathrm{MeV}$, such as ${ }^{238} \mathrm{U}$ or ${ }^{242} \mathrm{Pu}$, it remains small (e.g., a few barns) for fast neutrons..

- The potential to form other isotopes via radiative capture of (primarily thermal) neutrons. This process, either directly or after some radioactive decays, leads to new isotopes in the deposit that are likely to undergo fission preferentially with thermal neutrons. The sensitivity to thermal neutrons of a chamber based on these isotopes therefore increases gradually. Note that it was decided to not use screen-absorbers that could prevent thermal neutrons from reaching the chamber, because of their large size and of the local perturbation induced on the thermal flux.

Analytical simulations of candidate fissile deposits identified ${ }^{242} \mathrm{Pu}$ as the best choice to measure the fast component of a high neutron flux for cases where there is also a significant thermal contribution over the entire reactor cycle. Its sensitivity to fast neutrons is excellent at the beginning of irradiation and slowly decreases with fluence. Prototypes of fission chambers with ${ }^{242} \mathrm{Pu}$ deposit have been manufactured by CEA in Cadarache and tested in 2005 and 2006 in the $\mathrm{BR} 2$ reactor of $\mathrm{SCK} \cdot \mathrm{CEN}$. As part of an on-going ATR NSUF effort, the use of these fission chambers for ATR applications is being investigated. Initial evaluations began in the ATRC in October 2010 (see Section 5.5).

The signal given by a fission chamber at high counting rates is the sum of a mean constant current and a fluctuation around this value. Classically, fission chambers are used in "current mode" under high neutron flux where it is not possible to individually count each event in the detector. However it is also possible to use the signal variance. This parameter characterizes the random variations of the signal around its mean value, and is proportional to the incident neutron flux. This method is called Campbelling mode or MSV (Mean Square Voltage). When a fission chamber is installed in a MTR, all interactions contribute to the signal, even those due to gamma radiation, and that can be considered as parasitic for the neutron flux measurement. This difficulty is particularly strong in MTRs because of their very high gamma level. The advantage of the Campbelling mode is that the gamma contribution to the signal is drastically less than in current mode because it plays a part as the square of the charges, which are notably lower for events generated by gamma than for those induced by fission reactions. Thus, this mode is very useful 
for rejecting the gamma component. Tests performed in the BR2 reactor in 2005 and 2006 have demonstrated that the Campbelling mode is viable for measuring the fast neutron flux: the gamma contribution to the signal of a ${ }^{242} \mathrm{Pu}$ fission chamber was reduced from $50 \%$ in current mode to $0.6 \%$ in Campbelling mode.

\subsection{2. $\mathrm{Mo} / \mathrm{Nb}$ Thermocouples}

CEA, in collaboration with the THERMOCOAX Company, has been developing high-temperature in-pile thermocouples. ${ }^{19}$ This CEA/THERMOCOAX effort investigated thermoelements containing molybdenum and niobium because the low neutron absorption cross sections of these elements make them less susceptible to transmutation-induced drift during irradiation. Materials interactions tests conducted by CEA/THERMOCOAX in high temperature furnaces, in the range from 1000 to $1600{ }^{\circ} \mathrm{C}$, indicated that materials less susceptible to interactions with $\mathrm{Mo}$ and $\mathrm{Nb}$ thermoelement wires were $\mathrm{HfO}_{2}$ insulation and $\mathrm{Nb}$ or Ta sheaths. Investigations to quantify the thermoelectric response of a loose-assembly $\mathrm{Mo}-\mathrm{Nb}$ thermocouple found that its emf in its intended temperature range $\left(1000\right.$ to $\left.1600^{\circ} \mathrm{C}\right)$ is of the same order as commercially-available high-temperature Type $\mathrm{C}$ or $\mathrm{S}$ thermocouples.

Thermal stabilization of these thermocouples was also investigated. Candidate heat treatments to stabilize grain growth to minimize drift during high temperature use were evaluated using longduration high-temperature out-of-pile tests. Reference 13 reports that thermocouples were drifting at a rate somewhat lower than $0.02{ }^{\circ} \mathrm{C} / \mathrm{h}$ at $1100{ }^{\circ} \mathrm{C}$. After 5000 hours, this would result in $100{ }^{\circ} \mathrm{C}$ or $10 \%$ drift, which is higher than observed in the INL long duration evaluations at $1200{ }^{\circ} \mathrm{C}$ of a doped $\mathrm{Mo} / \mathrm{Nb}$ alloy thermocouples (see Section 5.1).

Reference 19 reported plans for an in-pile high-temperature qualification in the OSIRIS reactor that would include both standard high-temperature and new Mo-Nb thermocouples in a long-term neutron irradiation experiment called "THERMEX" (see Figure 3-5). During irradiation, the reference temperature will be regularly established by using a pure copper fixed point melting device from which results will be compared with temperatures measured by these Mo-Nb thermocouples. More recent information ${ }^{15}$ suggested that there were plans to irradiate these thermocouples in the HRF reactor as part of CEA's gas reactor research program and that THERMOCOAX was investigating the use of doped $\mathrm{Mo} / \mathrm{Nb}$-alloy thermoelement materials. ${ }^{1}$

\subsubsection{Improved Linear Variable Differential Transducers (LVDTs) and Diameter Gauges}

CEA, in collaboration with the Institute for Energy Technology at the Halden Reactor Project (IFE/HRP), have recently started an effort to improve the performance of Linear Variable Differential Transducers (LVDTs). Since 2005, LVDT technologies fabricated by IFE-Halden have been used in the OSIRIS reactor with accuracies of $+/-4 \mu \mathrm{m}$ and displacements up to $+/-$ $15 \mathrm{~mm}$ (total range) and +/- $6 \mathrm{~mm}$ (linear range). During 2007, CEA performed a series of out-of-

1. More recent information indicates that plans for irradiation qualification have been indefinitely delayed.. 


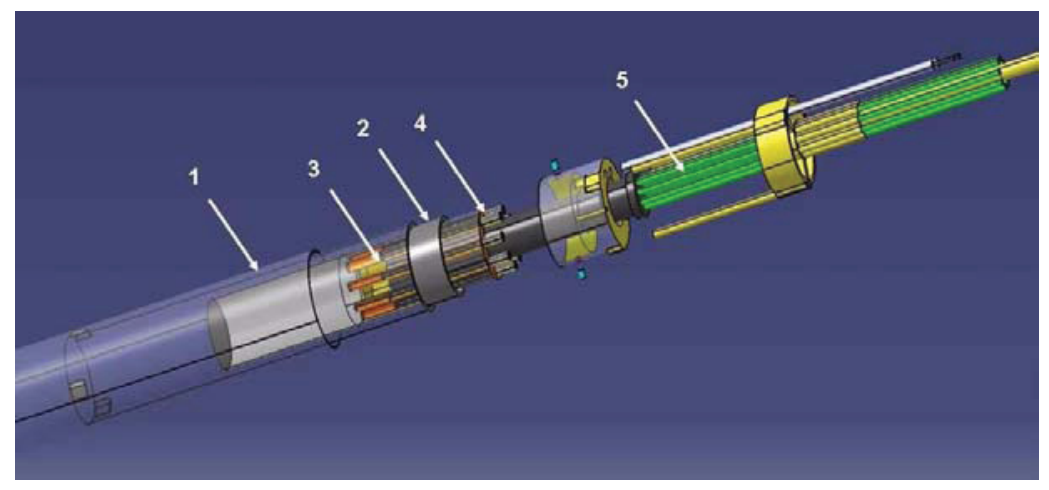

Figure 3-5. THERMEX experiment device: stainless steel capsule (1), graphite barrel (3) filled with pure copper (2), additional electric heating elements (4), thermocouples (5).

pile tests to characterize and try to improve the performance of these LVDTs and diameter gauges based on LVDT sensors. CEA investigations were focussed upon:

- Quantifying usable LVDT temperature range

- Quantifying maximum LVDT measurement range

- Developing the most appropriate LVDT signal correlation versus measurement ranges

- Developing post-test appropriate LVDT adjustments (Gain - Phase)

Tests were conducted at room temperature and at higher temperatures (up to $380{ }^{\circ} \mathrm{C}$ ) in inert gas, water, and sodium potassium conditions

As part of this effort, CEA proposed several improvements to LVDT designs currently manufactured by IFE/HRP. First, to extend their measurement range, CEA requested that a polynomial equation be used to characterize the signal of LVDTs procured from IFE/HRP. Second, CEA requested that IFE/HRP develop a 'fifth wire' or "self compensating electronics setup." Figure 3-6 illustrates the wiring used for such a setup (compared to the standard 4-wire setup that only uses the wires labeled 1,2,3, and 4). In this configuration, wire 3 and 4 are Type $\mathrm{K}$ " $\mathrm{B}$ " thermocouple wires and Wire 5 is a Type $\mathrm{K}$ " $\mathrm{A}$ " thermocouple wire. In a 4-wire configuration, only the voltage difference between the two secondary coils is measured. Hence, the voltage output is proportional to the core displacement, or

Displacement $=G \cdot\left(V_{C 1}-V_{C 2}\right)$

Where $G$ is the gain, and $V_{C 1}$ and $V_{C 2}$, represent the voltage of coils 1 and 2 , respectively. In the 5 -wire setup, the additional wire is connected as a zero reference between the two secondary coils. Hence, the ratio between the two secondary coils is used to estimate the displacement, using

Displacement $=G \cdot \frac{\left(V_{C 1}-V_{C 2}\right)}{\left(V_{C 1}+V_{C 2}\right)}$ 
Theoretically, the influence of global changes in the system will have negligible effect on the system because the resulting signal is a ratio. For example, this setup offers several potential improvements:

- improved linearity

- suppression of temperature sensitivity

- $\quad$ suppression of signal aberrations in its central area

- suppression of Curie temperature effects of nickel (although this requires experimental confirmation)

- suppression of signal shift due to irradiation (although this requires experimental confirmation)

In particular, the ratio of signals from the secondary are used to quantify elongation rather than the combined secondary signal. As long as the LVDT is at a uniform temperature, the signal should be more accurate (because it is no longer susceptible to Curie temperature effects). However experience indicates that the LVDT is not often at a uniform temperature.

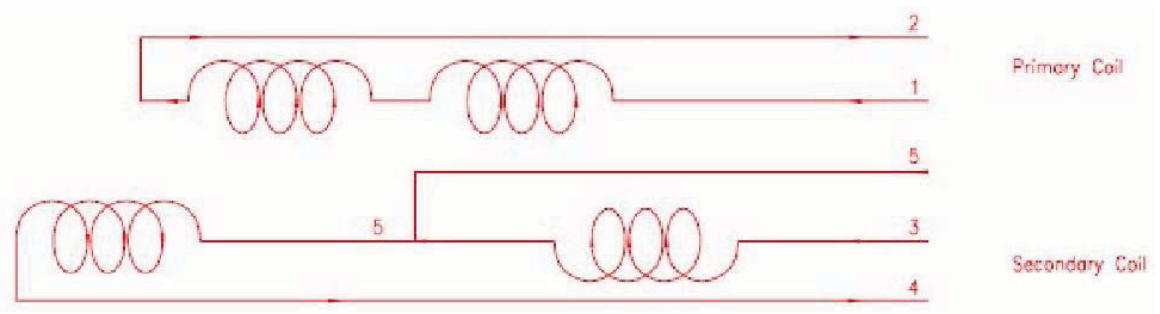

Figure 3-6. Wiring schematic for LVDTs using the five-wire method.

In the MELODIE and MUSCIA tests, it is planned to evaluate the performance of these improved designs in the OSIRIS reactor during 2010. As shown in Figure 3-7, the MELODIE tests is designed to provide real-time elongation and diameter change data from an in-core irradiation of a PWR fuel cladding tube $(90 \mathrm{~mm})$ at $350{ }^{\circ} \mathrm{C}$. The test capsule includes controlled mechanical loading ranging from 60 to $180 \mathrm{MPa}$ (with stress steps) and variable biaxial stress ratio: ranging from 0 (hoop stress) to infinity (axial stress).

\subsubsection{Fission Gas Release}

In-situ measurement of fission gas release is particularly important in fuel rod irradiations because fission gas release kinetics is an important indicator of nuclear reactions and its measurement is key in fuel performance studies. There is interest in detecting the composition and amount of fission gas release. To address this need, CEA is investigating counter-pressure and acoustical measurement techniques.

Figure 3-8 shows the counter-pressure sensor used by CEA to detect the pressure associated with fission gas release from a fuel rod during irradiation. The imbalance between the internal rod pressure and the counter-pressure is accurately detected by two electric contacts, activated by the 

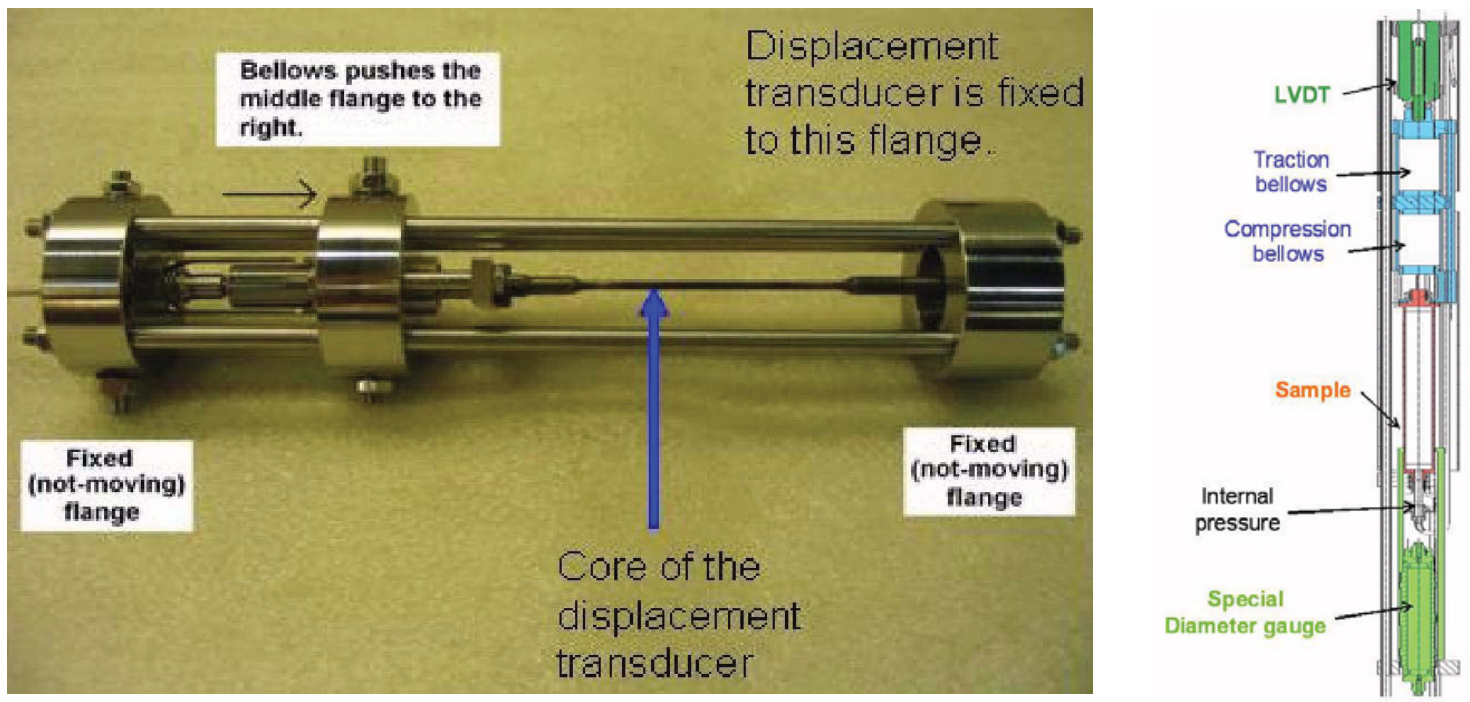

Figure 3-7. Proposed sensor for detecting elongation and diameter changes in OSIRIS testing.

motion of the bellows. The physical principles associated with the counter-pressure avoids any decalibration due to nuclear radiation. The automatic acquisition and control system drives the counter-pressure operation and checks the integrity of the double bellows as a safety barrier. The sensor was firstly qualified in-pile on a dummy fuel rod with a controlled internal pressure. The measured accuracy is $< \pm 0.5$ bar in the whole pressure range of interest. The counter-pressure sensor has been used successfully in REMORA-1 and REMORA-2 experiments. Design and manufacturing of a special counter-pressure sensor for high-pressure measurements (up to 250 bar) is underway.

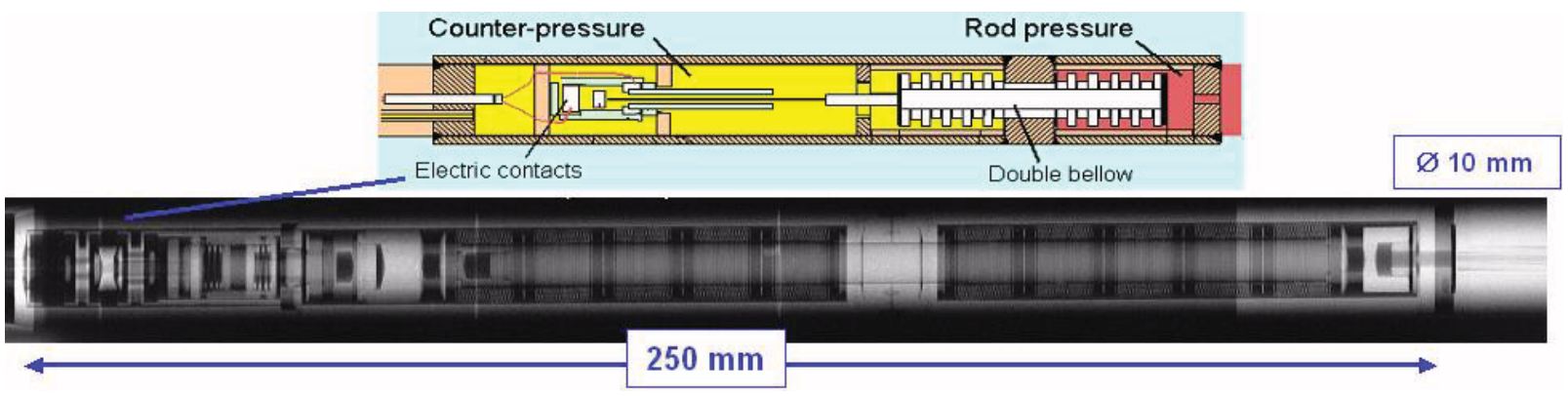

Figure 3-8. CEA counter-pressure sensor for detecting fission gas release amount.

A dedicated acoustic sensor (containing a pizeoelectric transducer) has been developed by CEA to measure online fission gas release in a fuel rod during irradiation experiments. Figure 39(a) illustrates some of the details related to the design of this acoustic fission gas release sensor. ${ }^{14}$ This assembly is composed of a small cylindrical cavity containing the gas to be analyzed. The upper part of the cavity is closed by a thin stainless steel plate. The piezoelectric transducer is fixed on this plate, in order to generate and measure acoustic waves, through the plate, in the gas cavity. Wires are directly welded on the piezoceramics electrodes. Acoustic waves propagate in 
the gas inside the cavity which is connected to the fuel rod plenum. The measurement of the reflected waves allows determination of the acoustic impedance of this system. Figure 3-9(b) illustrates the acoustic sensor principle. The signal and its echoes are recorded, and the time of flight of the signal and its attenuation are measured. From these measurements, it is possible to deduce simultaneously the molar mass of the gas (from the acoustic waves velocity) and the pressure of the gas (from the echoes attenuation). The online assessment of these two parameters is then used to obtain information regarding the fraction of fission gases released in the fuel rod..
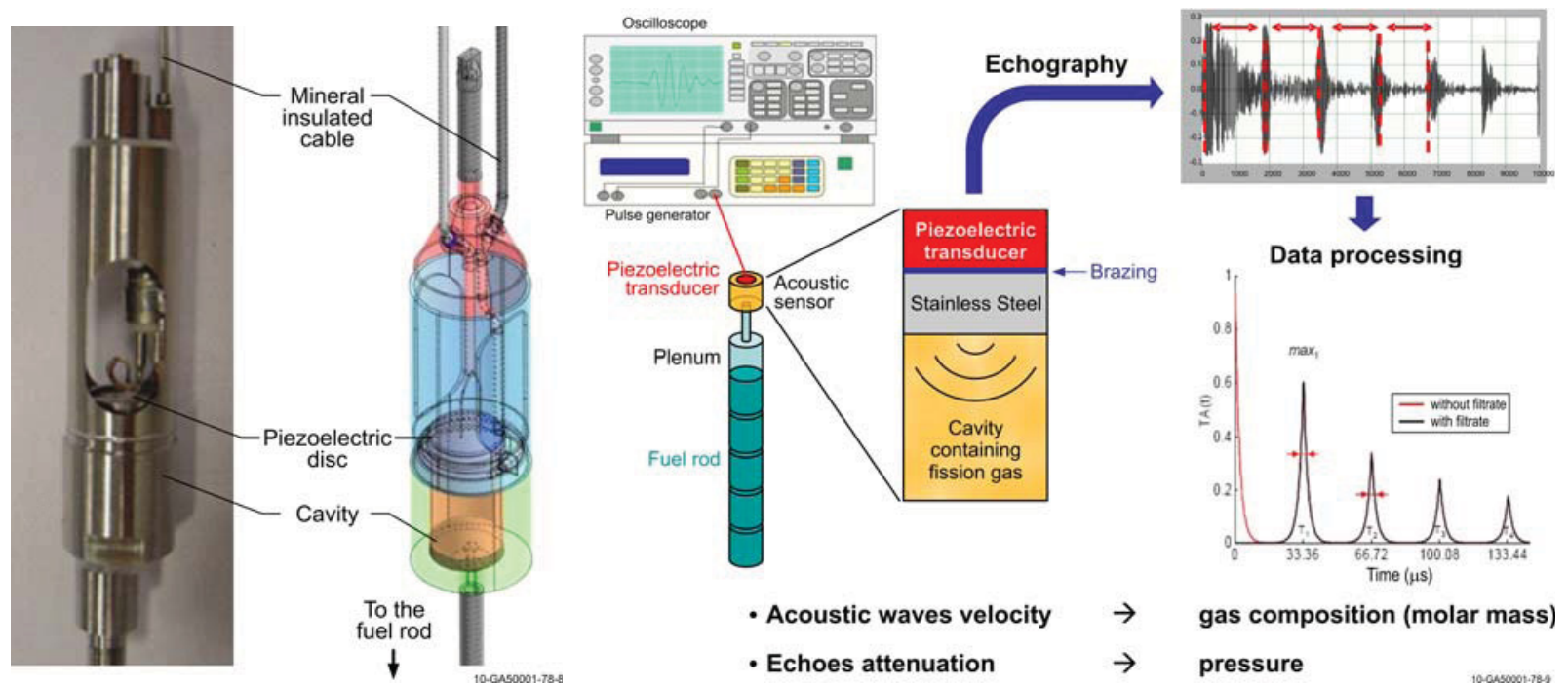

Figure 3-9. CEA fission gas release pressure and composition detection (a) sensor and (b) system operation.

Initial laboratory testing of acoustic sensor prototypes have been completed by CEA. In 2008, final sensors for use on a pre-irradiated fuel rod were designed and manufactured. The irradiation experiment REMORA-3, which started in 2010 in OSIRIS, includes this sensor installed on a pre-irradiated Pressurized Water Reactor fuel rod.

\subsection{SCK·CEN}

In support of their BR-1 and BR-2 reactors in Belgium and to facilitate irradiations at other nuclear reactors, Studiecentrum voor Kernenergie - Centre d'Étude de l'énergie Nucléaire $(\mathrm{SCK} \cdot \mathrm{CEN})$ continues to perform research focussed upon in-pile instrumentation development, evaluations, and fabrication. ${ }^{16}$ Selected projects currently investigated by SCK·CEN are summarized in this section. Some of these instrumentation development efforts are collaborations between SCK·CEN and CEA, such as the SMFCs discussed in Section 3.1.1 and the fission gas release sensors discussed in Section 3.1.4. Another interesting capability now available at the BR2 reactor is in-pile tensile testing with sensors to detect the load applied to the specimen and the elongation of the specimen (see Section 3.2.4). ${ }^{27}$ 


\subsubsection{Real-time measurement of gamma and neutron fluxes}

In 1999, SCK ·CEN manufactured the experimental device, DOLMEN (Device for On-Line MEasurement of the Neutron flux). This instrument contains SPNDs, activation dosimeters and gamma thermometers that can be moved vertically in any BR2 channel. Prior to manufacturing this device, SCK · CEN optimized the DOLMEN design using data from an irradiated RhodiumSPND and two specifically designed gamma-thermometers in various BR2 reactor channels. In addition, SCK $\cdot$ CEN theoretically studied the sensitivities of each type of SPND versus neutron and gamma spectra. The SCK·CEN-developed computer model SEDEIRA (SElf-powered DEtector of Ionizing RAdiation) showed the importance of the insulator in the SPND and the role played by the neutron spectrum on the detector performance. SCK CEN is developing a new Monte-Carlo model, which will allow analysts to evaluate the signals from in-pile monitoring devices in the BR2 reactor and parasitic effects of neutron and gamma fluxes in the instrumentation chain. The DOLMEN device has been inserted into the BR2 reactor. Objectives of this irradiation include developing an algorithm for estimating the actual neutron flux using the measured electric signal, identifying the sensitivity to each parameter (neutron spectrum, gamma spectrum), qualifying a calibration method, and assessing the best suitable SPND for specific applications.

\subsubsection{Radiation-hardened Micro-electronics for Nuclear Instrumentation}

SCK CEN has also initiated an effort to develop new electronics and communication equipment capable of withstanding in-pile irradiations with radiation levels in excess of several MGy. Goals of this task are to identify commercially available equipment and to ultimately design improved radiation tolerant ( $>$ several MGy) integrated electronic circuits. Using a stepwise approach, SCK $\cdot \mathrm{CEN}$ is first designing circuits with discrete components that can withstand radiation and then looking for an equivalent integrated technology. This will enable SCK·CEN to develop innovative instrumentation and communication tools for the next generation of nuclear reactors, where both radiation hardening and miniaturization play a dominant role.

\subsubsection{Fiber Optic Testing}

MTRs could benefit from advantages offered by fiber-optic communication and sensing systems. However, the deployment of such systems in nuclear environments has been limited up to now, mainly due to reliability and safety constraints. Prior investigations (see Reference 21 for a review) have shown that the lifetime of fiber-optic components depends on the fiber composition, the temperature, the total dose, and the operating wavelength. Radiation affects the optical transmission of silica by creating various point defects of different nature that in turn absorb light at specific wavelengths. This Radiation-Induced Absorption (RIA) is particularly strong in the ultraviolet (UV) spectrum, which limits the fiber applicability to a very low dose (typically less than 10 -100 Gy). Compared to the UV spectrum, fiber-optic transmission in the visible spectrum is less critical, but transmission can still remain a concern (especially for long fiber paths) due to the formation of an absorption band at $600 \mathrm{~nm}$, which is believed to pertain to the creation of nonbridging hole centers. However, hydrogen treatment applied to the silica fibers can reduce the for- 
mation of non bridging oxide hole centers (NBOHCs) and has been shown to improve their radiation resistance in the visible spectrum. Optical absorption of less than $0.5 \mathrm{~dB} / \mathrm{m}$ at $630 \mathrm{~nm}$ has been demonstrated in aluminum-coated fibers irradiated with $\gamma$-rays up to $6 \mathrm{MGy}$ and less than 5 $\mathrm{dB} / \mathrm{m}$ under fission reactor irradiation up to about $20 \mathrm{MGy}$ and neutron fluences of $5 \mathrm{x} 10^{19} \mathrm{n} / \mathrm{cm}^{2}$ $\left(\mathrm{E}_{\mathrm{n}}>0.1 \mathrm{MeV}\right)$.

At higher doses, optical fiber applications may be possible for wavelengths above $850 \mathrm{~nm}$. Previous in-core reactor experiments at MTRs in Europe and Japan demonstrated that RIA can remain limited to few $\mathrm{dB} / \mathrm{m}$ in the $800-1100 \mathrm{~nm}$ even after intense irradiation levels. Such RIA in the near infrared spectral region opens perspectives for the development of new types of in-core reactor instrumentation based on optical fiber sensors (OFS) technology. OFSs offer attractive and unique sensing capabilities which can be of particular benefit for measurements inside MTRs. The major advantages are the capability for passive remote sensing with the potential for high accuracy and operation at high-temperature (500-1000 $\left.{ }^{\circ} \mathrm{C}\right)$. In addition OFSs feature capabilities for distributed sensing with extremely limited intrusiveness. Low intrusivity appears to be a key factor in MTRs, not only because of limited space availability but also because small sensors will not disturb the temperature and radiation profile of the material under study.

As part of a collaboration between $\mathrm{CEA}$ and $\mathrm{SCK} \cdot \mathrm{CEN}$, a program was initiated to develop a new OFS prototype with the aim of measuring dimensional changes on nuclear materials irradiated in MTRs. As part of this effort, the COSI experiment was completed in which the single mode (SM) and multimode (MM) optical fibers listed in Table 3-1 were irradiated in the OSIRIS reactor for 92 days (corresponding to a thermal fluence of $10^{21} \mathrm{n}_{\mathrm{th}} / \mathrm{cm}^{2}$ and a fast fluence of $10^{20}$ $\mathrm{n}_{\text {fast }} / \mathrm{cm}^{2}$, and a calculated gamma dose rate of $7.2 \times 10^{6} \mathrm{~Gy} / \mathrm{hr}$, with an integrated ionizing dose of 16 GGy). This duration, which corresponds to representative conditions during a typical materials irradiation program, is over an order of magnitude increase than other tests reported in the literature.

Table 3-1. Single mode and multimode optical fibers tested in OSIRIS COSI test

\begin{tabular}{|c|c|c|c|c|}
\hline Fibers & Manufacturer & $\begin{array}{c}\text { Manufacturer Designator } \\
\text { (SM or MM) }\end{array}$ & $\begin{array}{c}\text { Core/Cladding } \\
\text { Diameter }\end{array}$ & Coating \\
\hline $\begin{array}{c}\text { FORC1 } \\
\text { FORC2 } \\
\text { FORC3 }\end{array}$ & $\begin{array}{c}\text { Fiber Optic } \\
\text { (Moscorch Center }\end{array}$ & -/SM & $\sim 10 \mu \mathrm{m} / 150 \mu \mathrm{m}$ & acrylate \\
\hline B11 & $\begin{array}{c}\text { Blaze Photonics } \\
\text { (Cristal Fiber) }\end{array}$ & HC 1060-02/SM & $9.7 \mu \mathrm{m}(\mathrm{hole}) / 125 \mu \mathrm{m}$ & acrylate \\
B13 & Polymicro & FIP100.110.125 STU//MM & $\sim 100 \mu \mathrm{m} / 110 \mu \mathrm{m}$ & polyimide \\
\hline STU1 & Polymicro & FIP100.110.150/MM & $\sim 100 \mu \mathrm{m} / 150 \mu \mathrm{m}$ & aluminum \\
\hline FIL1 & & FIP100.110.150/MM & $\sim 100 \mu \mathrm{m} / 150 \mu \mathrm{m}$ & aluminum \\
\hline FIL2 & Polymicro & & & \\
\hline FVL2 & & & & \\
\hline
\end{tabular}

As shown in Figure 3-10, the fibers were mounted onto an aluminum plate and placed in a $2 \mathrm{~mm}$ internal diameter stainless steel tube. The fibers made a loop with a bend radius of either 
23 or $32 \mathrm{~mm}$. The fluence was measured with a SPND. Although placed in the periphery of the core, the central part of these $40 \mathrm{~m}$ fibers was close to the reactor core. Results from this test indicate that there are SM and MM optical fibers with acceptable losses for testing in MTRs. As shown by representative results in Figure 3-11, the most favorable spectral region lies in the 800$1200 \mathrm{~nm}$ range .

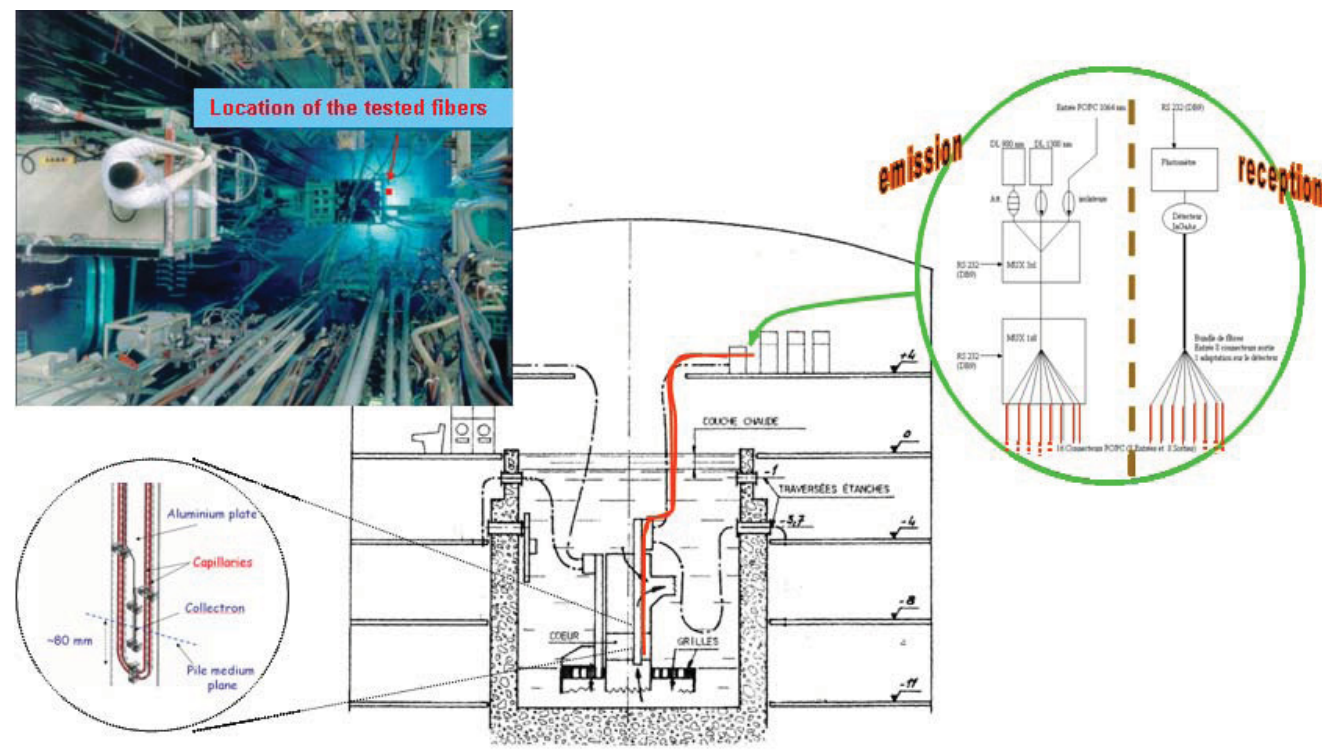

Figure 3-10. COSI test rig setup.

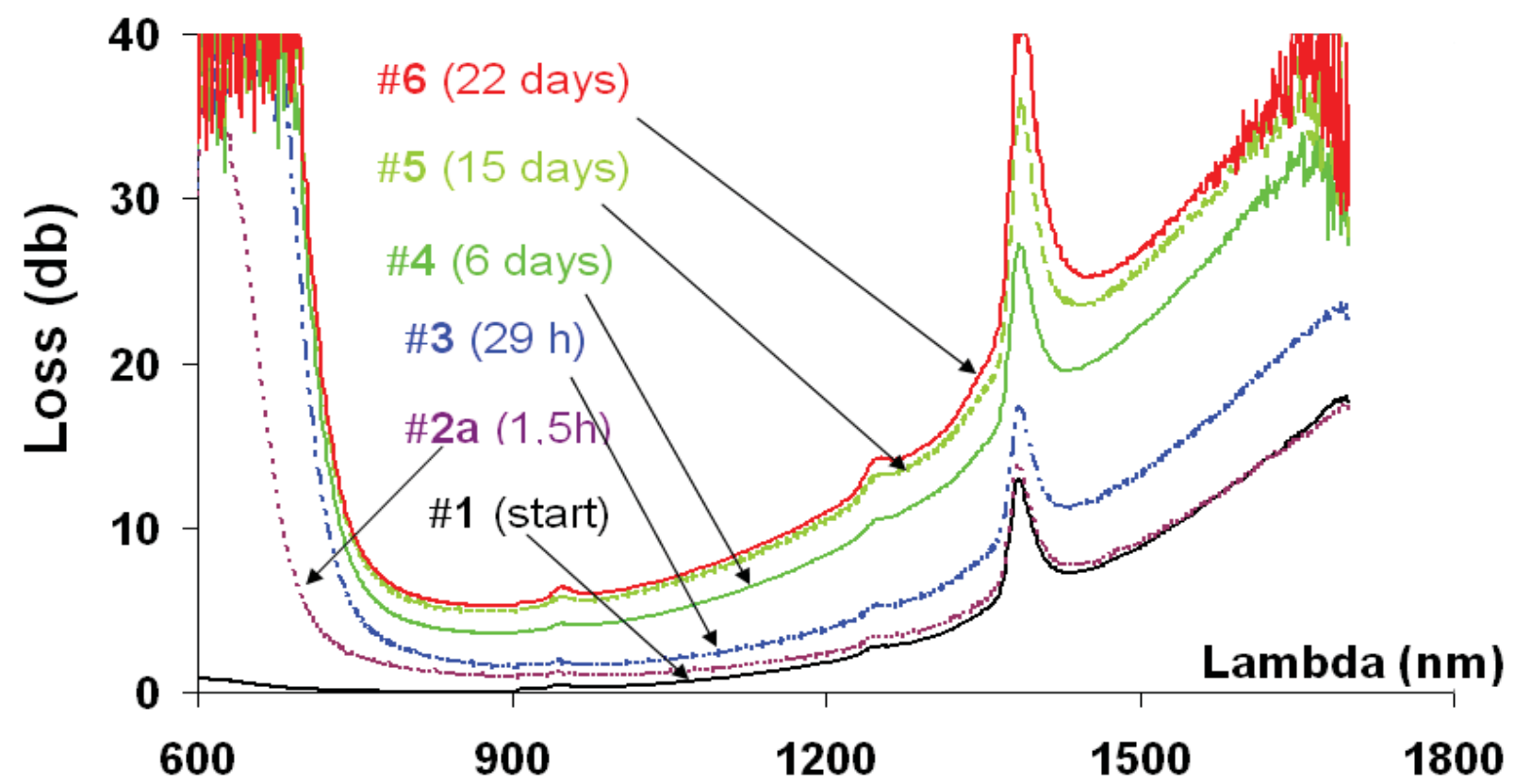

Figure 3-11. Representative results from COSI-Change in loss for the STU2 fiber (22 days corresponds to $3 \times 10^{20} \mathrm{n}_{\mathrm{th}} / \mathrm{cm}^{2}$ and $3 \times 10^{19} \mathrm{n}_{\text {fast }} / \mathrm{cm}^{2}$ ) 
To address concerns about degradation of fiber optic mechanical properties, SCK $\cdot \mathrm{CEN}$ tested four standard telecom acrylate-coated Ge-doped single-mode fibers from three different manufacturers and one acrylate-coated Ge-doped multi-mode fiber. Fiber samples of $50 \mathrm{~m}$ were loosely coiled with a diameter of $60 \mathrm{~mm}$ and exposed to a dose rate of $27 \mathrm{kGy} / \mathrm{h}$ up to a total dose of $15 \mathrm{MGy}$ at an ambient temperature of approximately $55^{\circ} \mathrm{C}$. Several mechanical tests were performed before and after irradiation, including a two-point bend test. These destructive two-point bend tests allow quantification of the fibers' strength (50\% failure stress) and the dynamic fatigue factor. Weibull analysis revealed a strength reduction of about $50 \%$ at these MGy dose levels. SEM (scanning electronic microscope) images of fiber samples, which had their coatings removed after irradiation, suggest that 'roughening of the outer glass surface' may cause this degradation. These results indicate that the long-term mechanical strength of optical fibers could be seriously affected when exposed to MGy dose levels.

Figure 3-12 shows a fiber-optic based sensor jointly developed by CEA and SCK CEN for detecting elongation of material samples during irradiation. This sensor is based on an extrinsic Fabry Perot interferometer using a radiation-resistant pure silica core fiber: a cavity is positioned at the end of the fiber, and thus sets an optical path difference (OPD) that can be modulated by the external actions such as sensor elongation. This OPD gives rise to a characteristic optical interference pattern from which the cavity length can be retrieved by signal demodulation. The signal of this miniaturized sensor (outer diameter is about $250 \mu \mathrm{m}$ ) gives the absolute length of the cavity, which is mechanically linked to the sample elongation.
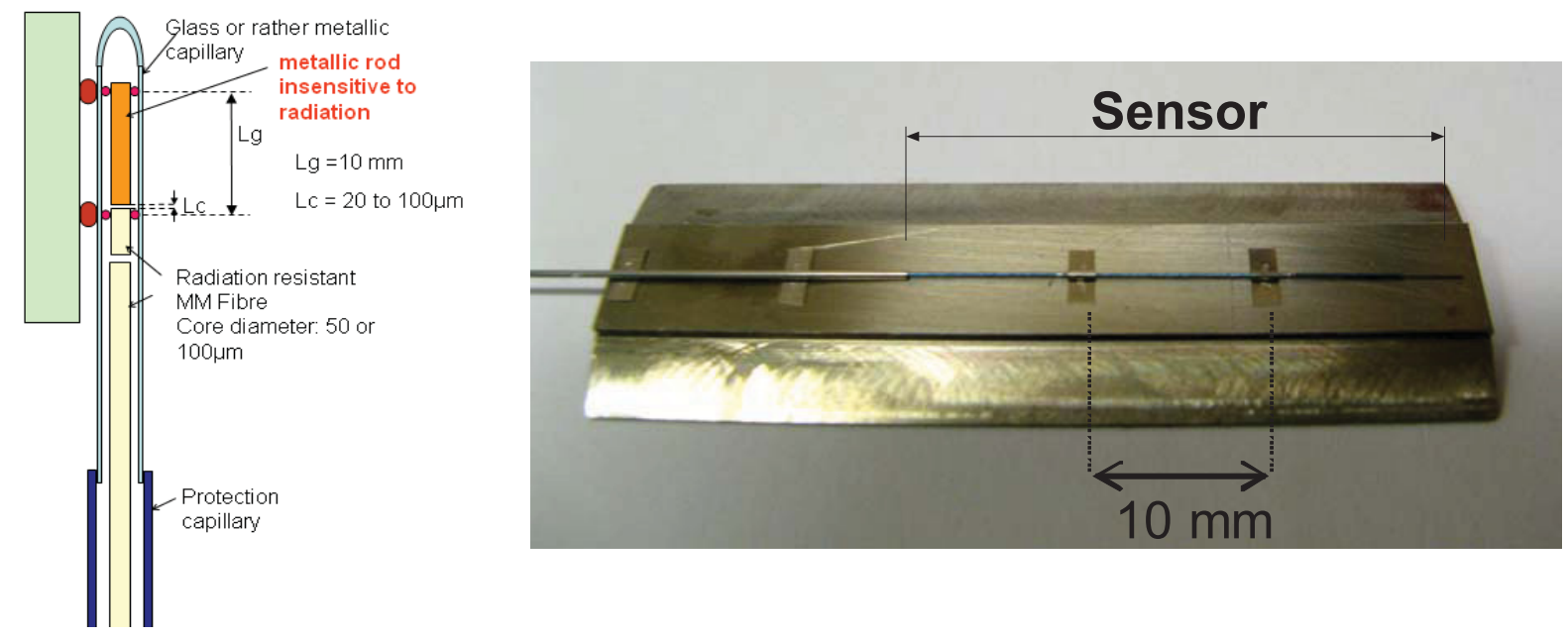

Figure 3-12. Optical fiber based elongation detection sensor developed by CEA and SCK-CEN.

Improvements were made to minimize the consequence of radiation-induced silica compaction and to refine the fixing technique. Irradiation testing of the first prototypes of this sensor was performed in 2009 in the BR2 reactor. In addition, further enhancements have been implemented to increase the level of the modulation and upgrade the mechanical behavior of the sensor. Optimized prototypes will be irradiated at BR2 during 2011. ${ }^{22}$ 


\subsubsection{In-Pile Tensile Testing}

As part of a European Fusion Development Agreement (EFDA), the BR-2 has been used to demonstrate the performance of an in-pile tensile test module developed by the VTT Technical Research Center of Finland. As discussed in Reference 27, it is recognized that it is unlikely that the primary damage experienced by a specimen will be affected by the applied stress during irradiation. However, it is believed that the subsequent process of dislocation formation, that is responsible for radiation hardening, yield drop, and plastic flow localization, will be substantially altered by the applied stress. It is speculated that the fatigue lifetime during in-situ cyclic loading experiments may be significantly different from the ones obtained during fatigue experiments on specimens in the post-irradiated condition. Hence, an in-situ material testing system was developed by VTT and used to perform fracture mechanic, corrosion fatigue, tensile, and electrochemical measurements in the BR-2.

As shown in Figure 3-13, this test system is based on the use of a pneumatic loading unit, which loads a test specimen using gas to pressurize metallic bellows, and a LVDT from IFE/HRP (see Section 3.3.1) to measure the resulting displacement produced in the tensile specimen. The outside diameter of the module is $25 \mathrm{~mm}$, and the total length of the module with the LVDT is $150 \mathrm{~mm}$. Figure 3-14 shows the actual test rig with this module developed by Mol for irradiations in the BR-2 reactor. During irradiation, the test assembly remained submerged in stagnant demineralized water. For approximately 300 hours, the specimens were exposed to a neutron flux of $3 \times 10^{13} \mathrm{n} / \mathrm{cm}^{2} \mathrm{~s}(\mathrm{E}>1 \mathrm{MeV})$ corresponding to a displacement damage rate of $\sim 6 \times 10^{-8} \mathrm{dpa} / \mathrm{s}$. The temperature of the test module increased rapidly (up to $90{ }^{\circ} \mathrm{C}$ within 15 minutes) due to gamma heating power of $4.4 \mathrm{~W} / \mathrm{g}$. Then, the desired strain was imposed on the specimen.

The load generated by the pneumatic loading unit with the metallic bellows was calculated from the pressure difference experienced by the bellows. The stiffness and effective cross section of the bellows impacts the load produced by the specimen. However, the 'stiffness' of the pneumatic loading unit differs from the stiffness of the bellows. Hence, VTT developed a calibration unit (see Figure 3-15) to correlate the applied gas pressure in the bellows with the actual load acting on the tensile specimen. A two step calibration procedure was implemented. In the first step, the characteristic stiffness of the bellows together with friction forces of the moving parts of the module were determined. In the second step, the load induced on the tensile specimen by the applied gas was measured directly by a load cell.

\subsection{IFE/HRP}

The Organization for Economic Cooperation and Development (OECD)-sponsored Halden Reactor Project (HRP), which is operated by the Norwegian Institutt for Energiteknikk (IFE), has more than thirty years of experience in performing complicated in-core measurements and experiments in the Halden Boiling Water Reactor (HBWR); and a wide range of specialized sensors, equipment and techniques have been developed for this purpose. 


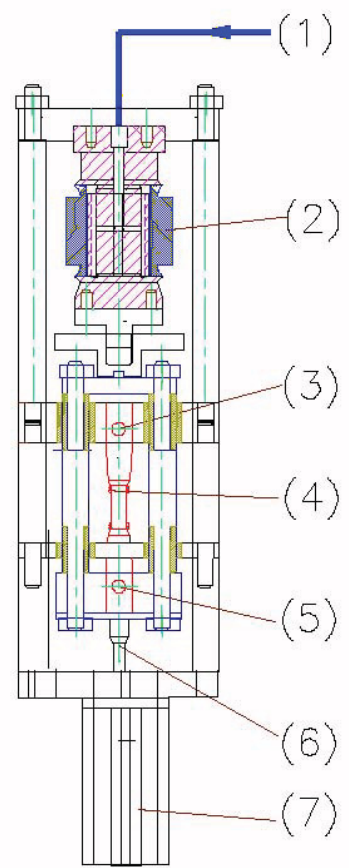

Figure 3-13. Schematic of tensile test module: (1) gas line, (2) pneumatic loading unit, (3) firm specimen fixing point, (4) specimen, (5) movable specimen fixing point, (6) LVDT plunger and (7) LVDT holder.
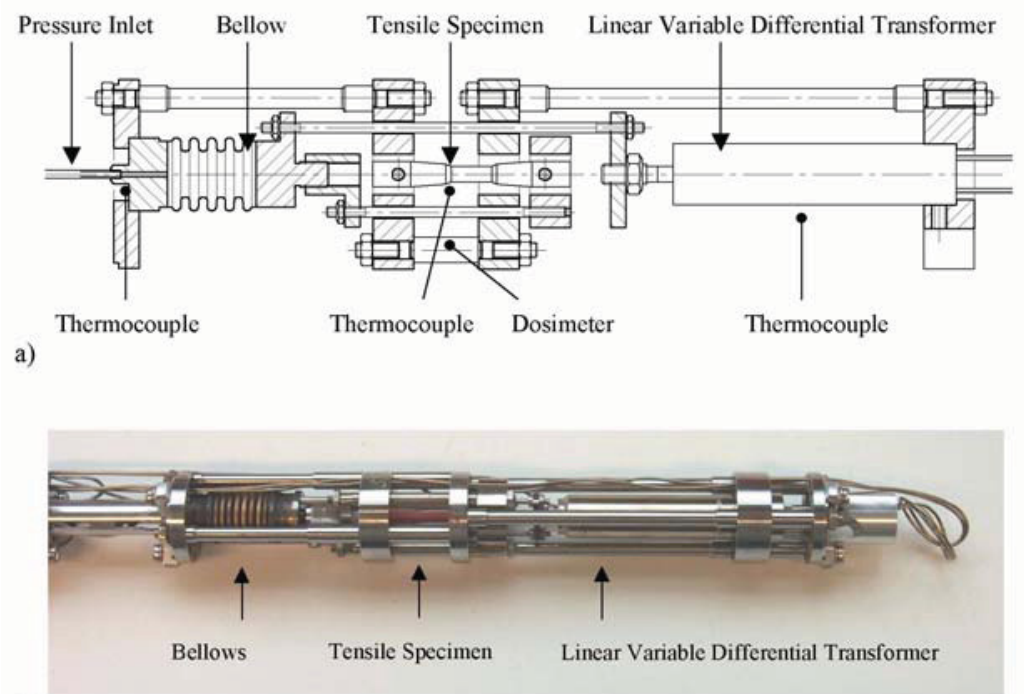

b)

Figure 3-14. Tensile test rig for BR-2 irradiations: (a) simplified layout and operational features including necessary instrumentation; and (b) final assembly of test module prior to installation in the test rig.

As listed in Table 3-2, a wide range of in-core instrumentation has been developed, fabricated, and used by the IFE/HRP for measuring key fuel and material performance parameters 


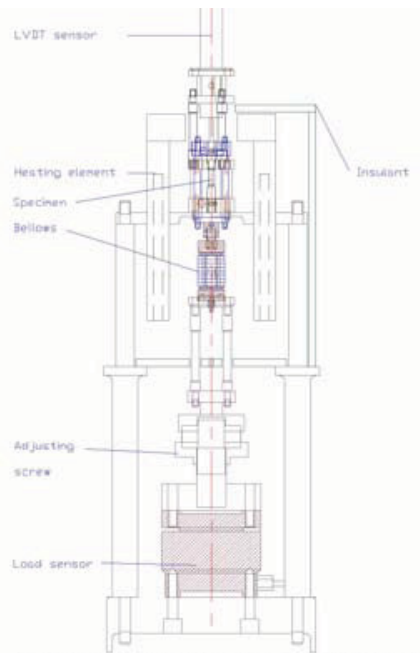

Figure 3-15. High temperature calibration device of the pneumatic loading unit.

such as fuel temperature, fuel swelling / densification, fission gas release, cladding creep, corrosion/crud buildup, and crack-growth rates. ${ }^{28-35}$ Instruments are also available for monitoring the irradiation environment (e.g. SPNDs and miniaturized gamma thermometers) and thermalhydraulic and water chemistry conditions (e.g. flow meters, ECP-electrodes and conductivity cells). HRP-developed sensors can be attached to non-irradiated fuel rods and material samples or to pre-irradiated fuel rods and material samples by using remote operated manipulators and specially-designed re-instrumentation equipment. Ongoing IFE/HRP instrumentation development focuses on high temperature conditions, new methods for crack detection and 
corrosion of fuel cladding materials, and online corrosion detection by means of Electrochemical Impedance Spectroscopy (EIS).

Table 3-2. Instrumentation available at HBWR.

\begin{tabular}{|l|l|}
\hline \multicolumn{1}{|c|}{ Instrument } & \multicolumn{1}{c|}{ Parameters } \\
\hline Turbine flow meter & $\begin{array}{l}\text { inlet /outlet flow (single or two phase); with channel power information, outlet } \\
\text { void fraction }\end{array}$ \\
\hline Thermocouples (Type K and C) & temperature ${ }^{\text {a }}$ and thermal conductivity \\
\hline Expansion Thermometer & temperature \\
\hline Gamma thermometer & gamma flux, fuel assembly power indication \\
\hline Self-powered neutron detectors & neutron flux, fuel heatup rate and burnup, power \\
\hline Void gauge & dynamic void measurements in a fuel channel \\
\hline $\begin{array}{l}\text { LVDTs (cladding extensometers, fuel } \\
\text { diameter gauges, position indicators) }\end{array}$ & $\begin{array}{l}\text { fuel rod mechanical deformation (e.g. creep and strain), fuel and cladding } \\
\text { length changes, profiles for changes in cladding diameter, temperature } \\
\text { (deduced from expansion of known material in an expansion rod), crack } \\
\text { initiation, and pressure (deduced from movement of plate attached to LVDT) }\end{array}$ \\
\hline Pressure gauges & fuel rod fission gas pressure \\
\hline Eddy current cladding defect sensor & cladding defects, crack growth \\
\hline Electrical impedance spectroscopy & corrosion growth \\
\hline Level gauges & moderator level \\
\hline $\begin{array}{l}\text { Electrical chemical potential } \\
\text { measurements (platinum or palladium } \\
\text { electrodes) }\end{array}$ & oxygen concentration, hydrogen concentration (e.g., corrosion potential) \\
\hline Gap meter (squeezing technique) & internal fuel rod gaps \\
\hline
\end{tabular}

a. Note HBWR-specific corrections are required to compensate for transmutation that occurs in Type $\mathrm{C}$ high temperature thermocouples during irradiation. However, similar temperatures and fluxes and temperature gradients and flux distributions must exist during irradiation in order to apply such correction factors, and the thermocouple lifetimes are generally limited to 1 year at high temperatures. Furthermore, informal HRP discussions indicate that there are batch-to-batch variations in the Type $C$ thermocouples that they receive. b. Thermal conductivity estimates require assumptions about fuel densification, and gap conductance (if it isn't assumed to close). ${ }^{32}$

The HRP relies heavily on specialized in-core instrumentation in order to perform fuel and material irradiation programs in the HBWR. In recent years, IFE/HRP has become a supplier of in-pile instrumentation for other test reactors (e.g., OSIRS, BR-2, and HANARO). This subsection provides additional information about selected IFE/HRP instrumentation development activities.

\subsubsection{Linear Variable Differential Transformers (LVDTs)}

Many IFE/HRP-developed sensors rely upon LVDTs as a base instrument. The principle design of an LVDT is shown in Figure 3-16. LVDTs are electrical transformers with three coils placed end-to-end around a tube (see Figure 3-16a). The center coil is the primary, and the two outer coils are the secondaries. A cylindrical magnetically-permeable core, attached to the object whose position is to be measured, slides along the axis of the tube. An alternating current is driven through the primary, causing a voltage to be induced in each secondary which is proportional to its mutual inductance in the primary. As the core moves, these mutual inductances change, 
causing the voltages induced in the secondaries to change. The coils are connected in reverse series, so that the output voltage is the difference between the two secondary voltages. When the core is in its central position, equidistant between the two secondaries, equal but opposite voltages are induced in these two coils, so the output voltage is zero (see Figure 3-16b).

In the IFE/HRP LVDTs, the primary coil is activated by a constant current generator (at 400-2500 Hz). The position of the magnetically-permeable core can be measured with an accuracy of $\pm 1-10 \mu \mathrm{m}$ (references vary on this value). Since the HRP started with in-core measurements, more than 2200 LVDTs of different types have been installed in different test rigs in the HBWR and other test reactors around the world. A failure rate of less than $10 \%$ after 5 years of operation is expected for their LVDTs operating in BWR, PWR or CANDU conditions. Hence, operating experience has shown that these sensors are a robust, frictionless instrument for detecting dimensional changes in lower-temperature, irradiation environments. .

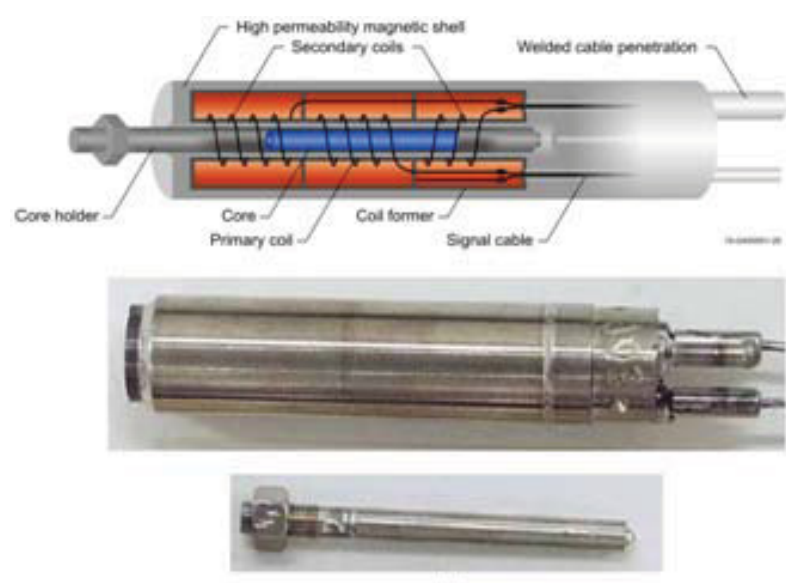

(a)

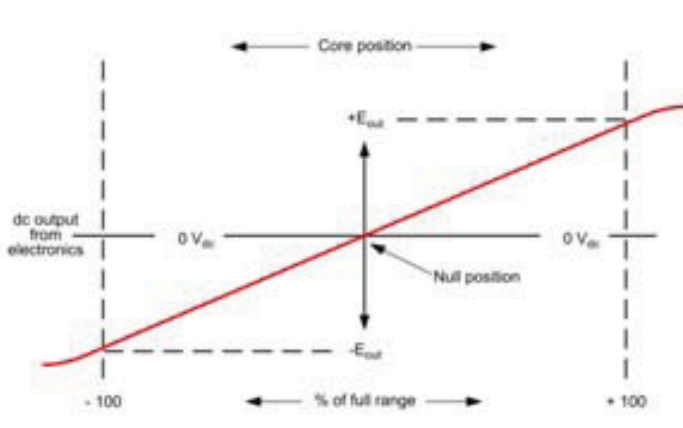

(b)

Figure 3-16. Principle design of a LVDT.

Using LVDTs as a base instrument, specialized sensors have been deployed by IFE/HRP that allow on-line monitoring of various parameters, such as fuel stack elongation, cladding elongation, fuel centerline temperature, fuel diameter, and fuel rod pressure. For example, build-up of a cladding oxide layer and detection of the point of dry-out can be derived from the above measurements. One example of note is a diameter gauge (see Section 3.3.5) that enables on-line measurement of cladding diameter changes due to pellet cladding interaction and creep. This, and other sensors used and developed at the HBWR are described in this section.

Recently, IFE/HRP has explored several improvements for LVDTs. As discussed in Section 3.1.3, IFE/HRP staff has collaborated with CEA to improve the accuracy of LVDTs when they are subjected to the Curie temperature. As noted in Section 5.3, the IFE/HRP is also collaborating with INL to investigate the use of alternate coil wires that eliminate Curie temperature effects and design modifications to improve the high temperature performance of LVDTs and diameter gauges. 


\subsubsection{Fuel centerline temperature measurements}

For monitoring fuel centerline temperatures, the IFE/HRP uses thermocouples and/or expansion thermometers. Fuel centerline temperature measurements provide important information on the thermal performance of the fuel and if desired, the fuel thermal conductivity. By monitoring the fuel thermal conductivity over a longer period of time, the fuel thermal conductivity degradation as a function of burn-up is studied. An example of $\mathrm{UO}_{2}$ thermal conductivity data derived from fuel centerline temperature measurements is illustrated in Figure 3-17. Informal discussions ${ }^{31}$ indicate that such tests have been done with specially-designed fuel rods with a small as-fabricated fuel-to-clad gap that minimizes the influence of gap conductance change (densification/swelling, fission gas release) on the fuel center temperature during the irradiation. Smaller diameter fuel rods are often used in such tests to increase the burnup accumulation rate. In addition, in-pile local power measurements are required for such tests.

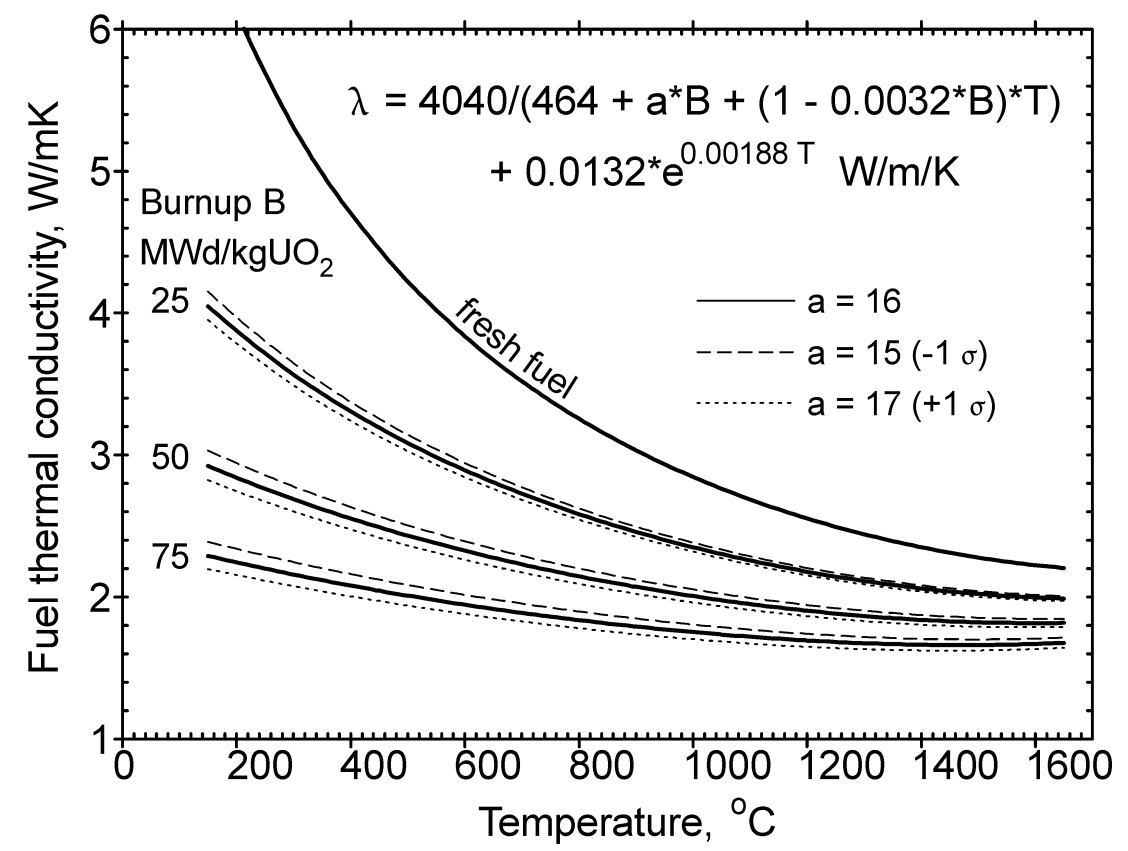

Figure 3-17. Fuel thermal conductivity derived from fuel centerline temperature measurements.

IFE/HRP fuel centerline thermocouples normally operate for several years in-core without failure, but the lifetime of the "Type C" tungsten-rhenium used in the HBWR thermocouples has been found to decrease with increasing fuel centerline temperatures. If the fuel centerline temperature exceeds 1400 to $1500{ }^{\circ} \mathrm{C}$, the expected lifetime of the Type $\mathrm{C}$ thermocouples, which must be used with an HBWR-specific correction factor to offset transmutation, is typically less than one year (although no fluence values were cited, the peak thermal flux at the HBWR is $1 \times 10^{14}$ $\mathrm{n} / \mathrm{cm}^{2} \mathrm{~s}$ ). Furthermore, informal discussions with HRP staff indicate that 'batch-to-batch' variations have been observed in Type $\mathrm{C}$ thermocouples procured from various vendors.

The IFE/HRP expansion thermometer (see Figure 3-18) consists of a tungsten rod (a molybdenum rod may also be used) that is inserted through a hole drilled in a fuel stack. The thermal 
expansion of the tungsten rod is measured using an LVDT. The fuel centerline temperature is then derived from the measured expansion of the tungsten rod. The expected lifetime of an expansion thermometer is longer than for a thermocouple, but the resolution of an expansion thermometer is less than a thermocouple because the expansion thermocouple only provides an estimate of the average temperature over the length of the rod. There is also the potential for mechanical interactions between the fuel and the tungsten rod that can affect expansion thermometer performance.

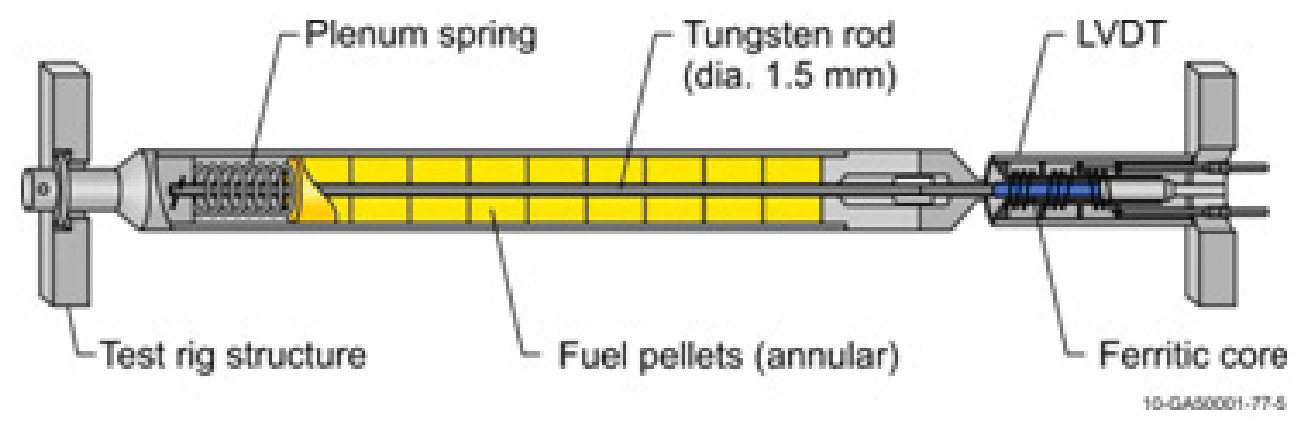

Figure 3-18. Thermal expansion thermometer.

\subsubsection{Fuel densification / swelling measurements}

The mechanical stability of nuclear fuels is an important performance parameter. For in-pile monitoring fuel stack-length changes, the HRP has also developed instruments based on LVDTs. In order to measure fuel densification and swelling, the magnetic core of the LVDT is attached to a spring-loaded plate in contact with a fuel pellet in one end of the fuel stack (see Figure 3-19). The magnetic core then follows the expansion and contraction of the fuel stack and provides data on the fuel's mechanical behavior.

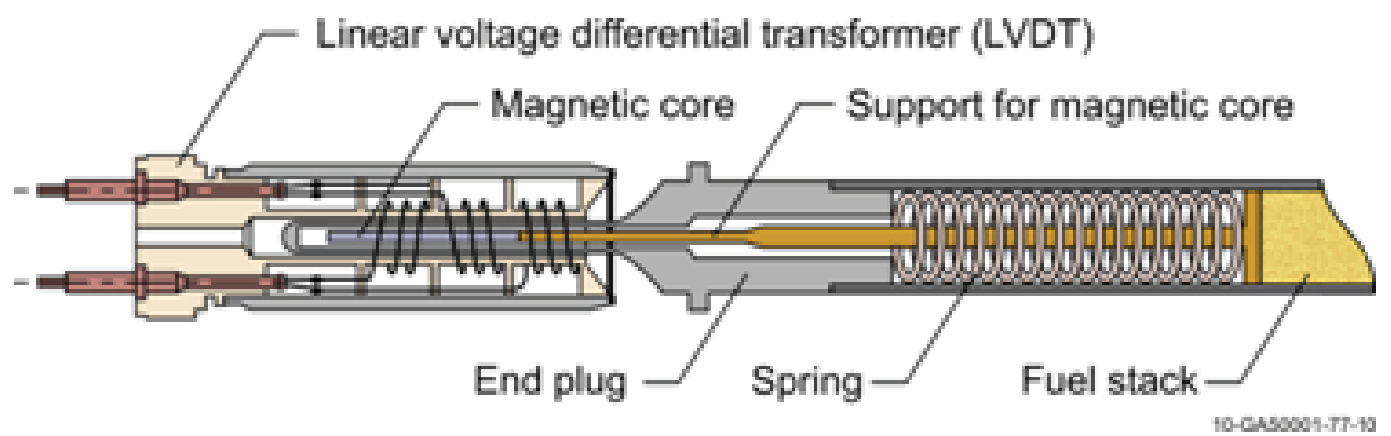

Figure 3-19. Fuel stack elongation detector.

\subsubsection{Fuel rod pressure measurements}

IFE/HRP monitors fuel rod internal pressure to gain insights about fission gas release during irradiation. The pressure transducer consists of a miniaturized bellows mounted in the fuel rod 
end plug (see Figure 3-20). A magnetic core is fixed to the free moving end of the bellows; the other end of the bellows assembly is fixed to the end plug. The bellows is typically pressurized to 2 bar less than the initial rod pressure and seal welded. Bellows/core movements are sensed by an LVDT. The bellows differential pressure will, in addition to release of fission gases, be dependent upon fuel densification/swelling characteristics, changes in gas temperature and fuel/cladding thermal expansion during operation. Densification will lower the fuel rod internal pressure, while swelling and gas temperature effects and fuel differential expansion will increase fuel rod internal pressure.

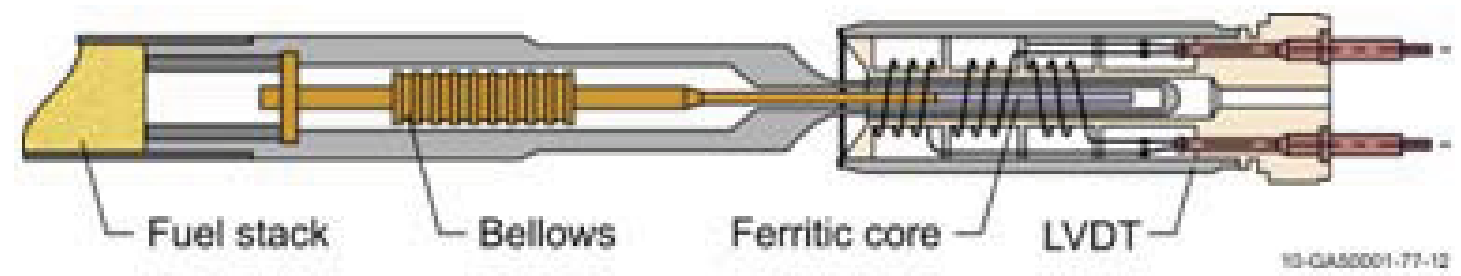

Figure 3-20. Pressure gauge

The pressure transducers are available for different pressure ranges. The most common ranges have a $\Delta \mathrm{p}$ (internal versus external pressure of the bellows) of 15 bar (type I), 30 bar (type II) or 70 bar (type III). The difference between these bellows is related to the stiffness/spring rate. During the initial stages of fission gas production, it is often necessary to use a bellows with high sensitivity (but a limited pressure range). For such conditions, the 15 bar bellows is an obvious choice. For high burnup tests in which high rod pressure is expected, the 70 bar bellows is more suitable. Higher pressure range is achieved by sacrificing sensitivity. The linear movement of the different bellows types are almost the same for the given pressure range; hence, the sensitivity (in $\mathrm{mV} /$ bar) is better for lower pressure range transducers. Under realistic conditions, the uncertainty of the pressure for the 30 bar sensor is \pm 0.2 bar; for the 70 bar sensor, the uncertainty is \pm 0.5 bar.

In order to keep the same precision as a type II transducer, while still being able to reach 70 bars, a new type of transducer has been designed. Two different bellows, having different levels of stiffness, are connected in series. In this way, the softer bellows is dominant at lower pressure. When reaching the maximum pressure for the softest bellows of the two, further compression of this bellows is restricted by an internal mechanical stop. The stiffer bellows then becomes the only contributor to the signal output.

Measurement ranges up to 150 bar (15 $\mathrm{MPa}$ or $2180 \mathrm{psig})$ are possible. To reduce material creep at high temperature and radiation intensity, the bellows are pre-pressurized (inside) and conditioned for several days at high pressure and temperature. The pressure transducer can be systematically re-calibrated during reactor outages using procedures developed at IFE/HRP (that IFE/HRP will provide to other facilities employing one of their sensors). 


\subsubsection{Fuel rod diameter measurements}

Specialized IFE/HRP sensors have been developed that allow on-line monitoring of various parameters, such as fuel rod diameter. The IFE/HRP diameter gauge enables on-line measurement of cladding diameter for assessing cladding creep, pellet-cladding mechanical interaction, fuel creep / relaxation and fuel rod crud deposits. The representative test rig shown in Figure 3-21a provides real-time in-pile detection of fuel rod diameter changes, temperature, neutron exposure and loop coolant temperature, flow, and chemistry (e.g., concentration, $\mathrm{pH}$, etc.). IFE/HRP relies on LVDT-based technology in this diameter gauge. As shown in Figure 3$21 \mathrm{~b}$, the diameter gauge contains a differential transformer with two feelers on opposite sides of the fuel rod. During testing, the diameter gauge travels along the fuel rod using an in-core hydraulic drive and positioning system. In some test rigs (see Figure 3-21a), the fuel rod is moved by the hydraulic drive. The accuracy of the diameter gauge is $\pm 2 \mathrm{~mm}$, and a calibration is performed in conjunction with each diameter trace by having calibration steps on both fuel rod end plugs. The diameter gauge can operate at up to 165 bar and $325^{\circ} \mathrm{C}$, However, IFE/HRP is investigating the potential to increase this temperature limit and sensor accuracy using alternate components and fabrication processes.

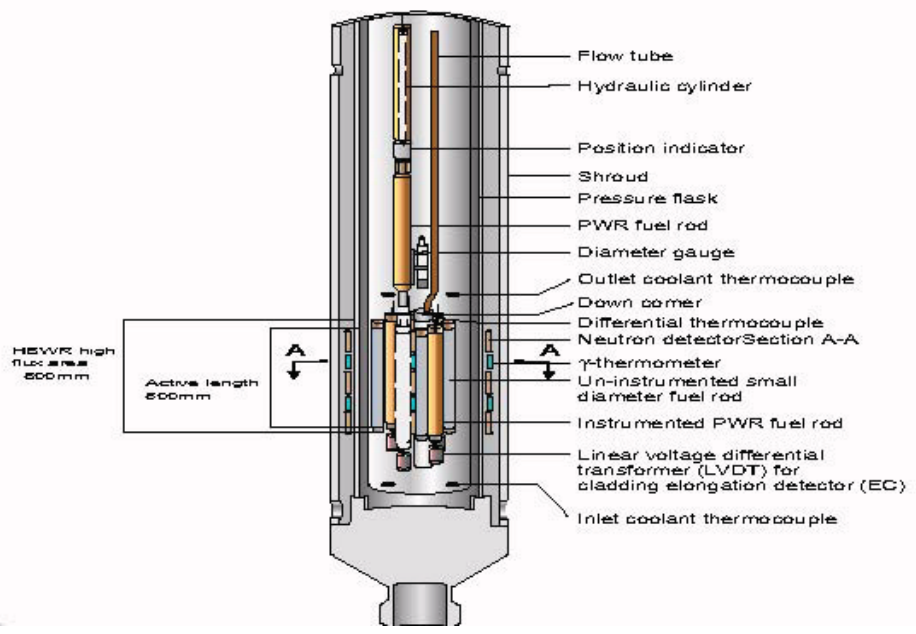

(a)

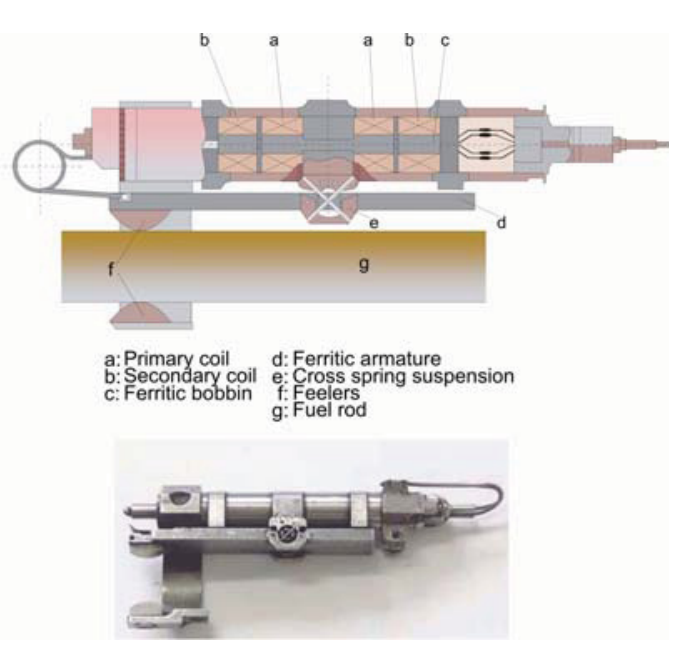

(b)

Figure 3-21. HRP fuel pellet cladding interaction/crud deposition test rig (a) with diameter gauge (b).

Figure 3-22 shows results from diameter measurements on a typical PWR fuel rod irradiated in the HBWR as part of a PWR crud evaluation program. The irradiation is performed in a PWR loop system that allows variations in water chemistry parameters during irradiation. Diameter gauge run no. 7275 was performed immediately after startup of the experiment to provide initial fuel rod diameter data. Diameter gauge run no. 7739 was performed after approximately 230 days at full power and shows cladding creep-down typical for PWR fuel rods. Diameter run. no. 7754 was performed after an additional 25 days after changing the water chemistry in the loop system. The water chemistry change included an increase in the iron and nickel content. The diameter 
trace shows that crud deposits formed on the upper part of the fuel rod. The possibility of observing the formation of crud by monitoring the fuel rod diameter on-line along with changes in neutron flux and fuel temperature provides the IFE/HRP insights into developing a remedy for crud and related phenomena such as the "Axial Offset Anomaly". 32

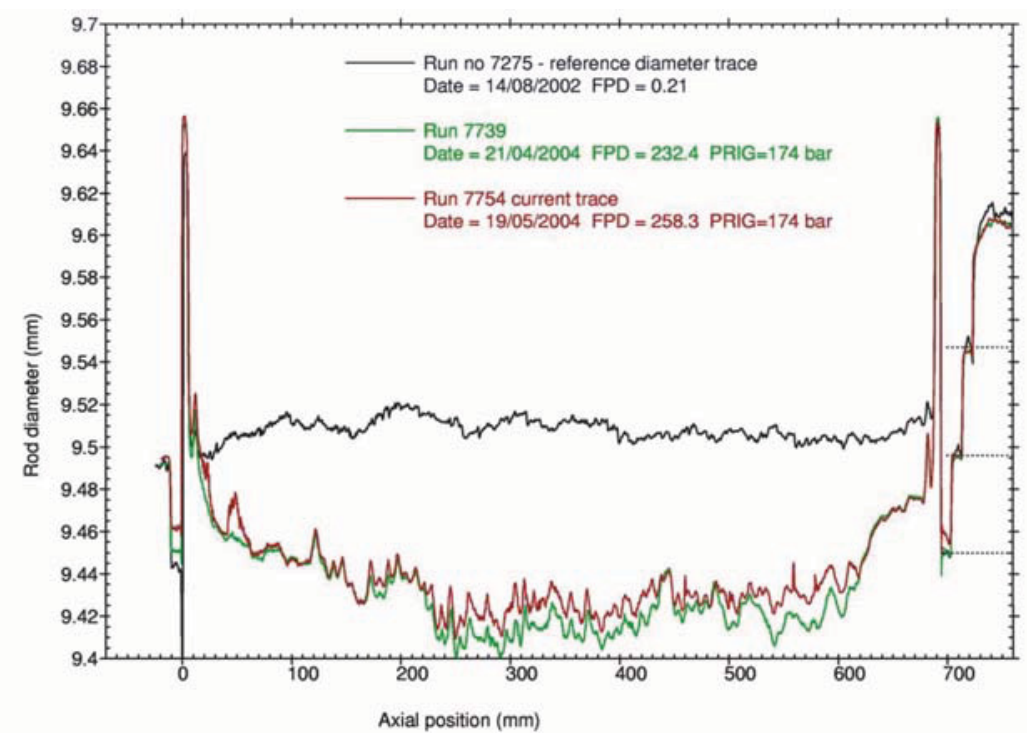

Figure 3-22. Fuel rod diameter traces showing cladding creep down and crud deposition.

\subsubsection{Crack-growth measurements}

In order to monitor crack-growth rates in core structural component materials, the IFE/HRP utilizes miniaturized Compact Tension (CT) specimens and the "direct current potential drop method" for measuring crack propagation. The direct current potential drop method (see Figure 323 ) is based on sending an electrical current through the specimen and measuring the potential (voltage) at several locations on the CT-specimen. The measured potentials depend on the propagation of the crack. Thus, the crack-length can be determined from the measured potential drops. Reference 35 reports results in which this approach was successfully applied to detect changes in crack growth rate due to variations in coolant $\mathrm{pH}$ for various metals. IFE/HRP has applied this technology to detect the impact of coolant parameters ( $\mathrm{pH}$, impurities, boron concentration, etc.) on fuel cladding corrosion. In addition, IFE/HRP can perform such measurements on pre-irradiated fuel removed from commercial reactors.

\subsubsection{Summary}

Although the HBWR has a much lower power rating and is considerably older than the ATR, the instrumentation capabilities developed by IFE/HRP staff have significantly extended its irradiation capabilities. In addition, the IFE/HRP has leveraged this expertise to supply instrumentation for commercial, naval, and other MTRs. 


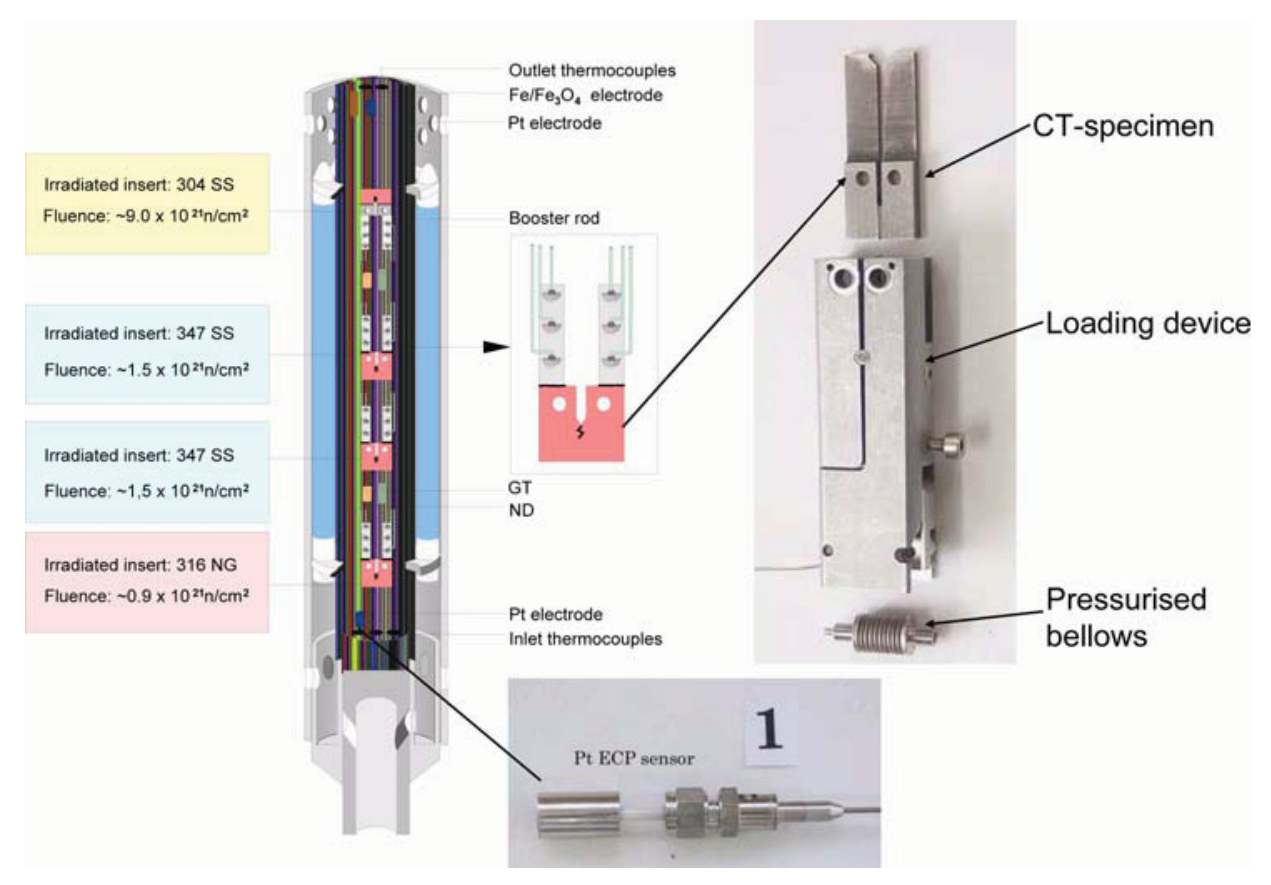

Figure 3-23. Crack growth test rig

The HRP relies heavily on specialized in-core instrumentation in order to perform fuel and material irradiation programs in the HBWR. Although not discussed in this section, the HRP also has the ability to attach in-core instrumentation to pre-irradiated fuel rods and material samples from power reactors. Typically, HRP applies instrumentation to detect fission gas release and thermal conductivity degradation to pre-irradiated fuel rods. Irradiated structural material samples have been instrumented to detect crack growth. The IFE/HRP continues to refine its existing inpile instrumentation and develop new instruments. Current IFE/HRP instrumentation development plans focus on high temperature conditions and new methods for crack detection and corrosion of fuel cladding materials.

\subsection{JAEA}

The Japan Atomic Eneryg Agency (JAEA) [formerly the Japan Atomic Energy Research Institute (JAERI)] provides several types of instrumentation to support tests in the Japan Materials Test Reactor (JMTR). ${ }^{36}$ Commercially-available sensors procured from Japanese vendors allow JMTR customers to detect temperatures (via Type N, K, and C thermocouples and In, Sn, $\mathrm{Pb}, \mathrm{Ag}$, and $\mathrm{Zn}$ melt wires), length and diameters (using LVDT-based sensors made by Japanese vendors), fission gas release, and neutron flux (using $1.8 \mathrm{~mm}$ diameter fission chambers, SPNDs containing $\mathrm{Rh}, \mathrm{Co}$, or Pt-40\%Rh, or flux wires--Fe for fast flux and Al-Co, V-Co, or Ti-Co for thermal neutrons), and crack growth (using bellows to load a precracked sample with direct current potential drop techniques). Reference 36 also indicates that JAEA can reinstrument previously irradiated fuel rods. JAEA continues to conduct research to enhance specialized instrumentation to support high temperature irradiations conducted in their High Temperature 
Test Reactor (HTTR) prototype gas reactor and Japan Materials Test Reactor (JMTR). As discussed in References 36 through 40, research is focussing on new technologies for in-pile measurements of temperature, creep, neutron flux, and gamma-ray intensity distributions.

\subsubsection{Creep and Deformation}

Reference 38 describes JAEA efforts to develop irradiation equipment for in-pile creep and deformation of specimens subjected to loads of up to $10 \mathrm{kN}$ at temperatures up to $600{ }^{\circ} \mathrm{C}$. The invessel parts of this unit (see Figure 3-24) are installed in the reactor pressure vessel through an HTTR standpipe. This in-vessel part is $8.9 \mathrm{~m}$ long with the lower portion consisting of three tubular parts, two irradiation units and a guide tube, that are each $2.6 \mathrm{~m}$ long and $0.113 \mathrm{~m}$ in diameter. Although the specimens are primarily heated from HTTR core heat, a smaller $300 \mathrm{~W}$ electric heater is included for supplementary temperature control. The neutron flux that specimens experience is monitored using SPNDs containing rhodium as the emitter. Small fluence wires are also included for post-irradiation fast and thermal fluence measurements. Temperature is monitored using Type $\mathrm{K}$ thermocouples, and specimen elongation is monitored by LVDTs containing "fine mineral insulated cable" coil material. Reference 38 notes that JAEA developed these LVDTs specially for these tests, but doesn't provide any additional information about what metals are used in the coil material and if this material is subject to any Curie temperature effect (such as the materials used in the HRP coils). Furthermore, Reference 38 doesn't cite any additional references where additional information on JAEA LVDT design and performance evaluations can be found.

\subsubsection{Optical Diagnostic Techniques}

JAEA has been active in research to use optical diagnostic techniques to measure temperatures, reactor power, and other operating parameters. Reference 39 reports research results indicating that newly-developed fluorine doped (F-doped) optical fibers can withstand radiation damage better than silicon core fibers. Results for an F-doped optical fiber indicate that the radiation-induced optical absorption at about $600 \mathrm{~nm}$ was less than $0.2 \mathrm{~dB} / \mathrm{m}$ for an electronic excitation exposure dose of 1.9E6 Gy (1.9e13 rads).

\subsubsection{Neutron Flux and Gamma-Ray Intensity Detection}

For real-time measurement of thermal neutron flux and gamma-ray intensity distributions, JAEA is exploring two methods: a scintillator optical fiber with a scanning driver and a self-powered detector with the driver. Tests were completed using the driver system to insert each type of detector into irradiation holes of the TRIGA II reactor at the Institute for Atomic Energy at Rikkyo University. Results indicate that scanning a one meter long core using an optical fiber with a scintillator (ruby) attached to the tip yields neutron flux distributions similar to that obtained with

foil activation methods (see Figure 3-25). If the scintillator powder is mixed with ${ }^{6} \mathrm{LiF}$ powder, it 


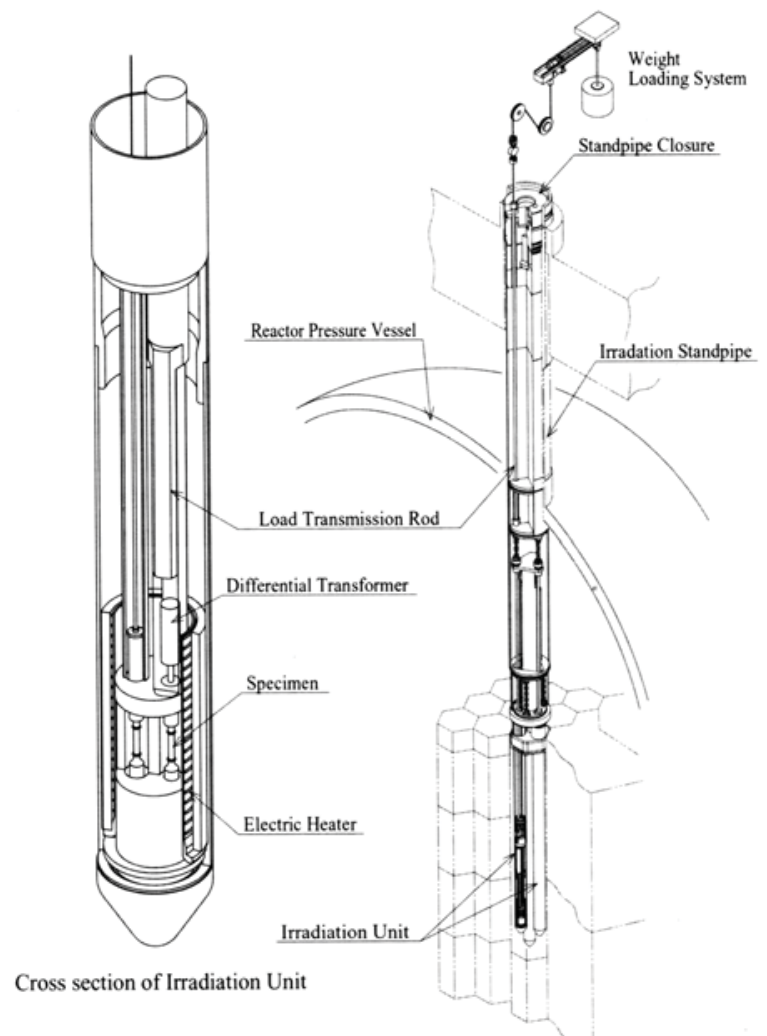

Figure 3-24. I-I type irradiation unit with weight loading equipment

can be used for gamma-ray measurement. However, the foil activation method require 4 to 5 hours whereas the fiber method only requires 10 minutes.

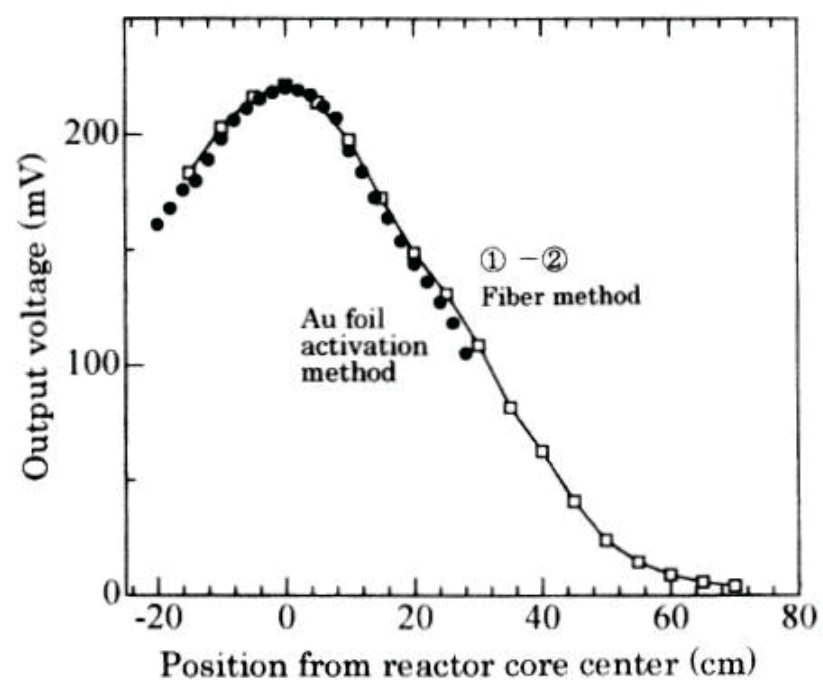

Figure 3-25. Signals obtained with optical fiber detector and Au foil activation methods. 
Because light emission of the ruby scintillator decreases at high temperatures, this method is limited to temperatures of around $100{ }^{\circ} \mathrm{C}$. Although JAEA is continuing to explore the potential of other scintillators, Reference 40 also reports results from tests using the driver system with self-powered detectors containing quartz insulators were found to function for temperatures up to $500{ }^{\circ} \mathrm{C}$. Detectors with alumina tubes were only found to function up to $400{ }^{\circ} \mathrm{C}$.

\subsection{NRG}

The High Flux Reactor (HFR) at Petten, which is owned by the European Communities and operated by the Netherlands Energy Research Foundation (ECN), has been conducting fuel irradiations using instrumented test rigs for over 40 years. The Nuclear Research and consultancy Group (NRG) was established as a Partnership Firm in 1998 through the merger of ECN's $(70 \%$ share) and KEMA's (30\% share) business activities in the nuclear fields. HFR test capsules have been successfully used to investigate power cycles and ramping behavior on PWR and BWR fuel rods. ${ }^{41}$ Although the HTR originally focussed on LWR fuel irradiations, significant testing of HTR and SFR fuels have also been conducted in this facility. Typical instrumentation in such capsules allows measurement of fuel stack displacement, fuel rod length, fuel rod internal pressure, neutron flux, gamma flux, and fuel rod central temperatures (up to $1350{ }^{\circ} \mathrm{C}$ ). Discussions with Petten staff indicates that instruments are primarily obtained from commercial vendors or IFE/HRP. ${ }^{42,43}$ Typical instruments employed in specialized ECN test rigs (and the vendors from whom they are typically obtained) are listed in Table 3-3. Reference 44 describes a testing facility installed in Petten for continuous in-pile crack testing of samples up to $730{ }^{\circ} \mathrm{C}$. In recent years, NRG has been involved in several internationally-sponsored tests for advanced reactor fuels. ${ }^{45}$ In particular, this reference discusses recently completed and ongoing campaigns to evaluate gas reactor fuel elements (the HFR-EU1bis and HFR-EU1 tests), gas reactor fuel coating materials (the PYCAASSO I and II tests), liquid metal fast reactor and accelerator driven system fuel tests (CONFIRM, FUJI), transmutation fuel tests (HELIOS irradiations), and advanced fuel cycle (e.g., $\mathrm{U}-\mathrm{Pu}$ and $\mathrm{Th}-\mathrm{U}$ cycle tests). 
Table 3-3. Sensors typically deployed in HFR test rigs

\begin{tabular}{|c|c|c|c|c|}
\hline Parameter & Sensor & Description & Manufacturer & Limitations \\
\hline \multirow[t]{2}{*}{ Neutron Fluence } & $\begin{array}{c}\text { Neutron } \\
\text { metrology sets }\end{array}$ & $\begin{array}{l}\text { SS tubes containing quartz } \\
\text { minitubes with flux wires } \\
(\mathrm{Nb}, \mathrm{Ti}, \mathrm{Fe}, \mathrm{NiCo})\end{array}$ & NRG & $\begin{array}{c}\text { Maintain below } 800-1000^{\circ} \mathrm{C} \text { (to } \\
\text { prevent damage to quartz } \\
\text { minitubes containing wires). }\end{array}$ \\
\hline & $\begin{array}{l}\text { Self Power } \\
\text { Neutron } \\
\text { Detectors }\end{array}$ & $\begin{array}{l}\text { Contains tube with } \\
\text { emitter,that transmutes and } \\
\text { decays, emitting electrons } \\
\text { that produce electrical } \\
\text { current. Response time } \\
\text { depends on emitter } \\
\text { material }(\mathrm{Co} \text { and } \mathrm{Pt} \sim, 0.05 \\
\text { sec; } \mathrm{V}, \mathrm{Rh} \text {, and } \mathrm{Ag} \sim 51 \\
\text { sec. to } 5.4 \text { min.) }\end{array}$ & $\begin{array}{l}\text { Thermocoax, } \\
\text { IFE/HRP/ }\end{array}$ & $\begin{array}{l}\text { Properties of SPND change due } \\
\text { to emitter transmutation. } \\
\text { Lifetime limited by emitter ( V } \\
\text { and Co } \sim 20 \text { year lifetime; Rh } \sim \\
3 \text { year lifetime in } 10^{9} \mathrm{nt} / \mathrm{cm}^{2} \mathrm{~s} \text { ) }\end{array}$ \\
\hline Temperature & Thermocouples & Type $\mathrm{K}$ and Type $\mathrm{N}$ & Thermocoax & $1000^{\circ} \mathrm{C}$ \\
\hline \multirow[t]{2}{*}{ Pressure } & $\begin{array}{l}\text { Silicon Chip } \\
\text { Transducer } \\
\text { (XTL-190M) }\end{array}$ & $\begin{array}{l}\text { Tube containing silicon } \\
\text { chip influenced by } \\
\text { pressure. }\end{array}$ & Kulite & $\begin{array}{l}\text { Below } 210 \text { bar (measurement } \\
\text { range depends on requested } \\
\text { pressure --- } 9 \text { ranges available } \\
\text { between } 0 \text { and } 140 \text { bar). }\end{array}$ \\
\hline & $\begin{array}{l}\text { LVDT pressure } \\
\text { transducer }\end{array}$ & $\begin{array}{l}\text { SS tube containing sealed } \\
\text { bellow, magnetic core, and } \\
\text { LVDT. } \\
\text { Dimensions: } 13 \mathrm{~mm} \\
\text { (diameter) } \mathrm{x} 130 \mathrm{~mm} \\
\text { (length) }\end{array}$ & IFE/HRP & $\begin{array}{l}\text { Successfully used in gamma } \\
\text { field. Probably usable in neutron } \\
\text { field (but not tested). }\end{array}$ \\
\hline
\end{tabular}

\subsection{KAERI}

The Korea Atomic Energy Research Institute (KAERI) utilizes specialized instrumentation in test capsules supporting materials and fuel irradiations in their $\underline{\text { High flux }}$

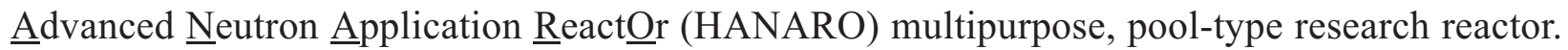
HANARO was designed to provide a peak thermal and fast flux of $5 \times 10^{14} \mathrm{n} / \mathrm{cm}^{2} \cdot \mathrm{sec}(\mathrm{E}<$ $0.625 \mathrm{eV})$ and $2.1 \times 10^{14} \mathrm{n} / \mathrm{cm}^{2} \cdot \mathrm{sec}(\mathrm{E}>1.0 \mathrm{MeV})$ at a $30 \mathrm{MW}$ thermal power, respectively. Since HANARO began operation in 1995, numerous experimental facilities have been developed and installed in its 32 vertical holes and 7 horizontal beam ports to support fuels and material irradiations. $^{46}$ and 47

Test equipment for irradiating nuclear fuels and materials in HANARO are classified into two categories, capsules (non-instrumented and instrumented) and FTL (Fuel Test Loop). Instrumented capsules for materials irradiations may include thermocouples, fluence monitors, and heaters. Fuel tests may include thermocouples (Types K and C), pressure transducers and elongation detectors to measure fuel temperature, internal pressure of the fuel rod, and fuel 
deformation, respectively, and SPNDs to detect neutron flux. In addition, KAERI has developed specialized capsules for creep and fatigue testing. These capsules often include thermocouples, fluence monitors, and heaters. KAERI typically procures commercially-available sensors from Thermocoax (thermocouples and SPNDs), Studsvik (SPNDs) and IFE/HRP (LVDTs). Recently, KAERI has initiated efforts to obtain enhanced instrumentation for testing of LWR and advanced reactor fuels and materials, including instrumentation being developed in other countries. ${ }^{47}$

\subsection{NECSA}

The SAFARI-1 test reactor, which is operated by the South Africa Nuclear Energy Corporation, has in recent years been primarily utilized for the production of isotopes that are needed by the international industrial and medical sectors. However, preparations are underway to implement test rigs to allow reactor materials and fuel irradiations. It is planned to include the following instrumentation in these irradiation test rigs: 48

- SPNDs to continuously monitor the thermal flux

- Thermocouples imbedded in irradiation devices

- Flux monitors (e.g., flux foils and/or wires) to measure fluence at selected locations

- Calorimeters to measure total heat deposited in various materials.

It is planned to procure most of this instrumentation from commercial vendors or from research organizations producing specialized sensors, such as the INL-developed HTIR-TCs (see Section 5.1.3). A wide range of measurements was also to be included in the Pebble Bed Modular Reactor (PBMR) Demonstration Power Plant (DPP) that will be built in South Africa. As indicated in Reference 49, the Core Structure Instrumentation (CSI) system will measure the neutron flux and temperature distribution in the reactor's graphite reflector. Most of this instrumentation is commercially available instrumentation, such as source range monitors, SPNDs, strain gauges, LVDTs, and Type $\mathrm{N}$ thermocouples. In some cases, however, newer technologies are under consideration. For example, PBMR is considering the use of fiber optics to detect temperature and strain.

\subsection{ORNL}

The High Flux Isotope Reactor (HFIR), which is located at and operated by Oak Ridge National Laboratory (ORNL), is an 85-MW isotope production and test reactor that is berylliumreflected, light-water-cooled and -moderated, with highly enriched uranium-235 as the fuel. HFIR provides one of the highest steady-state neutron fluxes available in any of the world's reactors, and neutron currents from its four horizontal beam tubes are among the highest available.

Originally, HFIR was primarily designed for producing transuranium isotopes. However, many experiment-irradiation facilities were included in its original design; and several others have been added. Experiment-irradiation facilities available include (1) four horizontal beam 
tubes, which originate in the beryllium reflector; (2) the hydraulic tube facility, located in the very high flux region of the flux trap, which allows for insertion and removal of irradiation samples while the reactor is operating; (3) thirty target positions in the flux trap, which normally contain transuranium production rods but which can be used for the irradiation of other experiments (two are instrumented target positions provided by a recent modification); (4) six peripheral target positions located at the outer edge of the flux trap; (5) numerous vertical irradiation facilities of various sizes located throughout the beryllium reflector; (6) two pneumatic tube facilities in the beryllium reflector, which allow for insertion and removal of irradiation samples while the reactor is operating for activation analysis; and (7) four slant access facilities, called "engineering facilities," located adjacent to the outer edge of the beryllium reflector. In addition, spent fuel assemblies are used for gamma irradiation in the gamma irradiation facility in the reactor pool.

Today, HFIR is principally used to provide a stable neutron source for fundamental scientific experiments associated with neutron scattering. A 5 inch deep flux trap located at the center of the HFIR fuel element provides a thermal neutron flux of $2 \times 10^{15} \mathrm{n} / \mathrm{cm}^{2}$-sec for instrumented lead capsules and loop tests; reflector positions are available for exposing samples in static capsules, loop, and isotope production tests to fluxes of $1 \times 10^{15} \mathrm{n} / \mathrm{cm}^{2}$-sec. Access to some experimental positions is via a pneumatic tube to allow rapid insertion and removal during reactor operation. One unique sensor currently deployed at HFIR, SiC temperature monitors for detecting peak temperature in static capsule tests, is discussed in Section 3.8.1.

\subsubsection{Silicon Carbide Temperature Monitors for Peak Temperature Detection}

Since the early 1960s, the observation that irradiation-induced swelling of silicon carbide (SiC) begins to anneal out at temperatures exceeding its irradiation temperature has been used as a post-irradiation temperature monitor. ${ }^{51}$ Various approaches (e.g., changes in length, density, thermal conductivity, and electrical resistivity) have been used to infer irradiation temperature from this observed phenomena. Snead et al. ${ }^{52}$ recommends using changes in resistivity because of improved accuracy, ease of measurement, and reduced costs. Work presented by Snead in Reference 52 was conducted on SiC produced by chemical vapor deposition (CVD). This material is fully dense $(3.203 \mathrm{~g} / \mathrm{cc})$ and stoichiometric. Comparisons between $\mathrm{SiC}$ measurements and thermocouples indicate that accuracies of approximately $20^{\circ} \mathrm{C}$ are possible for dose ranges of 1 to 8 dpa and temperatures from 200 to at least $800{ }^{\circ} \mathrm{C}$. Absolute limits for this approach are $150{ }^{\circ} \mathrm{C}$ (an amorphorous threshold) and $875^{\circ} \mathrm{C}$ (due to recrystallization). Note that Reference 53 cites that measurements should be taken in a controlled environment (within $0.4{ }^{\circ} \mathrm{C}$ ) with annealing periods of approximately 30 minutes to obtain these accuracies.

Figure 3-26 (from Reference 52) shows data obtained from this technique. The curves shown in this figure represent data obtained from a series of samples, all irradiated in the ORNL HFIR core at similar dose rates of $\sim 8 \times 10^{14} \mathrm{n} / \mathrm{cm}^{2}$-s $(\mathrm{E}>0.1 \mathrm{MeV})$. The total dose for the curves is not identical. The curve for an irradiation temperature of $\sim 350{ }^{\circ} \mathrm{C}$ is at the lowest dose $(\sim 0.1 \mathrm{dpa}$, assuming $\left.1 \mathrm{dpa}=1 \times 10^{21} \mathrm{n} / \mathrm{cm}^{2} ; \mathrm{E}>0.1 \mathrm{MeV}\right)$ while the remainder are from $\sim 1-8 \mathrm{dpa}$. It is speculated that the apparent saturation in normalized resistivity for the $0.1 \mathrm{dpa}$ sample represents the 
point at which the simplest of the defects in the irradiated $\mathrm{SiC}$ have annealed away and represents conductivity at the new dopant level for the irradiated SiC.

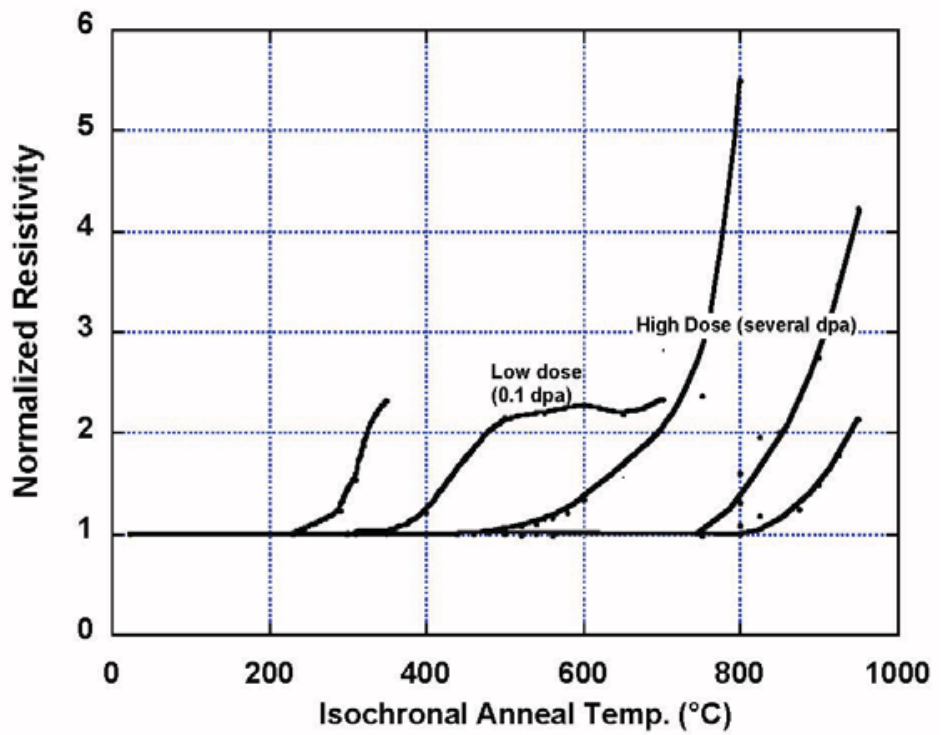

Figure 3-26. Electrical resistivity technique applied over a range of irradiation temperatures.

It should be noted that there are several limitations associated with the use of $\mathrm{SiC}$ temperature detectors. As discussed in Reference 54, temperatures are inferred by post-irradiation detection of changes in the stable defect population within $\mathrm{SiC}$ monitors that were incurred during irradiation. Some examples where errors could be inferred from SiC monitors cited in Reference 54 include:

- Irradiation temperatures rising during the latter part of irradiation. For damages greater than $0.1 \mathrm{dpa}$, the increasing temperature will anneal out defects that occur at the lower irradiation temperature, while creating stable defects at the higher temperature. When isochronal annealing is performed, lower temperature defects (to some or great extent) will have already been removed, and the recovery curve will be smeared to somewhat higher temperatures. If the temperature increase during irradiation is small, or the time at higher temperature is short, then the original departure from linearity will give the earlier irradiation temperature.

- Irradiation temperatures decreasing during irradiation. This decrease will lead to defects being created and frozen-in at the higher-temperature, while continuing to create lower temperature defects. The isochronal anneal will then give an indication of the lowest irradiation temperature (in this case at the end of the irradiation period), and the recovery curve will be smeared due to annealing of higher temperature defects.

- Upward or downward temperature spikes during irradiation. This case has the potential to lead to partially created or annealed defects, depending on the change and duration of the temperature increase and the damage to the $\mathrm{SiC}$ monitor during irradiation.

However, if irradiation tests are conducted at or near the same temperature when the reactor is at power, none of these situations are of concern. 


\section{PATH FORWARD FOR ENHANCED ATR INSTRUMENTATION}

INL has a long history of developing highly specialized instrumentation to meet demands of customers conducting unique tests in INL facilities. Such instrumentation was used in INL test reactors and in facilities from the Power Burst Facility (PBF) and Loss of Fluid Test (LOFT) research programs. Unfortunately, INL instrumentation development and research funding declined significantly in the 1980s, when large test facility programs ended. Until recently, ATR irradiation testing relied primarily on commercial vendors for instrumentation.

As documented in Section 3, several test reactor programs in Europe and Asia, such as the HFR (Petten) and HBWR (Halden) have maintained their instrumentation development and evaluation research capability. Others, such as CEA, are rapidly trying to regain this expertise. As part of the ATR NSUF, it was recognized that a similar focussed effort was needed at INL if the ATR is to become competitive as a world class irradiation facility. Hence, a research and development plan was launched in 2007 so that ATR users would have access to enhanced real-time in-pile instrumentation, comparable to (and, in some cases, superior to) that available at other MTRs, by 2015. As documented in this section, the plan identifies and prioritizes instrumentation research considering ATR NSUF customer and reactor staff needs along with technology readiness. INL progress in accomplishing the objectives outlined in the research plan are presented in this section.

When the ATR NSUF instrumentation strategic plan was originally developed, estimates for the required funding to obtain a world-class instrumentation capability for ATR were identified. Although ATR NSUF funding provided in FY10 was close to the estimated need, FY11 funding was significantly lower than the estimated need (and preliminary information from DOE suggests that funding sources will be more limited in FY12). However, as anticipated in the original version of this report, the instrumentation capability developed with ATR NSUF funds has been sufficient for this effort to attract funding from other sources. Hence, all of the FY10 instrumentation development activities were completed as planned. In FY11, the DOE-NE Fuel Cycle Research and Development (FCRD) program and the ATR Life Extension Project (LEP) are funding selected instrumentation development activities. In addition, selected programs are supported by INL's Laboratory Research and Development (LDRD) program. It should be emphasized that the schedule shown in Figure 4-1 will ONLY be fulfilled if this instrumentation development program can continue to attract multiple fund sources. Because it is key for US MTRs to be competitive, efforts continue to request funds from several direct programs, such as DOE's Nuclear Energy Enabling Technology (NEET) instrumentation and control initiative and the ATR NSUF initiative, work-for-others customers, such as Naval Reactors, the US Nuclear Regulatory Commission (NRC), NASA, and DOD organizations, and internal INL LDRD funds. 


\subsection{Motivation/Justification for Investment}

A research and development program to improve in-pile instrumentation for the ATR is sorely needed and necessary if this facility wishes to attract new researchers from universities, laboratories, and industry. Key points for the business case to support this effort include:

- Key Component for ATR NSUF Success. If the ATR NSUF is to become a world-class irradiation facility, adequate instrumentation must be available to its users. Clearly, the ATR has advantages over many other MTRs that are older with smaller irradiation test locations and lower flux levels. Yet, the instrumentation capabilities developed by research staff at other test reactors allow their customers to obtain real-time data from tests that cannot be obtained from tests conducted in the ATR.

- Focussed Instrumentation Development to Attract Near-term Customers. INL's position as the lead DOE-NE lab uniquely positions this research program so that it can easily focus instrumentation research so that it supports near-term irradiations, INL has focussed this instrumentation R\&D effort so that it can help meet near-term customer needs and help the ATR attract other customers.

- Expertise and Facilities for Deploying Unique Instrumentation. Much of the investment has already been made to obtain the right equipment and trained staff. INL's High Temperature Test Laboratory (HTTL) is a state-of-the-art facility with unique equipment for evaluating and fabricating required instrumentation. INL has a unique test reactor for demonstrating and using new instrumentation for in-pile measurements. Specialized instrumentation was once a core capability of this laboratory, and HTTL researchers still have access to this expertise. Engineering staff that support ATR irradiations at INL have a long history of designing specialized capsules and test fixtures.

- Market for research program task collaboration and products. Clearly, the primary market for products from this research program are ATR users. However, INL-developed instrumentation has the potential to attract customers that operate other MTRs (e.g., HBWR and MIT as noted in Section 5). In addition, there is the potential for instrumentation developed and deployed from this research to be used in commercial nuclear power plants and for nonnuclear applications.

Potential funding sources for an ATR NSUF instrumentation program and its products are summarized in Table 4-1. This table also lists potential collaborators for various instrumentation pro- 
gram elements.

Table 4-1. Funding sources and potential collaborators for INL instrumentation elements.

\begin{tabular}{|c|c|c|}
\hline Program Elements & Funding Sources & Collaborators \\
\hline Sensor Development & $\begin{array}{l}\text { DOE-NE LWRS } \\
\text { DOE-NE FCRD } \\
\text { DOE-NE NEET (ATR NSUF, Advanced Sensors } \\
\text { Initiative). } \\
\text { Others, such as the Nuclear Regulatory Commission; } \\
\text { Department of Defense; Naval Reactors, NASA). } \\
\text { INL LDRD }\end{array}$ & $\begin{array}{l}\text { IFE/HRP } \\
\text { CEA } \\
\text { SCK·CEN } \\
\text { KAERI } \\
\text { JAERI } \\
\text { International Funding Agencies } \\
\text { (OECD, IAEA, JRC) }\end{array}$ \\
\hline $\begin{array}{l}\text { Developed Sensors- } \\
\text { Nuclear Customers }\end{array}$ & $\begin{array}{l}\text { Other MTRs (NRG/JRC - Petten, KAERI-HANARO, } \\
\text { ORNL-HFIR, SNL-ACRR, MIT) } \\
\text { Commercial Nuclear Reactors } \\
\text { DOE-NE (NGNP, FCRD, LWRS, etc.) } \\
\text { Others, such as the Nuclear Regulatory Commission; } \\
\text { Department of Defense; Naval Reactors, NASA). }\end{array}$ & $\begin{array}{l}\text { Commercial Industry (fiber optic } \\
\text { and thermocouple vendors via } \\
\text { STTR or venture capital) to transfer } \\
\text { technology. }\end{array}$ \\
\hline $\begin{array}{l}\text { Developed Sensors- } \\
\text { Non-Nuclear Customers }\end{array}$ & $\begin{array}{l}\text { Department of Defense, Aircraft Industry, Petroleum } \\
\text { Industry, Coal Industry }\end{array}$ & \\
\hline
\end{tabular}

\subsection{Currently Available ATR Instrumentation}

Table 4-2 identifies instrumentation currently available for ATR experiments. As discussed in Section 2.1, ATR irradiation capabilities in static capsule, shuttle, instrumented lead, and PWR loop tests, are unparalleled. However, as indicated in column 5 of Table 4-2, available instrumentation for detecting parameters of interest during an irradiation test is limited at each irradiation location. As indicated by column 6, sensors available at other MTRs could increase detection capabilities during ATR irradiations. Furthermore, as indicated by column 7, there are several "Developmental" technologies that could also be explored for in-pile applications. . Note that adapting such instrumentation from other test reactors often requires laboratory demonstrations because of ATR-specific irradiation conditions and test capsule geometries. For example, devices may be required that can withstand higher temperatures and fluences. The column labeled "Developmental" under "Proposed Instrumentation Advancement" lists developmental or non-nuclear technologies that could be used in ATR irradiation tests. Technologies listed in this column are considered to be less "ready" for implementation.

As part of the ATR NSUF program (and now, as part of the FCRD program), several activities have been initiated to develop and implement new in-pile instrumentation capabilities. Blue text in Table 4-2 indicates current instrumentation research efforts, and red text indicates new or enhanced sensors now available to users as a result of recent instrumentation research. The instrumentation currently being developed was selected based on anticipated ATR NSUF user needs and 'technology readiness' (providing users needed instrumentation in the near-term). Many of these instrumentation development efforts are in collaboration with other organizations. As indicated in Table 4-2, three new or enhanced sensors are now available to ATR users as a result of this instrumentation development effort. The ultimate goal of this effort is to provide ATR users sensors for detecting all of the parameters listed in Table 4-2 . 
Table 4-2. Instrumentation available at ATR and proposed advanced technologies.

\begin{tabular}{|c|c|c|c|c|c|c|}
\hline \multirow[b]{2}{*}{ Parameter } & \multicolumn{3}{|c|}{ Location } & \multirow[b]{2}{*}{$\begin{array}{c}\text { Available Technology } \\
\text { at ATR }\end{array}$} & \multicolumn{2}{|c|}{ Proposed Advanced Technology } \\
\hline & $\begin{array}{c}\text { Static } \\
\text { Capsule/ } \\
\text { Shuttle }\end{array}$ & $\begin{array}{l}\text { Instr. } \\
\text { Lead }\end{array}$ & $\begin{array}{l}\text { PWR } \\
\text { Loop }\end{array}$ & & Available at Other MTRs & Developmental \\
\hline \multirow[t]{2}{*}{ Temperature } & $\checkmark$ & $\checkmark$ & $\checkmark$ & $\begin{array}{l}\text {-Melt wires (peak) } \\
\text {-SiC temperature } \\
\text { monitors (range) }\end{array}$ & -Paint spots (peak) & -Wireless ${ }^{b}$ \\
\hline & & $\checkmark$ & $\checkmark$ & $\begin{array}{l}\text {-Thermocouples (Type } \\
\text { N, K, C } \text {, and HTIR- } \\
\text { TCs) }\end{array}$ & -Expansion thermometer & $\begin{array}{l}\text { - Fiber optics } \\
\text {-Noise thermometry } \\
\text {-Ultrasonic thermometers }\end{array}$ \\
\hline \multirow{3}{*}{\begin{tabular}{|l} 
Thermal \\
Conductivity \\
Flux/Fluence \\
(neutron)
\end{tabular}} & & $\checkmark$ & $\checkmark$ & $\begin{array}{l}\text {-Out-of-pile } \\
\text { examinations }\end{array}$ & $\begin{array}{l}\text {-Degradation using signal } \\
\text { changes in thermocouples }\end{array}$ & -Hot wire techniques \\
\hline & $\checkmark$ & $\checkmark$ & $\checkmark$ & -Flux wires and foils & -Activating foil dosimeters & \\
\hline & & $\checkmark$ & $\checkmark$ & & $\begin{array}{l}\text {-Self-Powered Neutron } \\
\text { Detectors (SPNDs) } \\
\text {-Subminiature / miniature } \\
\text { fission chambers }\end{array}$ & \\
\hline $\begin{array}{l}\text { Gamma } \\
\text { Heating }\end{array}$ & & $\checkmark$ & $\checkmark$ & & $\begin{array}{l}\text {-Calorimeters } \\
\text {-Gamma thermometers }\end{array}$ & \\
\hline \multirow{2}{*}{$\begin{array}{l}\text { Dimensional } \\
\text { (stressed and } \\
\text { unstressed } \\
\text { samples) }\end{array}$} & $\checkmark$ & $\checkmark$ & $\checkmark$ & $\begin{array}{l}\text {-Out-of-pile } \\
\text { examinations }\end{array}$ & & \\
\hline & & $\checkmark$ & $\checkmark$ & & $\begin{array}{l}\text {-LVDT-based elongation } \\
\text { (stressed and unstressed) } \\
\text {-Diameter gauge } \\
\text {-Hyper-frequency resonant } \\
\text { cavities }\end{array}$ & $\begin{array}{l}\text {-Ultrasonic transducers } \\
\text {-Fiber optics }\end{array}$ \\
\hline $\begin{array}{l}\text { Fission Gas } \\
\text { (Amount, } \\
\text { Composition) }\end{array}$ & & $\checkmark$ & $\checkmark$ & $\begin{array}{l}\text { Sampling ('near' real- } \\
\text { time) and evaluation } \\
\text { using detectors } \\
\text {-Chromatography } \\
\text {-Pressure sensor }\end{array}$ & $\begin{array}{l}\text {-LVDT-based pressure } \\
\text { monitors } \\
\text {-Counter-pressure monitor }\end{array}$ & $\begin{array}{l}\text {-Acoustic measurements } \\
\text { with high-frequency } \\
\text { echography }\end{array}$ \\
\hline Loop Pressure & & & $\checkmark$ & $\begin{array}{l}\text {-Differential pressure } \\
\text { transmitters } \\
\text {-Pressure gauges with } \\
\text { impulse lines }\end{array}$ & & \\
\hline Loop Flowrate & & & $\checkmark$ & $\begin{array}{l}\text {-Flow venturis } \\
\text {-Orifice plates }\end{array}$ & & \\
\hline $\begin{array}{l}\text { Loop Water } \\
\text { Chemistry }\end{array}$ & & & $\checkmark$ & $\begin{array}{l}\text {-Off-line sampling / } \\
\text { analysis }\end{array}$ & $\begin{array}{l}\text {-Electrical chemical potential } \\
\text { probes }\end{array}$ & \\
\hline $\begin{array}{l}\text { Crud } \\
\text { Deposition }\end{array}$ & & & $\checkmark$ & $\begin{array}{l}\text {-Out-of-pile } \\
\text { examinations }\end{array}$ & $\begin{array}{l}\text {-Diameter gauge with } \\
\text { neutron detectors and } \\
\text { thermocouples }\end{array}$ & \\
\hline $\begin{array}{l}\text { Crack Growth } \\
\text { Rate }\end{array}$ & & & $\checkmark$ & $\begin{array}{l}\text {-Out-of-pile } \\
\text { examinations }\end{array}$ & $\begin{array}{l}\text {-Direct current potential drop } \\
\text { (DCPD) technique }\end{array}$ & -Ultrasonic transducers \\
\hline
\end{tabular}

a. Although melt wires have been used at ATR, recent efforts have expanded the types offered to our users, allowing more accurate estimates of peak temperature, and enhanced encapsulation methods.

b. Although listed under temperature, wireless technologies could be pursued for many parameters.

c. Type C thermocouple use requires a "correction factor" to correct for decalibration during irradiation. 


\subsection{Current Prioritization for Instrumentation Development}

Figure 4-1 presents a schedule for developing and demonstrating instrumentation needed to advance ATR NSUF testing capabilities. There are two major activities identified: "Nearer-Term Instrumentation Development" and "Developmental Technologies." Qualitative judgments with respect to ATR capabilities compared to other test reactors are shown at the bottom of this figure. As indicated, it is planned to have comparable instrumentation by the end of FY12 and "world class" (e.g., comparable, and in some cases, superior) irradiation capabilities by FY15.

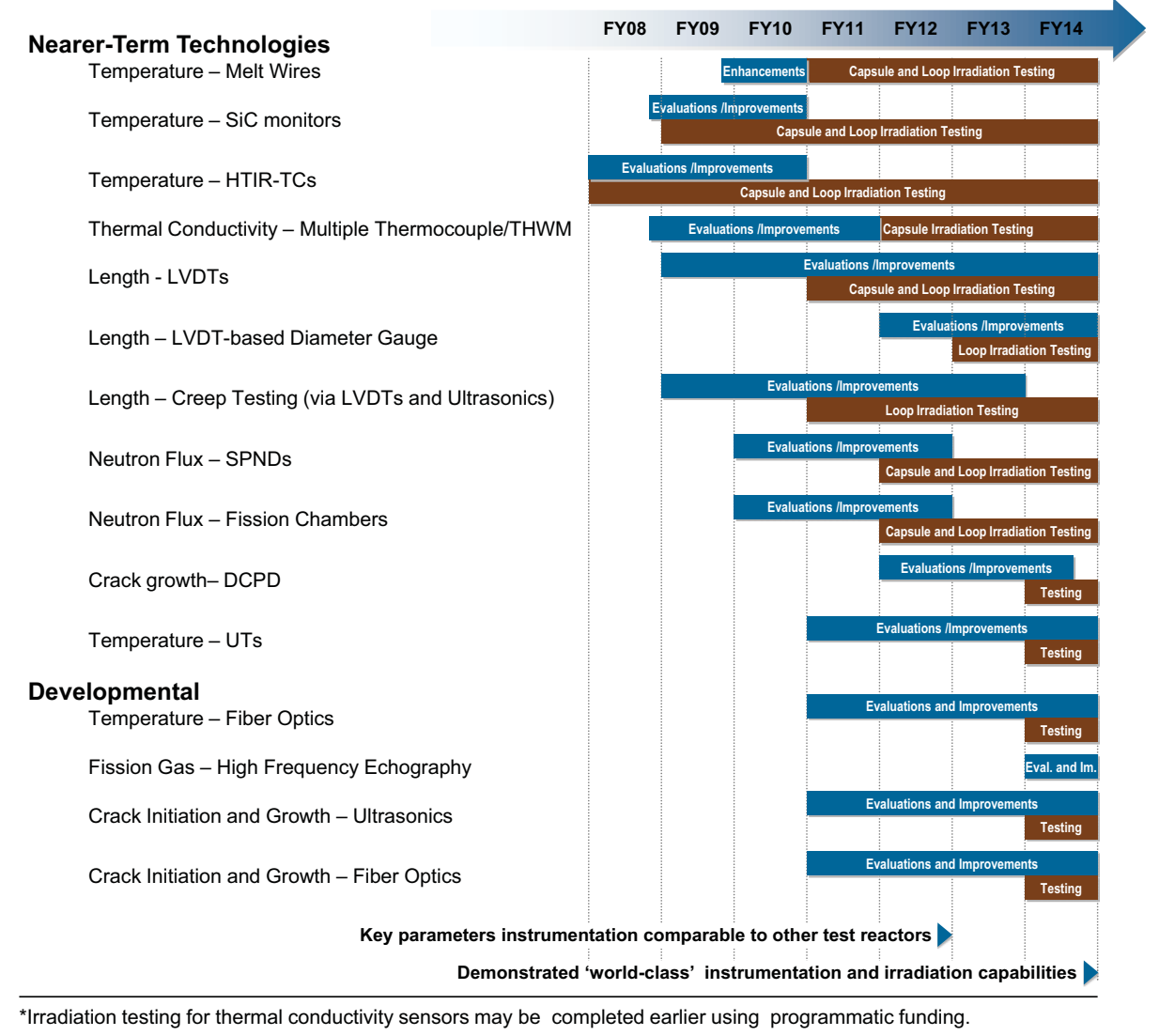

Figure 4-1. Current schedule for ATR NSUF advanced instrumentation research and development.

Note that the ATR NSUF-funded instrumentation development effort began in FY 2009. Prior to that time, new ATR instrumentation was primarily developed using a limited amount of INL LDRD funding. Sensors were developed that addressed needs identified by current and potential customers. Then, programmatic funding covered the costs required for qualifying the instrumentation for ATR irradiations. Although such an approach did allow a limited amount of instrumentation to be developed, the limited amount of LDRD funding devoted to this effort were inadequate for the ATR NSUF to have instrumentation comparable to that in other test reactors by 2015. Evaluations indicate that a sustained effort of at least $\$ 1.5 \mathrm{M}$ per year is needed to support 
this effort. With this level of funding, all 'Nearer Term' technologies can be adapted and demonstrated for ATR applications (at least demonstrated to the point that direct programmatic funding can be obtained for additional instrument qualifications). Note that this requested level of funding will also provide for selected research of 'Developmental Technologies.' However, the selected priority for "Developmental Technologies" research is based on customer and reactor staff prioritization recommendations at the time that funding becomes available. ATR NSUF funding (or other programmatic funding) is expected to cover costs required to develop and deploy test trains to demonstrate instrumentation performance in inert gas and PWR loop conditions.

Table 4-3 summarizes the status of the effort to provide enhanced in-pile instrumentation to ATR users. Note that this table only lists parameters deemed to be of most interest to ATR users. Similar to Table 4-2, blue text indicates current instrumentation research efforts, and red text indicates new sensors now available to users as a result of recent instrumentation research. More detailed information about on-going instrumentation activities is provided in Section 5. As indicated in Tables 4-2 and 4-3, considerable progress has been made in this program during the last 3 years. Several new sensors are available to users; and as indicated in Section 5, several new sensors should be fully qualified within FY11. It is encouraging to see that some level of research has been initiated on most of the sensor technologies identified in this table. Nevertheless, additional effort is needed to to provide ATR users a world-class instrumentation capability.

Table 4-3. Status of ATR NSUF sensor development and evaluation efforts.

\begin{tabular}{|c|c|c|}
\hline Parameter & Sensor & Status \\
\hline \multirow[t]{5}{*}{ Temperature } & Melt Wires & $\begin{array}{l}\text { Procedures completed for DSC testing of melt wires; numerous melt } \\
\text { wires evaluated; Developing reference document for interpreting } \\
\text { results. }\end{array}$ \\
\hline & SiC Temperature Monitors & $\begin{array}{l}\text { Initial in-pile irradiations underway. Development and evaluation of } \\
\text { post-irradiation measurement capability completed (including com- } \\
\text { parison evaluations with ORNL); Evaluation of SiC monitors irradi- } \\
\text { ated in ATR expected in FY11. }\end{array}$ \\
\hline & $\begin{array}{l}\text { High Temperature Irradia- } \\
\text { tion Resistant Thermo- } \\
\text { couples (HTIR-TCs) }\end{array}$ & $\begin{array}{l}\text { Initial out-of-pile testing completed. In-pile testing (in the AGR-1 gas } \\
\text { reactor fuel irradiation test) and sensor enhancement evaluations } \\
\text { completed; HTIR-TCs provided to MIT in FY10 and preparations for } \\
\text { HTIR-TC testing by IFE/HRP initiated. }\end{array}$ \\
\hline & Fiber-Optics & Evaluation as a FCRD effort initiated in FY11. \\
\hline & Ultrasonic Thermometers & $\begin{array}{l}\text { Successfully developed and deployed to support high temperature } \\
\text { fuel testing several decades ago. Enabling technology information } \\
\text { documented; preparations initiated for developing a prototype for } \\
\text { FCRD evaluations in FY11. }\end{array}$ \\
\hline \multirow[t]{2}{*}{$\begin{array}{l}\text { Thermal } \\
\text { Conductivity }\end{array}$} & Multiple thermocouples & $\begin{array}{l}\text { Initial laboratory testing completed. Anticipate that inclusion of } \\
\text { HTIR-TCs could allow detection at higher temperatures than current } \\
\text { methods used by IFE/HRP. }\end{array}$ \\
\hline & Hot-wire method & $\begin{array}{l}\text { Prototype design developed and initial laboratory testing completed. } \\
\text { Anticipated that inclusion of HTIR-TCs could allow detection at } \\
\text { higher temperatures. Prototype THWM probe shipped to MIT for } \\
\text { inclusion in hydride fuel test. }\end{array}$ \\
\hline
\end{tabular}


Table 4-3. Status of ATR NSUF sensor development and evaluation efforts.

\begin{tabular}{|l|l|l|}
\hline \multicolumn{1}{|c|}{ Parameter } & \multicolumn{1}{|c|}{ Sensor } & \multicolumn{1}{c|}{ Status } \\
\hline $\begin{array}{l}\text { Elongation, Crud } \\
\text { deposition, Corro- } \\
\text { sion }\end{array}$ & LVDTs & $\begin{array}{l}\text { Out-of-pile testing completed on developmental LVDT that resists } \\
\text { high temperature degradation and eliminates Curie temperature } \\
\text { effects. }\end{array}$ \\
\cline { 2 - 3 } & Diameter gauge & $\begin{array}{l}\text { Currently used in HBWR for detecting swelling, corrosion, and crud } \\
\text { buildup. Investigations delayed due to funding limitations. }\end{array}$ \\
\cline { 2 - 3 } & $\begin{array}{l}\text { Ultrasonic Transducers } \\
\text { (UTs) }\end{array}$ & $\begin{array}{l}\text { Scoping tests completed on prototype; additional prototype out-of- } \\
\text { pile testing needed. }\end{array}$ \\
\hline In-pile Creep Test & $\begin{array}{l}\text { LVDT-based rig with bel- } \\
\text { lows }\end{array}$ & $\begin{array}{l}\text { Design developed. Prototype evaluated at PWR conditions in a lab- } \\
\text { oratory autoclave. Follow-on work should develop design with } \\
\text { variable load capability }\end{array}$ \\
\hline Neutron Flux & $\begin{array}{l}\text { SPNDs and Fission } \\
\text { Chambers }\end{array}$ & $\begin{array}{l}\text { Initiated evaluations of candidate specially-developed fixturing } \\
\text { installed at ATRC. In FY11, additional evaluations of detectors will } \\
\text { be performed and new fixturing, for simultaneous placement of } \\
\text { detectors in the NW LIPT, will be developed. }\end{array}$ \\
\hline Gamma Heating & Gamma thermometers & $\begin{array}{l}\text { Currently used at HBWR; Investigations delayed due to funding } \\
\text { limitations. }\end{array}$ \\
\cline { 2 - 3 } & Fiber optics techniques & $\begin{array}{l}\text { Efforts initiated under FCR\&D program in FY11 } \\
\text { FYog; funding constraints limited progress in FY10. }\end{array}$ \\
\cline { 2 - 3 } & $\begin{array}{l}\text { Ultrasonic techniques } \\
\text { Specimens }\end{array}$ & Efforts initiated under FCR\&D program in FY11 \\
\hline
\end{tabular}

In addition to providing ATR customers the instrumentation required for their irradiation tests, this program has clearly added to the prestige and capabilities of the ATR NSUF, INL, and to the DOE. International collaborations have been established with leaders in the world of in-pile testing, such as IFE/HRP and CEA. Partnerships with universities have not only helped students successfully complete their graduate level research, but have led to new INL employees. Over 12 peer-reviewed conference papers and 20 archival journal papers have been produced, and several patents have been awarded or are pending from this research. Finally, the specialized fixtures and software developed and installed at the ATRC for evaluating flux detectors expands the capability of this facility. It is anticipated that this new capability will be used in future years to develop and evaluate new, improved sensors for measuring flux and other parameters. 
INL/EXT-11-21231 


\section{DEVELOPMENT - IDAHO NATIONAL LABORATORY}

Several INL efforts are underway to enhance in-pile instrumentation for ATR users. As indicated in Section 4, these efforts focus on obtaining instrumentation for measuring a wide range of parameters and conditions. This section summarizes the status of on-going and planned sensor development and evaluation efforts at INL.

\subsection{Temperature Sensors}

Temperature is a key parameter of interest during fuel and material irradiations. As indicated in Table 4-2, available temperature detection sensors to ATR NSUF users are comparable, if not superior, to those used at other MTRs. Melt wires and temperature-sensitive paint spots, along with commercially available thermocouples (e.g., Types K, N, and C) have been available for decades. To meet recent customer requests, an increased selection of melt wires with enhanced encapsulation and $\mathrm{SiC}$ temperature monitors are available for all irradiation locations and doped molybdenum/niobium alloy thermocouples are available for instrumented lead and PWR loop applications. Investigations into the use of ultrasonic thermometers and fiber optics for temperature measurement are also underway.

\subsubsection{Melt wires}

Metal wires of a known composition and melting temperature are placed in an environment to determine if a specific peak temperature is reached. Note that a post-test examination of the wire is required to determine if melting actually occurred indicating that the corresponding melting temperature was reached (or exceeded). As described in ASTM E 1214$06,{ }^{50}$ melt wire materials should consist of metals with $99.9 \%$ purity or be eutectic alloys such that their measured melting temperatures are within $\pm 3{ }^{\circ} \mathrm{C}$ of the recognized melting temperatures. Transmutation-induced changes of these wires should not be considered significant up to $1 \times 10^{20} \mathrm{n} / \mathrm{cm}^{2}(\mathrm{E}>1 \mathrm{MeV})$. As noted in Reference 50, melt wires should be selected to measure temperature at 5 to $12{ }^{\circ} \mathrm{C}$ intervals, with at least one melt wire that possesses a melting temperature greater than the highest anticipated temperature. Melt wires are often encased in vanadium or quartz containers. As part of the ATR NSUF effort, INL has developed in-house capabilities to verify the melting temperature of candidate wire materials (ranging from $\sim 85$ to $1200^{\circ} \mathrm{C}$ ) and to encase multiple types of melt wires into a single small diameter unit for irradiation testing. Figure 5-1 shows a quartz tube containing multiple melt wires, but metallic tubes are also available.

\subsubsection{Silicon Carbide Temperature Monitors}

In recent years, several research organizations have explored the use of $\mathrm{SiC}$ temperature monitors for static capsule peak temperature detection because these monitors can be used to detect the maximum temperature reached within a range of temperatures. For example, Snead et 


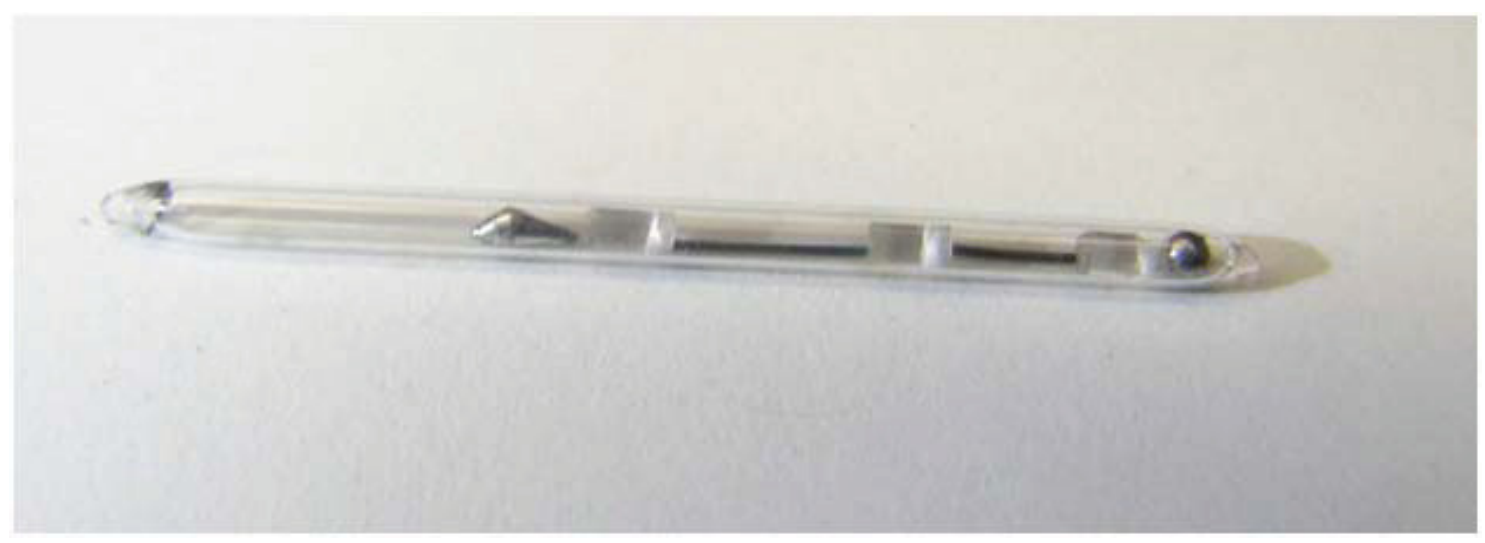

Figure 5-1. Quartz tube containing four melt wires in separated compartments.

al. (ORNL) $)^{52}$ successfully used changes in resistivity to detect peak irradiation temperature with accuracies of approximately $20^{\circ} \mathrm{C}$ for dose ranges of 1 to 8 dpa and temperatures between 200 and $800{ }^{\circ} \mathrm{C}$. Experimental data ${ }^{52}$ suggest that upper and lower bounds for this range may be extended.

The technique implemented by Snead et al., ${ }^{52}$ is now also available at INL. Specialized equipment at INL's High Temperature Test Laboratory (HTTL) now allows peak temperature detection of static capsules using SiC monitors. In this technique, the SiC sensor electrical resistivity is measured after heating in a furnace located within a stainless steel enclosure at the HTTL (see Figure 5-2). After heating, cooled samples are placed into a constant temperature environmental test chamber to insure electrical resistivity measurements are taken within $0.2^{\circ} \mathrm{C}$ of a predetermined temperature, $30^{\circ} \mathrm{C}$. A high accuracy (9 digit) multimeter, which is placed outside the stainless steel enclosure, is used to obtain resistance measurements. Specialized fixturing (see Figure 5-2) was developed to insure that measurements are always taken with the $\mathrm{SiC}$ sensors placed in the same orientation. A four point probe technique is used with the four points connected to the sample through spring-loaded angled electrodes that hold the $\mathrm{SiC}$ temperature monitor in place. Current and voltage are provided to the sample through wires that are threaded through the holes in the electrodes. The accuracy of this new INL capability was verified by completing tests with unirradiated samples of various grades of SiC temperature monitors (which vary in resistivity) and by completing comparison measurements with ORNL on identical sensors that had been subjected to identical irradiation conditions. ${ }^{55}$ Results, as shown in Figure 5-3, indicate that similar peak irradiation temperatures are inferred from ORNL and INL measurements for such cases.

\subsubsection{High Temperature Irradiation Resistant Thermocouples (HTIR-TCs)}

For decades, real-time temperature measurements during irradiation tests have been made with commercially-available, mineral insulated, metallic sheathed thermocouples. These thermocouples are used to monitor or/and control the temperature achieved during irradiation. For 


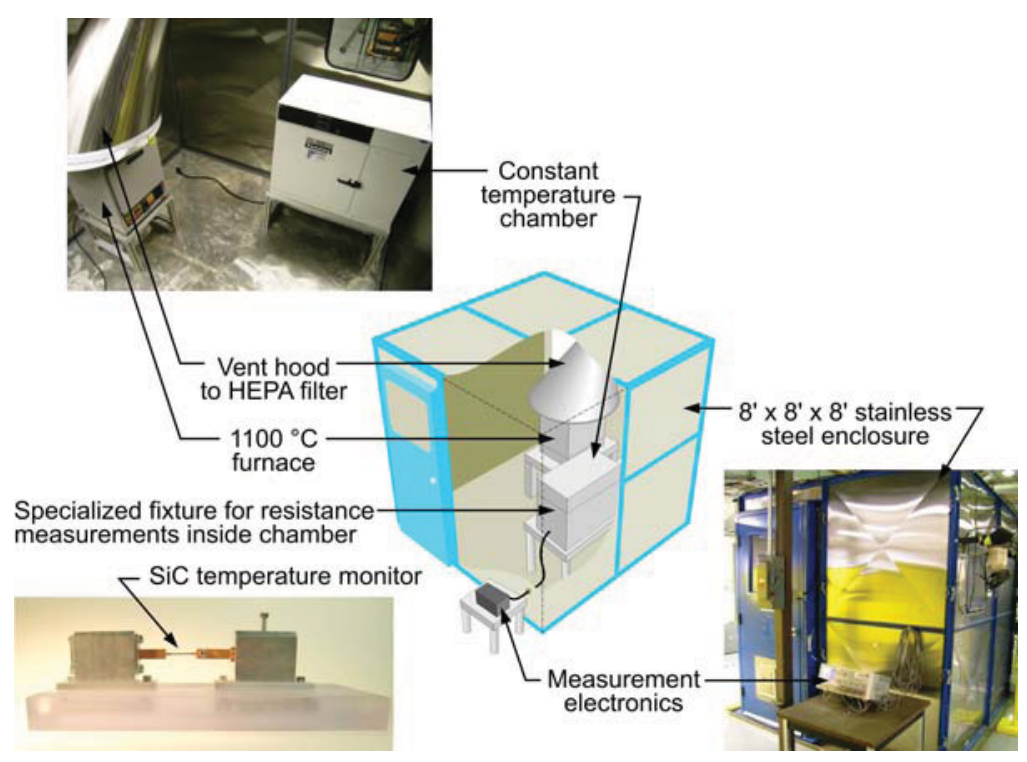

Figure 5-2. Setup to anneal and measure electrical resistivity of $\mathrm{SiC}$ temperature monitors.

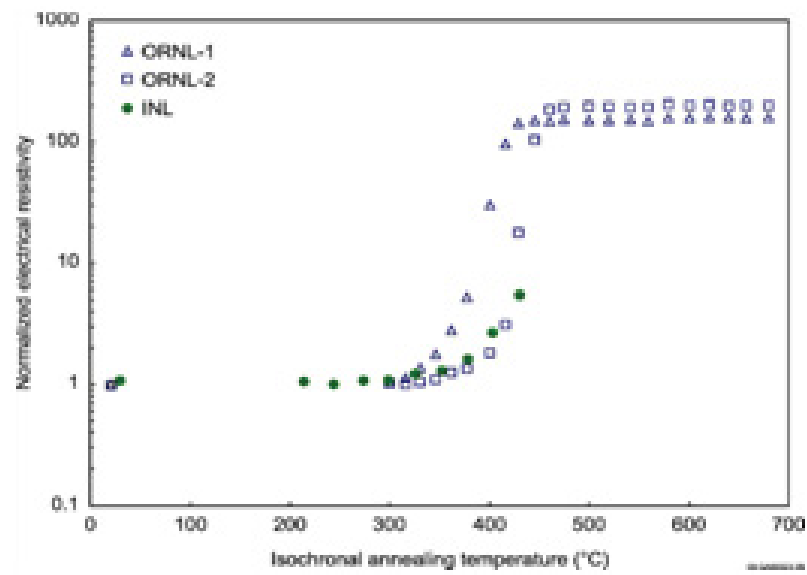

Figure 5-3. Electrical resistivity measurement comparison on $\mathrm{SiC}$ monitors irradiated at $300{ }^{\circ} \mathrm{C}$.

temperatures below $1000{ }^{\circ} \mathrm{C}$, experimental needs are typically met using Type $\mathrm{K}$ or Type $\mathrm{N}$ thermocouples, which have demonstrated excellent reliability and signal stability under irradiation, even for very high neutron fluences exceeding $10^{22} \mathrm{n} / \mathrm{cm}^{2}$ (thermal neutrons). However, these thermocouples decalibrate when exposed to temperatures above $1100{ }^{\circ} \mathrm{C}$. High temperature thermocouples, such as Type $\mathrm{C}$ or D thermocouples, decalibrate due to transmutation when their tungsten-rhenium thermoelements, with high absorption cross sections, are exposed to a thermal neutron flux. Hence, thermocouples were needed that can withstand both high temperature and high radiation environments. 
To address this need, INL developed a High Temperature Irradiation Resistant ThermoCouple (HTIR-TC) sensor that contains commercially-available doped molybdenum paired with a niobium alloy. HTIR-TC component materials were selected based on data obtained from materials interaction tests, ductility investigations, and resolution evaluations (see References 58 through 65). HTIR-TC long duration performance has been demonstrated through testing, in which thermocouples were held at elevated temperatures (from $1200{ }^{\circ} \mathrm{C}$ to $1800{ }^{\circ} \mathrm{C}$ ) for up to 6 months. The $1200^{\circ} \mathrm{C}$ test included nineteen commercially-available Type $\mathrm{N}$ thermocouples, three commercially-available Type K thermocouples, and nine INL-developed swaged HTIR-TCs. As indicated in Figure 5-4, some Type K and N thermocouples drifted by over $100{ }^{\circ} \mathrm{C}$ or $8 \%$. Much smaller drifts (typically less than $20^{\circ} \mathrm{C}$ or $2 \%$ ) were observed in the INLdeveloped HTIR-TCs. As documented in Reference 64, similar drifts (2\%) were observed in HTIR-TCs in a long duration (4000 hour) test completed at $1400{ }^{\circ} \mathrm{C}$ and smaller drifts (less than $1 \%$ ) have been observed in HTIR-TCs with enhanced fabrication techniques for higher temperatures (up to $1800^{\circ} \mathrm{C}$ ).

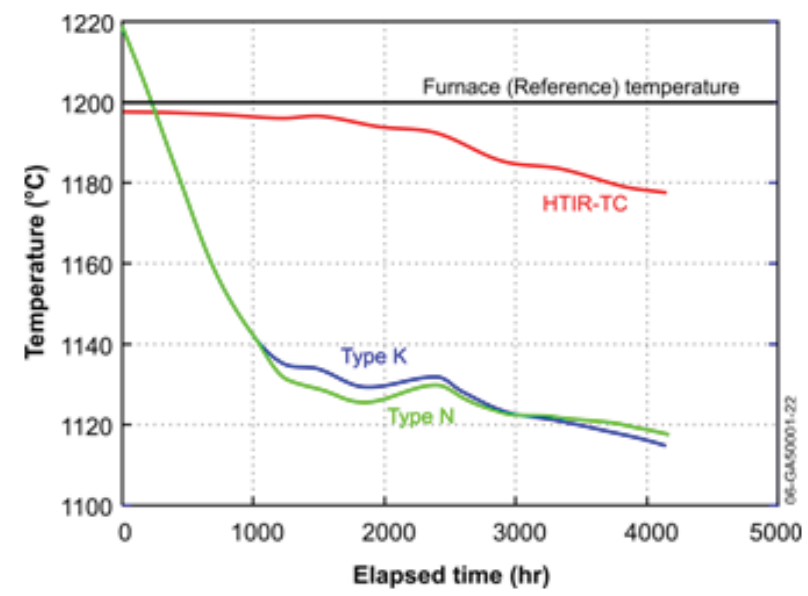

Figure 5-4. Representative thermocouple response in INL $1200^{\circ} \mathrm{C}$ tests.

HTIR-TCs were also installed in a multi-capsule experiment where gas reactor fuel samples were irradiated at temperatures up to $1200{ }^{\circ} \mathrm{C}$ in INL's ATR. The test started in February 2007 and ended in October 2009. Figure 5-5 shows signals from two INL-developed HTIR-TCs and one Type N thermocouple located within one of the capsules (Capsule 4). Signal variations are due to ATR power fluctuations and outages (e.g., gray regions correspond to when the ATR was shutdown). As shown in this figure, the HTIR-TC (TC-4-1) located near the Type N thermocouple (TC-4-3) yielded a signal consistent with the signal from this Type $\mathrm{N}$ thermocouple at the beginning of this irradiation. In addition, the HTIR-TC located at a higher temperature region within the capsule (TC-4-2) yielded a consistent, but higher temperature, signal. However, in October 2008, the Type $\mathrm{N}$ thermocouple failed; and its signal ceased. The successful operation of HTIR-TCs in this test has led to INL supplying them to other test reactors around the world. In 2010, three HTIR-TCs were supplied to MIT for an irradiation test in their research reactor. In addition, efforts were initiated to fabricate three thermocouples for the HBWR. These HTIR-TCs will be shipped to IFE/HRP in 2011. 

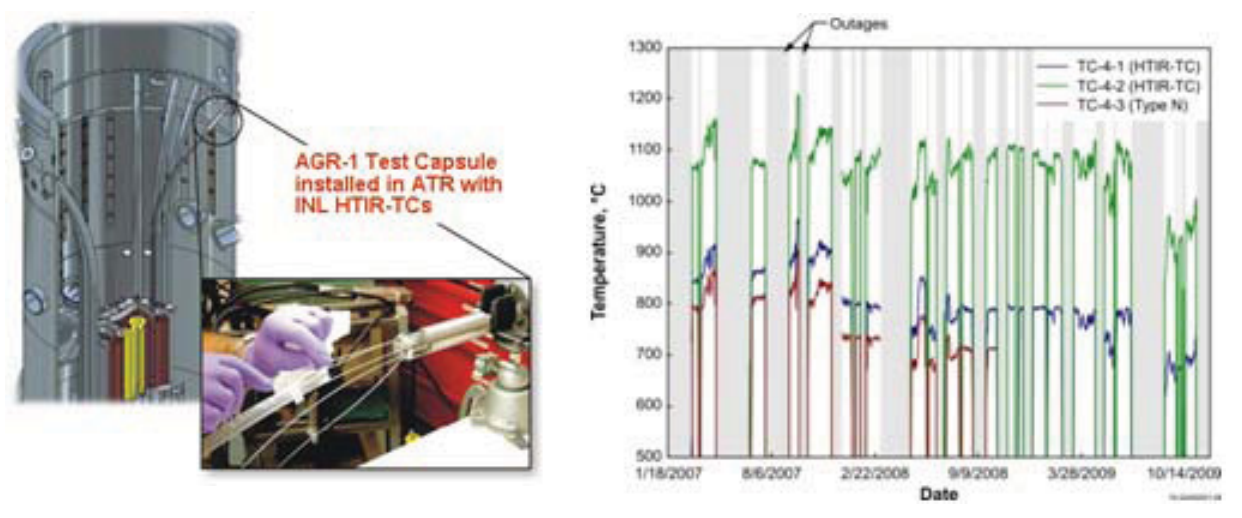

Figure 5-5. HTIR-TCs installed in AGR-1 test capsule and representative HTIR-TC and Type N data during ATR irradiation.

\subsubsection{Ultrasonic Thermometers}

Ultrasonic thermometry has the potential to improve upon temperature sensors currently used for in-core fuel temperature measurements. Even though the HTIR-TCs developed by INL have overcome most of the difficulties associated with the nuclear-based application of thermocouples, the resistivity of electrical insulators can degrade if subjected to high temperatures $\left(>1800^{\circ} \mathrm{C}\right)$, causing shunting errors. Furthermore, thermocouples typically only allow measurement at a single location, and examination of melt wires or silicon carbide monitors only allow estimation of the maximum test temperatures at the point of installation. Ultrasonic thermometry offers the potential for real time in-pile measurement of a temperature profile using a single multi-segment sensor. Prior applications of ultrasonic thermometers have demonstrated the viability of this technology, but in-pile applications were primarily limited to hightemperature fuel damage tests, which ceased several decades ago.

As part of the FCRD program, INL recently initiated an effort to investigate the use of ultrasonic thermometry for measuring a temperature profile using a single, small diameter multisegment sensor. ${ }^{66,67}$ Tests will be performed at INL's HTTL to demonstrate the viability of and optimize ultrasonic techniques using the setup shown in Figure 5-6. Initial testing is focusing on a simplified, single segment probe, which can be made with very small diameters while maintaining a high level of durability. The probe consists of a small diameter rod (typical diameters range from $0.25 \mathrm{~mm}$ to $1 \mathrm{~mm}$, though a sheath may be required for some environments). In fact, a small diameter rod is desirable, as wave dispersion is avoided when the rod diameter is small compared to the acoustic wavelength. Temperature measurements may be made near the melting point of the probe material(s). As no electrical insulation is required, shunting effects found in thermocouples and resistance temperature devices (RTDs) are eliminated. A clear line of sight is not required, as is the case for most optical pyrometry applications. With proper selection of materials, UTs may be used in very harsh environments, such as high temperature steam or liquid metals. Perhaps the most appealing characteristic of UTs 
is the ability to make temperature measurements at several axial positions using a single sensor, thereby measuring a temperature profile.

As part of this optimization effort, various design alternatives are being explored. Alternate wave guide, sensor, and sheath materials with high melting temperatures and insensitivity to neutron radiation (such as molybdenum), are under evaluation. Also, different methods of generating ultrasonic pulses (magnetostrictive and piezoelectric materials), as well as different pulse modes (longitudinal and torsional) are being considered. As part of this effort, an instrumented-lead irradiation test capsule will be designed, fabricated, and tested in the ATR. This test will include an irradiation evaluation of the most promising candidate piezoelectric and magnetostrictive transducer materials. To maximize the benefit of this irradiation test, appropriate individuals from various DOE-NE programs, such as the Advanced Reactor, LWRS, Small Modular Reactor, and NGNP efforts, will be contacted. In addition, recent results from piezoelectric irradiation studies in foreign research reactors will also be considered. This test will be an instrumented lead test, such that real time signals are received from the transducers. This will enable an accurate measure of the performance and possible degradation of candidate transducer materials under irradiation. Note that this test will include at least one magnetostrictive candidate for comparison purposes, as magnetostrictive materials have been successfully deployed in previous ultrasonic in-pile applications.

As noted above, a key feature of the ultrasonic thermometry system is the ability to measure a temperature profile. However, these sensors will also require development of a signal conditioning and processing system for the multiple signals generated by a multi-segment sensor. Ultimately, it is planned that the optimized UT design for in-pile temperature detection will be evaluated in an ATR NSUF test.

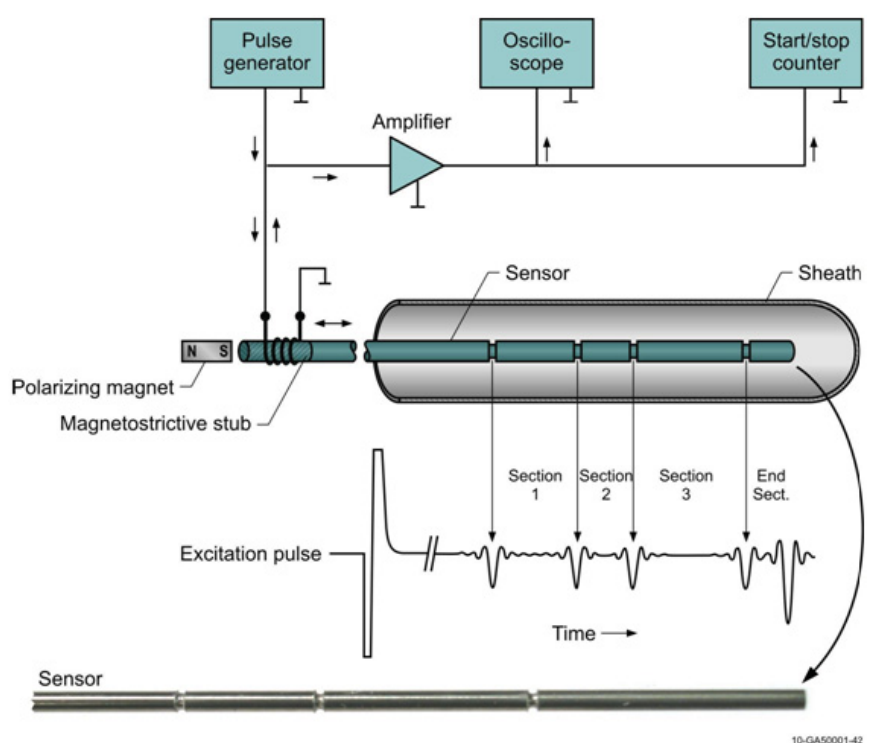

Figure 5-6. A typical multi-sensor pulse/echo ultrasonic thermometry system and 'notched' sensor. 


\subsubsection{Fiber Optics}

As discussed in Section 3.2.3, optics-based sensing techniques have proven to offer a wide range of capabilities for measuring chemical, physical and mechanical properties of materials through optical spectroscopy and laser ultrasonic methods. Many of these techniques are amenable to fiber optic delivery. Furthermore, fiber optic based sensors capable of measuring strain and environmental conditions, such as temperature and pressure, have become commercially available.

Fiber optic sensing techniques may offer a number of advantages for incorporation into advanced instrumented tests at ATR. The optical fibers are small. Common optical fibers measure only $250 \mu \mathrm{m}$ in diameter, allowing as many as 20 fibers to fit into a $1.6 \mathrm{~mm}$ ID tube. Optical fibers can be used in distributed measurement techniques where a property such as temperature can be measured at several locations along a single fiber. Another benefit of fiber optics sensors is that they require no electrical power and don't transmit electrical signals.

A major factor limiting implementation of fiber optic techniques in a nuclear reactor is the deterioration in fiber transmission due to optical damage caused by irradiation. Development of radiation hardened optical fibers has been of much interest to the research community for many years. Short optical wavelengths (from the visible to the UV) appear to be the most dramatically affected by radiation damage. ${ }^{68,69}$ Many optical glass materials darken significantly even under only high flux gamma radiation. ${ }^{a}$ Recent successes in material fabrication have been reported that reduce the radiation sensitivity ${ }^{74,75}$ or that have found wavelength regions around $1 \mu \mathrm{m}$ of reduced sensitivity to damage. ${ }^{76}$

As discussed in Section 3.2.3, several optical fibers were recently tested in the CEA OSIRIS nuclear reactor to determine the radiation induced attenuation. ${ }^{77}$ The wavelength region between 800-1200 nm showed the least radiation induced attenuation. The best fibers showed radiation attenuation of approximately $10 \mathrm{~dB} / \mathrm{m}$ at an accumulated dose of $1.2 \times 10^{21} \mathrm{n}_{\mathrm{th}} / \mathrm{cm}^{2}, 1.3$ $\mathrm{x} 10^{20} \mathrm{n}_{\text {fast }} / \mathrm{cm}^{2}$, and 16 GGy gamma radiation. Photonic Bandgap Fibers (PBG) are a relatively new type of optical fiber which guide light on a bandgap principle as opposed to the total internal reflection of standard fibers. Consequently, they can be constructed with a hollow core. A cross sectional view of one such fiber is shown in Figure 5-9. These fibers showed the least radiation induced attention right up until they ceased to function. The PBG fibers showed less than $4 \mathrm{~dB} / \mathrm{m}$ RIA for a dose of $10 \times 10^{20} \mathrm{n}_{\mathrm{th}} / \mathrm{cm}^{2}$, and $10 \mathrm{GGy}$ gamma radiation prior to failure. Based on published radiation levels in the ATR, one would expect similar attenuation levels after several days in the ATR (depending on irradiation location). Luna Innovations has conducted fiber sensor radiation testing in the University of Michigan's Ford nuclear reactor. ${ }^{78,79}$ In these tests, 14 out of 19 FBG sensors were still delivering readable signals after a dose of $2.0 \times 10^{19} \mathrm{n}_{\mathrm{fast}} / \mathrm{cm}^{2}$ and 0.87 GGy gamma. These fluences correspond roughly to 1 day in a midcore flux trap position in the ATR with the reactor at $110 \mathrm{MW}_{\text {th }}$.

a. In a test, optical attenuation increased after extensive gamma radiation at ATR by 50\%@532 nm and only 1\%@1064 nm in a borosilicate glass provided by S. Raman. 


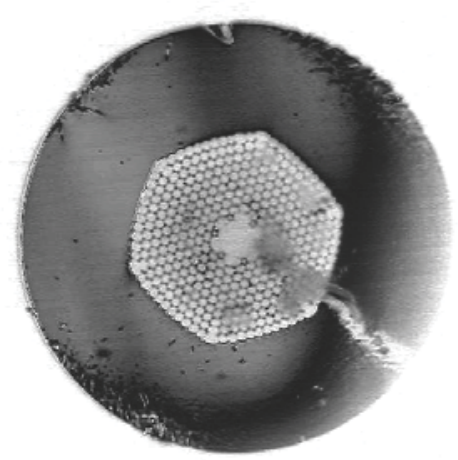

Figure 5-7. Photonic bandgap fiber.

In addition to the potential for neutron and gamma radiation damage, the optical fibers must also endure the environmental conditions in the reactor. High temperature water has been shown to etch silica. Optical fibers which consist primarily of silica would not last long in the reactor coolant environment if left unprotected. Standard fiber buffer coatings have limited high temperature capabilities or become brittle at higher temperatures which can induce micro-cracks and ultimately, fracture the optical fibers. Metallic coated fibers are available, as are hermetically sealed carbon coated fibers such as those offered by Verrillon. These types of coatings could protect the fibers from the reactor environment, but fiber type and coating would need to be matched to the application for best results. Another option, if compatible with the experiment, would be to seal the fiber inside of a metallic tube so that it is not exposed to high temperature, high pressure water.

A number of fiber optic sensing techniques exist for measuring environmental parameters such as temperature and pressure that could be used for in-pile testing. The primary limitation to the use of optical fibers for in-reactor measurements is the tendency of optical fibers to darken under irradiation, thereby increasing the attenuation of light propagating in the fiber. Extrapolating data from radiation testing in other reactors suggests that optical fibers would last long enough to provide meaningful data for at least the first day and possibly up to several weeks in the radiation levels present in the ATR. In addition, it appears promising that pressure boundary seals for optical fibers exist that would allow optical fiber sensors to be incorporated into ATR instrumented tests. Hence, the FCRD program has initiated an effort in FY11 to investigate the feasibility of fiber optics to provide new insights about changes in fuel behavior during irradiation. 


\subsection{Thermal Conductivity Sensors}

Thermal conductivity is another key property needed to characterize fuel or material performance during irradiation testing. Thermal conductivity is highly dependent on the physical structure, chemical composition, and the state of the material. Currently, changes in fuel or material thermal conductivity during ATR irradiations are evaluated out-of-pile. However, as discussed in this section, real-time methods for detecting changes in thermal conductivity during irradiation in instrumented lead and loop tests are available.

Historically, in-pile thermal conductivity measurements have been made using an approach (see Figure 5-8a) with one (or more) thermocouples embedded near the center of the fuel rod and one exterior to the fuel (in the coolant or a structure outside the fuel element). As part of a collaborative effort with Utah State University (USU) and the Institute for Energy Technology at the Halden Reactor Project (IFE/HRP), INL is evaluating the multiple thermocouple steady-state thermal conductivity approach and a transient hot wire thermal conductivity method (with a single probe containing a line heat source and thermocouple embedded in the fuel as shown in Figure 5-8b) as candidate in-pile effective thermal conductivity measurement techniques. ${ }^{83-87}$ Evaluations compare the accuracy of each approach for various fuel types and test conditions. Details about the status of these evaluations are summarized in this section.
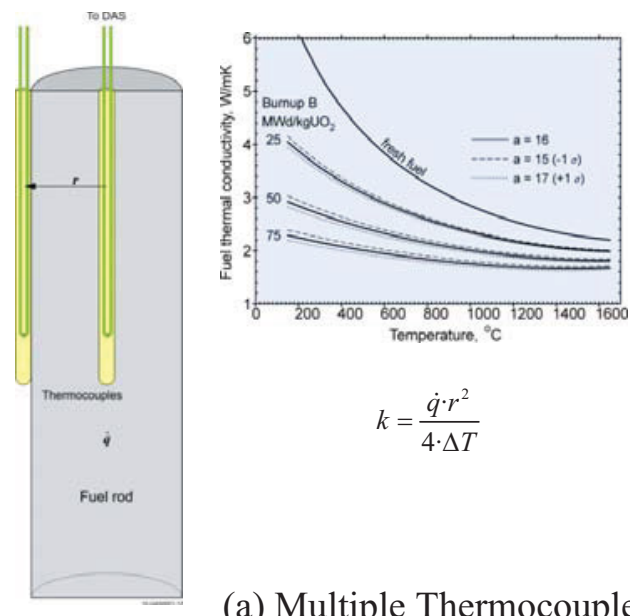

$k=\frac{\dot{q} \cdot r^{2}}{4 \cdot \Delta T}$

(a) Multiple Thermocouple
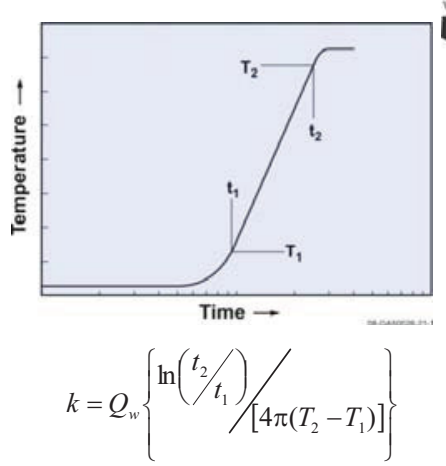

(b) Transient Hot Wire Method

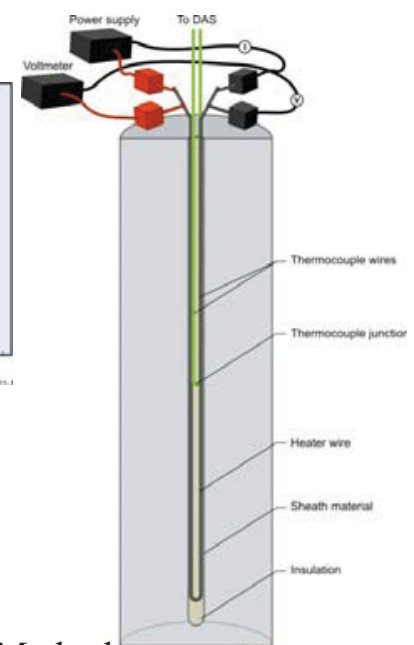

Figure 5-8. In-pile thermal conductivity methods under evaluation (see text for variable definitions).

\subsubsection{Multiple Thermocouple Method}

Variations of the two-thermocouple approach for detecting thermal conductivity changes in oxide and metal fuel during irradiation have been explored since 1960 (e.g., see References 89 through 91). Typically, results from this approach correlate in-pile degradation of fuel during irradiation (due to swelling, cracking, etc.), as an indication of thermal conductivity degradation 
(because the 'effective' thermal conductivity of the fuel, cladding, and gap are measured, and one is really just detecting all the changes that impact the thermal conductivity). Most earlier efforts were conducted with metal fuel pellets encased in cladding with sodium bonding (thus, minimizing any concerns about fuel pellet-to-gap resistance). The HBWR is currently the only test reactor where in-pile thermal fuel thermal conductivity measurements are performed using a multiple thermocouple approach.

INL and USU completed evaluations to estimate the thermal conductivity of a surrogate fuel rod using two thermocouples inserted into the rod with volumetric heat generation simulated by Joule heating. One thermocouple monitors centerline temperature, while the other monitors temperature at a measured radial position within the rod. As shown in Figure 5-8a, the thermal conductivity, $k$, is calculated from the radial temperature drop, $\Delta \mathrm{T}$, the radial distance between the thermocouples, $r$, and volumetric heat generation, $\dot{q}$. High temperature carbon structural foam was selected as the surrogate material in these evaluations because of its electrical resistivity, low thermal conductivity, and high temperature resistance to oxidation and melting. Figure 5-9 shows a schematic of the surrogate rod and test setup used to obtain data. Surrogate rods containing two thermocouples (Figure 5-9a) were positioned inside a tube furnace with an argon cover gas to provide a controlled sample test temperature (Figure 5-9b). Voltage and current from the power supply were supplied to the rod using Inconel electrodes connected to Inconel clamps. Leads attached to Inconel clamps at each end of the rod were used to measure the voltage drop across the rod. A precision current shunt was used to measure current within the experimental test loop. Volumetric heat generation was calculated using the measured current, $I$; and the sample voltage drop, $V$; sample dimensions, and the fact that power is the product of the current and voltage. Signals were processed by a data acquisition system to give temperatures from thermocouples and power in the sample. Results for tests with the supplied power held constant at $100 \mathrm{~W}$ in the 500 to $700{ }^{\circ} \mathrm{C}$ temperature range were within $2 \%-8 \%$ of the surrogate rod thermal conductivity values obtained using material property measurement systems (e.g., laser flash diffusivity, pushrod dilatometry, and differential scanning calorimetry) available at INL's HTTL.

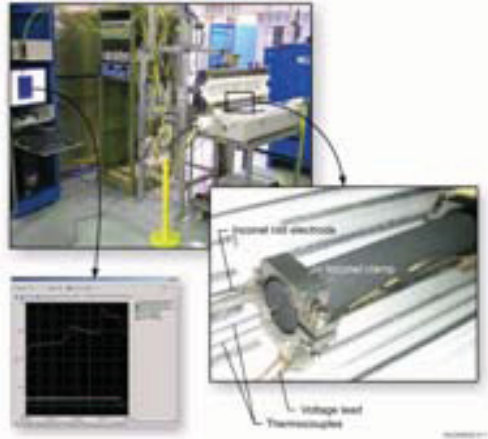

(a)

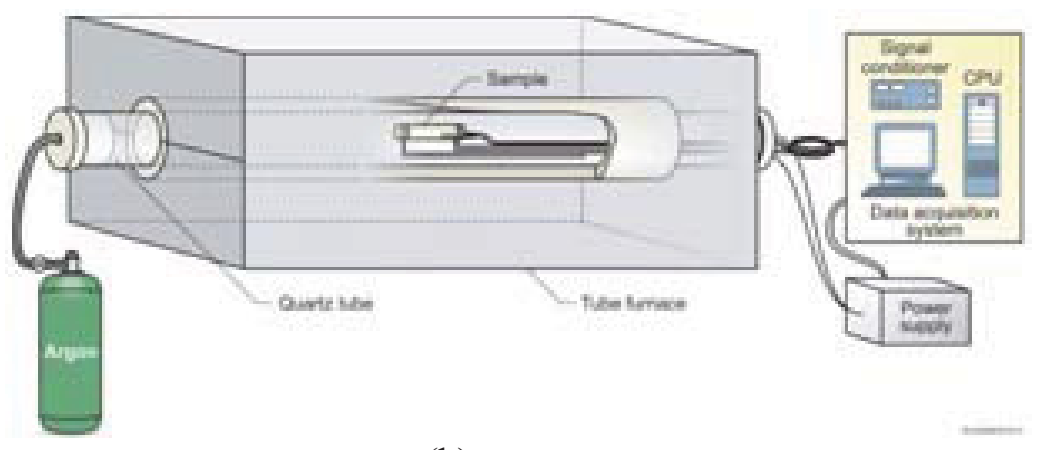

(b)

Figure 5-9. Setup for evaluating the two thermocouple method. 


\subsubsection{Hot-wire Transient Needle Probe}

USU/INL also evaluated the viability of using a needle probe based on the Transient Hot Wire Methods (THWM) or the line heat source method that was first suggested by Schleirmacher. ${ }^{92}$ Numerous references may be found in the literature describing applications of this method to measure the thermal conductivity of solids, fluids, and gases (e.g., see References 93 through 98). The THWM is applied by embedding a line heat source in a sample whose thermal conductivity is to be measured. From a condition of equilibrium, the heat source is energized and heats the sample with constant power. The temperature response of the sample is a function of its thermal properties. As indicated in Figure 5-8b, the thermal conductivity, $k$, is calculated from a relation that includes $Q_{w}$, the linear power dissipated by the heater and the measured increase in temperature, $T_{2}$ and $T_{1}$, between times, $t_{2}$ and $t_{1}$.

INL/USU explored the use of a hot wire probe design, containing a resistance heater and thermocouple embedded in a single probe (see Figure 5-10), that was developed based on ASTM D $5334-05.18 .{ }^{93}$ As shown in Figure 5-10b, the probe contains a heat source element and a temperature sensor inserted into a sample. The thermal conductivity is determined from the temperature rise in the sample. Needle probes were designed and fabricated at INL's HTTL for both room temperature proof-of-concept evaluations and high temperature testing. Using the setup shown in Figure 5-10, experimental results show that the INL/USU designed needle probes can measure the thermal conductivity of fused silica, the ASTM recommended reference material, within $2 \%$ at room temperature, $250{ }^{\circ} \mathrm{C}, 400{ }^{\circ} \mathrm{C}$, and $600{ }^{\circ} \mathrm{C}$. In these evaluations, the probe design was selected such that materials and geometry were optimized to improve accuracy for the proposed test temperature and surrogate rod material (e.g., wire diameters and materials used for probes differed to optimize heating in the surrogate fuel rod and reduce other losses). These optimization techniques were used to develop a probe design for an upcoming fuel irradiation at the Massachusetts Institute of Technology Nuclear Research Reactor (MITR), where the distance from the fuel rod to the data acquisition equipment is even longer with more dramatic temperature differences.

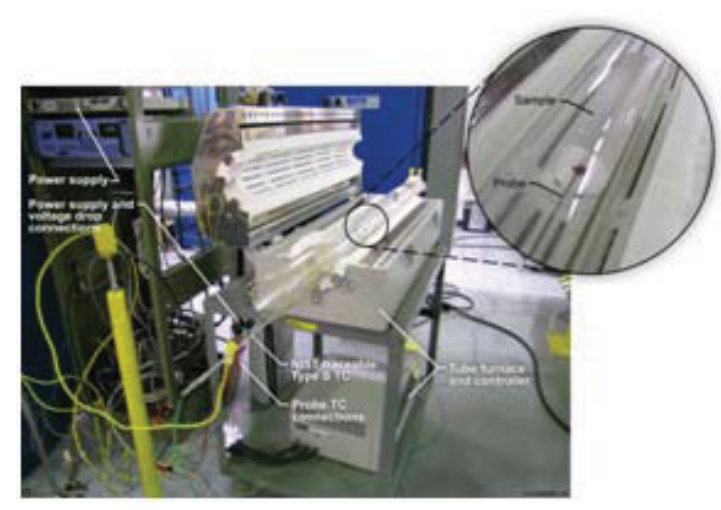

(a)

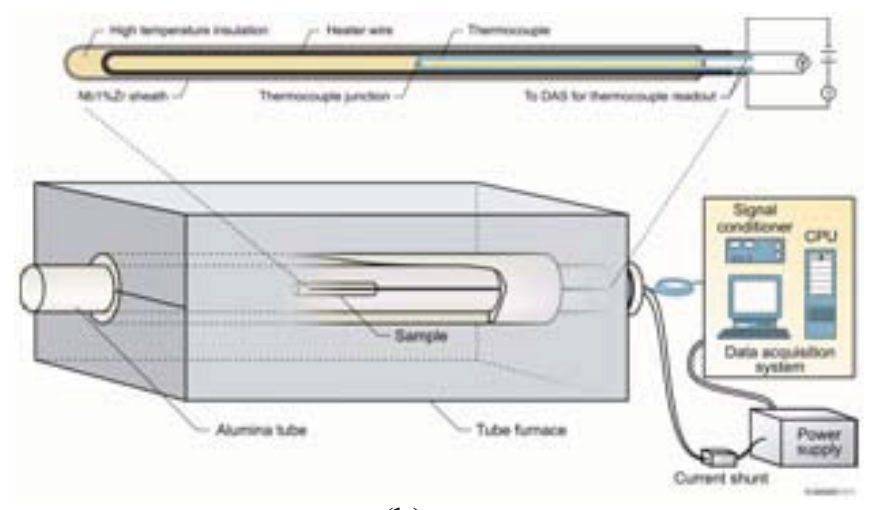

(b)

Figure 5-10. Setup for evaluating transient hot wire needle probe. 
During FY10, investigations primarily focused on the THWM approach because of the increased accuracies possible with this technique, and results from evaluations of a prototype probe completed in FY10 are very promising The needle probe was demonstrated to work very well for materials with thermal conductivity ranges from 0.2 to $16 \mathrm{~W} / \mathrm{m}-\mathrm{K}$ with measurement errors of less than $5 \%$, delivering thermal conductivity measurements with a high degree of accuracy and consistency (see Figure 5-11). The test results indicated that special design considerations are needed for materials with a high thermal conductivity, or samples with a small diameter. High thermal conductivity and small diameter sample materials pose some challenges, but methods for improving the technique are being developed, primarily to reduce signal noise and better characterization of the probe response time. Results from long term evaluations indicate that the needle probe is a robust sensor that could survive in the harsh environments associated with in-pile fuel testing. In FY11, a prototype needle probe will be prepared for an upcoming irradiation of hydride fuel in the MITR.

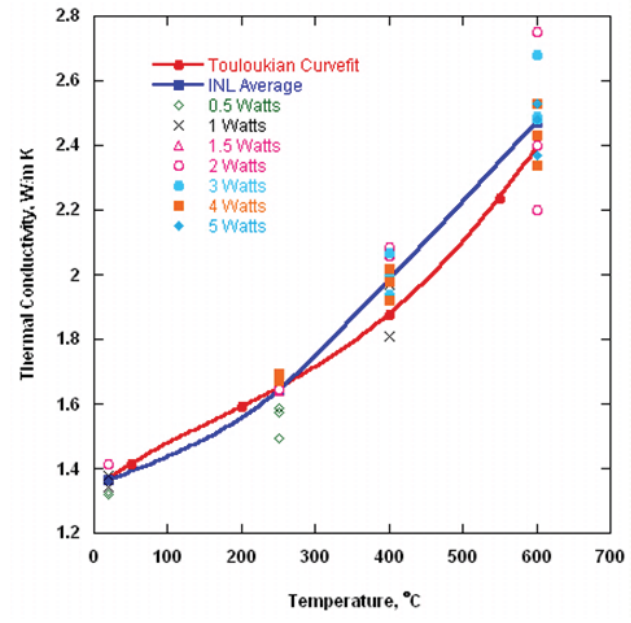

(a)

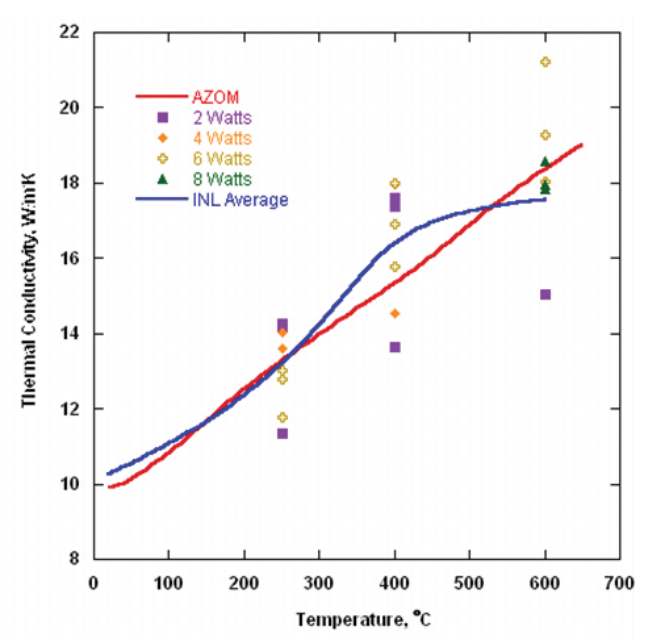

(b)

Figure 5-11. Comparison of THWM needle probe results obtained at various power levels for (a) fused silica and (b) Inconel 625.

\subsection{Elongation/Deformation/Creep/Swelling}

New materials are being considered for fuel, cladding, and structures in next-generation and existing nuclear reactors. Such materials can experience significant dimensional and physical changes during irradiation. Currently, such changes are measured at the Advanced Test Reactor (ATR) by repeatedly irradiating a specimen for a specified period of time and then removing it from the reactor for evaluation. The labor and time to remove, examine, and return irradiated samples for each measurement makes this approach very expensive. In addition, such techniques provide limited data, and handling may disturb the phenomena of interest. For lower temperature (up to $500{ }^{\circ} \mathrm{C}$ ) applications, commercially-available Linear Variable Differential Transformers (LVDTs) are being evaluated as a near-term option for detecting geometry changes in ATR irradiations. In addition, as discussed in Section 5.3.3, ultrasonic transducers are being explored 
as a more compact sensor that can measure geometry changes and crack growth with higher precision in multiple dimensions at higher temperatures.

\subsubsection{Elongation}

Earlier references 99,100 report using miniature strain gauges encased in zircaloy sheaths welded on the cladding in the circumferential and axial directions. These references indicate that strain gauge measurements were unstable due to high sensitivities of the gauges to temperature and neutron fluence. Today, most MTRs rely on LVDTs to detect changes in length during irradiation.

As discussed in Section 3.3, LVDTs are electrical transformers with three coils placed end-to-end around a tube (see Figure 5-12a). The center coil is the primary, and the two outer coils are the secondaries. A cylindrical magnetically-permeable core, attached to the object whose position is to be measured, slides along the axis of the tube. An alternating current is driven through the primary, causing a voltage to be induced in each secondary which is proportional to its mutual inductance in the primary. As the core moves, these mutual inductances change, causing the voltages induced in the secondaries to change. The coils are connected in reverse series, so that the output voltage is the difference between the two secondary voltages. When the core is in its central position, equidistant between the two secondaries, equal but opposite voltages are induced in these two coils, so the output voltage is zero (see Figure 5-12b). Many features of LVDTs (e.g., frictionless measurements, long lifetime, high resolution, etc.) make them ideal for in-pile applications.

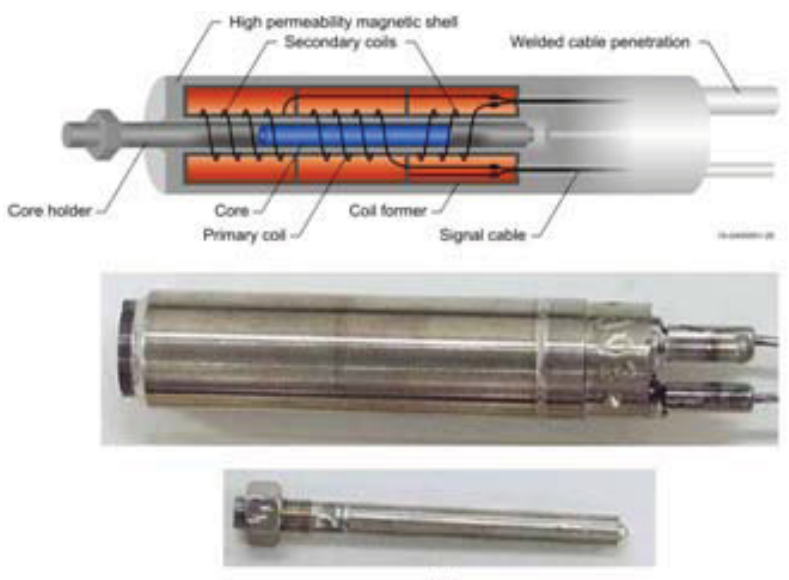

(a)

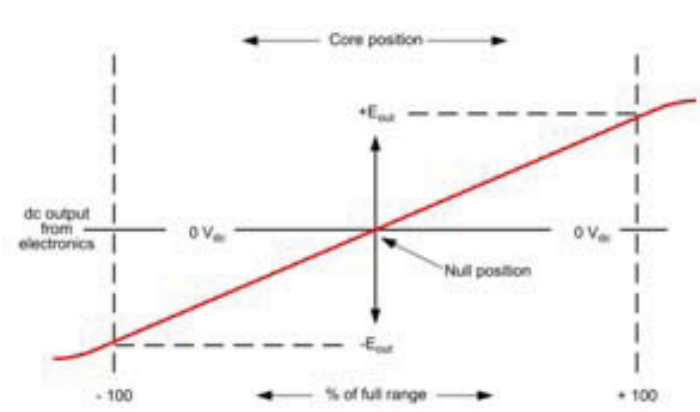

(b)

Figure 5-12. LVDT components (a) and operation (b).

Most research reactors rely on LVDTs made by the IFE/HRP. In the IFE/HRP LVDTs, the primary coil is activated by a constant current generator (at 400-2500 Hz). The position of the magnetically-permeable core can be measured with an accuracy of $\pm 1-10 \mu \mathrm{m}$ (references vary on this value). Since the HRP started with in-core measurements, more than 2200 LVDTs of different types have been installed in different test rigs in the HBWR and other test reactors around the 
world. A failure rate of less than $10 \%$ after 5 years of operation is expected for their LVDTs operating in BWR, PWR or CANDU conditions. Hence, operating experience has shown that these sensors are a robust, frictionless instrument for detecting dimensional changes in lowertemperature, irradiation environments. Evaluations completed in this project were designed to develop a much-needed high temperature sensor for detecting dimensional changes during irradiation testing at the ATR and other MTRs.

Nuclear-grade LVDTs from US and foreign sources were evaluated as candidates for inpile deployment. FY9 and FY10 efforts, which included calibration evaluations and long duration, high temperature testing (see Figure 5-13a), clearly indicated the superiority of LVDTs supplied by the IFE/HRP. However, evaluations of Curie point effects, due to the nickel contained in the LVDT coil material, indicates the potential for a change in accuracy (under certain operating conditions) near $360{ }^{\circ} \mathrm{C}$, the temperature that corresponds to the Curie point for the copper nickel wire used in the LVDT windings. Consequently, temperatures could be an issue depending on the in-core position of the sensor and the corresponding gamma heating levels. For that reason, INL has worked with IFE/HRP to develop and evaluate developmental LVDTs with an alternate coil material that is not susceptible to the Curie effect. Calibration and long term high temperature testing of the developmental LVDTs performed by INL demonstrate that the new LVDTs can operate in a very stable manner for long periods $(1000 \mathrm{~h})$ at high temperatures $\left(500{ }^{\circ} \mathrm{C}\right)$. As shown in Figure 5-13b, the degradation of the original LVDTs provided by IFE/HRP and by another nuclear-grade LVDT manufacturer was not observed in the developmental LVDTs provided by IFE/HRP. Hence, the developmental LVDTs are recommended for use in ATR high temperature irradiation tests.

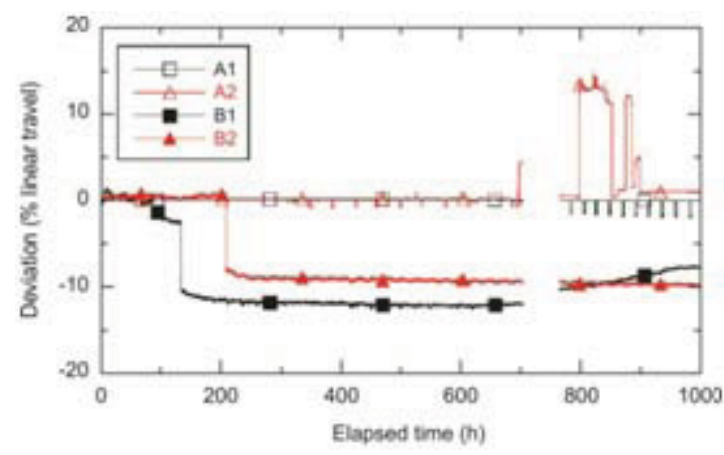

(a)

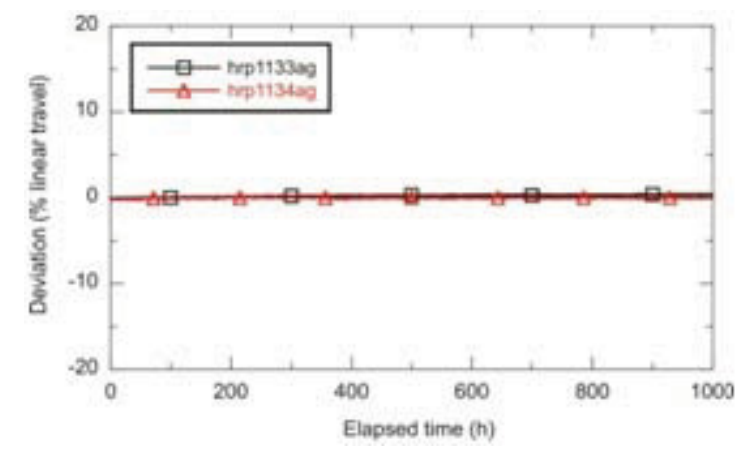

(b)

Figure 5-13. LVDT response during long duration ( 1000 hour) test at $500{ }^{\circ} \mathrm{C}$ : (a) LVDTs originally provided by nuclear grade vendors (LVDTs designated with an "A" were provided by IFE/HRP; and (b) developmental LVDTs provided IFE/HRP.

\subsubsection{LVDT/bellows-based Creep and Tensile Test Rigs.}

Several organizations (e.g., VTT Technical Research Center of Finland, INL, KAERI, and CEA) have been involved in developing and deploying in-pile tensile test rigs to detect growth of 
tensile and creep specimens using a bellows to apply a load to a specimen and LVDTs to detect growth of the specimen. Although it is unlikely that the primary damage experienced by a specimen will be affected by the applied stress during irradiation, the subsequent process of dislocation formation, that is responsible for radiation hardening, yield drop, and plastic flow localization, will be substantially altered by the applied stress. Furthermore, it is speculated that the fatigue lifetime during in-situ cyclic loading experiments may be significantly different from the ones obtained during fatigue experiments on specimens in the post-irradiated condition. Hence, several organizations are pursuing an in-situ material creep testing system for inclusion in PWR loops. Figure 5-14 shows the system developed by VTT and tested in the BR-2 reactor. This system includes a pneumatic loading unit, which loads a test specimen using gas to pressurize metallic bellows, and a LVDT from IFE/HRP to measure the resulting displacement produced in the tensile specimen. The outside diameter of the module tested in the BR-2 reactor is $25 \mathrm{~mm}$, and the total length of the module with the LVDT is $150 \mathrm{~mm}$.
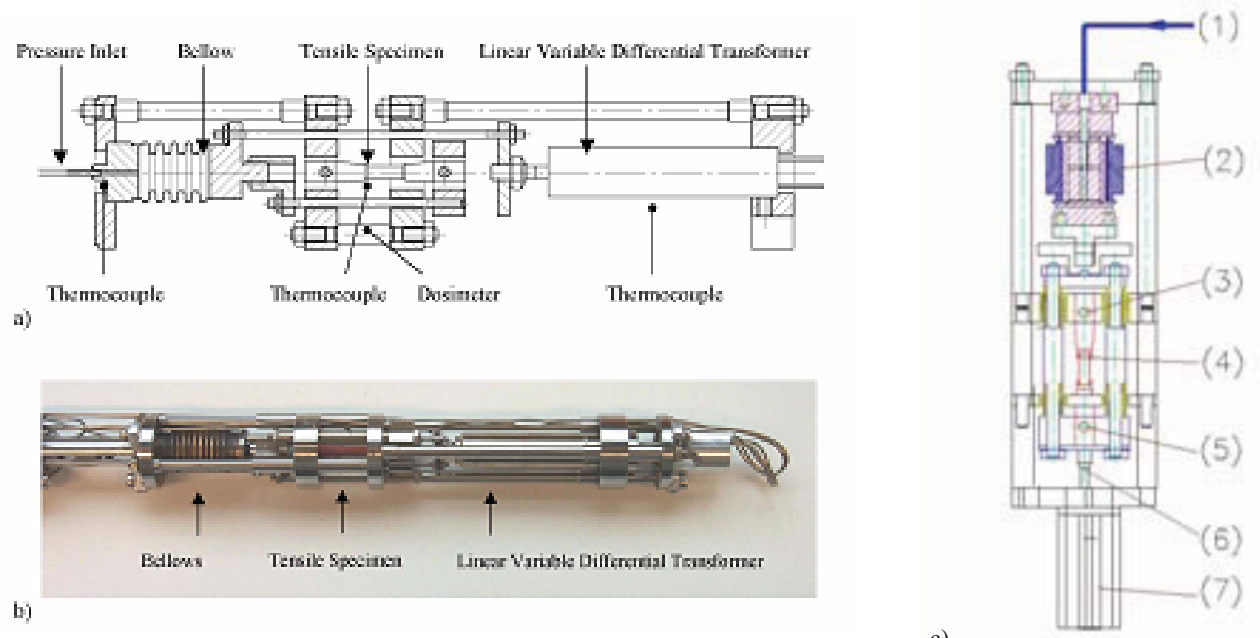

Figure 5-14. Tensile test module irradiated in the BR-2 ( $a$ and $b$ ) with schematic of tensile test module (c) that includes: (1) gas line, (2) pneumatic loading unit, (3) firm specimen fixing point, (4) specimen, (5) movable specimen fixing point, (6) LVDT plunger and (7) LVDT holder.

INL is currently developing an in-pile creep test rig for deployment in an ATR PWR loop in 2011. As discussed in References 101 and 102, a prototype of the prototype creep test rig shown in Figure 5-15 was recently evaluated in an autoclave at INL's HTTL. Initial evaluations with stainless steel tensile specimens in the elastic region yield data that are consistent with results obtained from a load frame for this material. Testing in the plastic region has also shown very close agreement between LVDT measurements and post-test micrometer measurements for stainless steel and copper tensile specimens. As discussed in Ref. 106, specimens with (nominal) gauge diameter of $2 \mathrm{~mm}$ and a (nominal) gauge length of $28 \mathrm{~mm}$ were intentionally loaded beyond their yield strengths as a result of autoclave pressures and temperatures up to $\sim 16 \mathrm{MPa}$ and $\sim 350^{\circ} \mathrm{C}$, respectively, in these tests. In all these tests, disparities between LVDT and micrometer measurements with respect to final lengths were found to be very small $(<0.9 \%)$. 
These disparities correspond with errors in length of $0.26 \mathrm{~mm}$ or less, which is considered to be close agreement given the measurement techniques that were used.
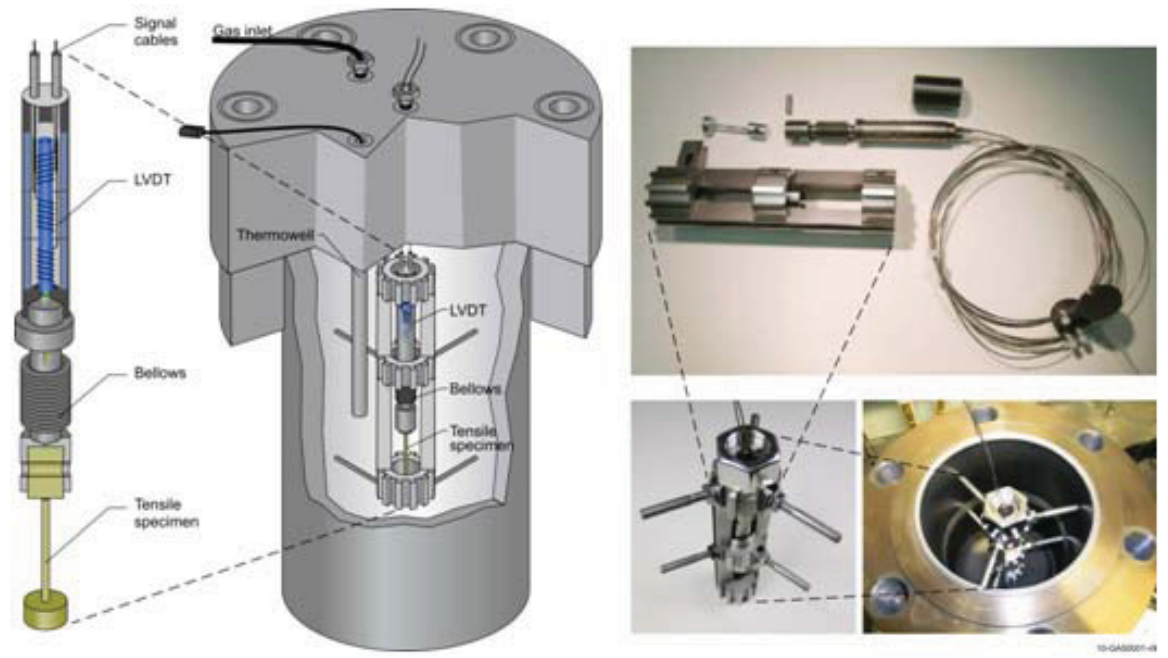

Figure 5-15. Creep test rig positioned in autoclave for testing.

\subsubsection{Ultrasonics}

Although LVDTs have been successfully deployed at other test reactors and are being investigated for ATR applications, ultrasonics offer the potential for a more compact, higher temperature, more accurate, and multi-dimensional real-time sensor for detecting geometry changes during irradiation. In FY10, INL and Pennsylvania State University (PSU) initiated an investigation to evaluate the feasibility of ultrasonic testing (UT) for detecting geometry changes.

UT utilizes high frequency sound waves to examine a given specimen. A transducer is used to convert an electrical signal to mechanical vibrations which transmits the ultrasonic waves into the specimen. After propagating through the specimen, the ultrasonic waves are either reflected back to the transmitter (pulse-echo mode) or are picked up by a second transducer (through-transmission mode). The received signal is then converted back into an electrical signal by one of the transducers. The recorded waveform can then be analyzed to determine various properties of the structure. For example, the time-of-flight in a creep specimen will increase due to specimen elongation. Also, the plastic deformation associated with creep can alter the frequency spectrum of the received signal.

The use of ultrasonic inspection techniques as an in-pile sensor is challenging for two reasons. First, typical operating conditions $\left(350^{\circ} \mathrm{C}\right)$ are well above the Curie temperature of piezoelectric transducer materials ${ }^{107}$ and the transducer will stop functioning. Second, piezoelectric transducers are typically not suitable for radiation exposure. Radiation can damage piezoelectric transducer materials and degrade their performance. ${ }^{108-109}$ Furthermore, 
conventional piezoelectric transducers often contain elements, such as lead, lithium, and gold, that transmute into toxic substances.

One possible solution is to locate the transducer outside of the radiation environment and transmit the ultrasonic waves to the specimen via a wire waveguide. ${ }^{110-111}$ This is possible because of guided wave phenomena. Guided waves occur when the ultrasonic waves interact with the boundaries (surfaces) of a specimen and constructive interference leads to a unique wave structure. Because the boundaries of the specimen contain the ultrasonic energy, a specimen can be interrogated at the end of a very long waveguide.

During FY10, efforts were initiated to identify and optimize key components of a candidate in-pile setup based on this approach. As shown in Figure 5-16, the setup included a magnetostrictive transducer (e.g., driver coil and a Remendur wave guide), a coupling between the Remendur guide, a long stainless steel wave guide that allows the transducer to be located outside of the reactor, and a creep specimen with an "acoustic horn." Testing demonstrated that energy can be transmitted into the sample and can be received in both pulse-echo and through-transmission mode. (A through transmission signal was monitored using a contact piezo $1.5 \mathrm{MHz}$ broadband transducer). Testing also demonstrated that the use of a magnetostrictive sleeve (Figure 5-17 shows candidate designs) could provide a temporary alternative for a brass joint to connect magnetostrictive material to stainless steel. However, results suggest that the laser weld used to join the acoustic horn to the 30 foot wave guide hinders transmission and reception of the signal. A coupling method was developed that allows the magnetostrictive transducer to be directly coupled to a 30 foot long stainless steel waveguide with minimal loss in signal. Welding methods were tested to determine a suitable way to attach the 30 foot long waveguide to the creep specimens. Results indicate that TIG and butt welding can provide good mechanical strength and minimal loss in the ultrasonic signal. The electronics for performing the measurements were tested to optimize measurement variables. Computer programs were written to perform data collection and increase system automation.

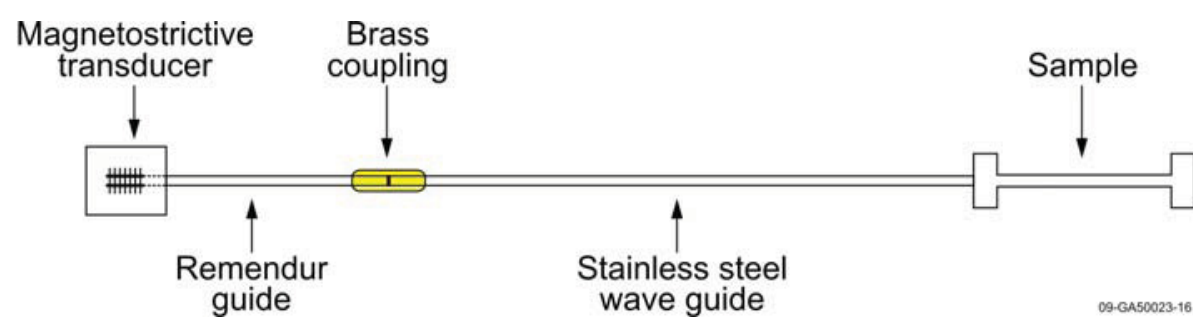

Figure 5-16. Typical setup for detecting sample length changes with an ultrasonic transducer.

Using the equipment shown in Figure 5-18, bench-top tests were completed to investigate this design. The setup includes the magnetostrictive transducer (e.g., driver coil and the Remendur and magnetostrictive sleeve), a coupling, the stainless steel wave guide, and the sample. Testing considered the sample geometry shown in Figure 5-18 because prior evaluations ${ }^{110}$ indicate that this acoustic horn minimizes losses of the reflected signal at the waveguide/sample interface. Evaluations included several different sets of electronics to optimize the signal. 

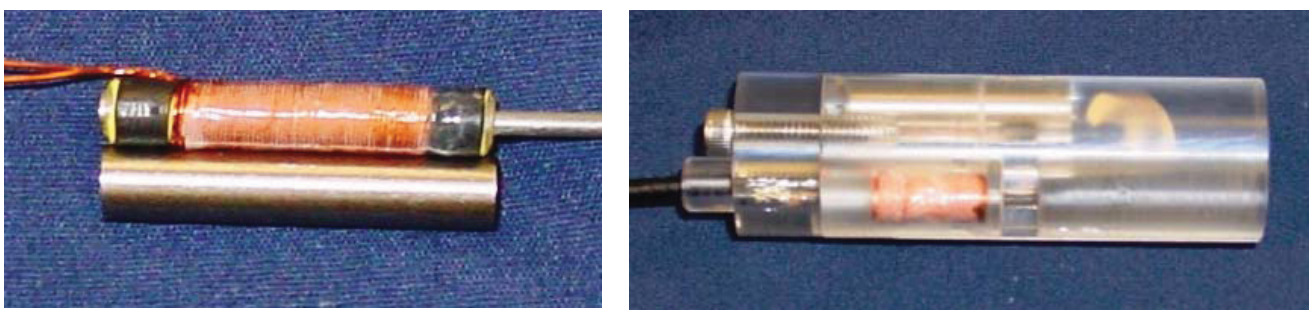

Figure 5-17. Candidate magnetostrictive sleeve designs investigated.

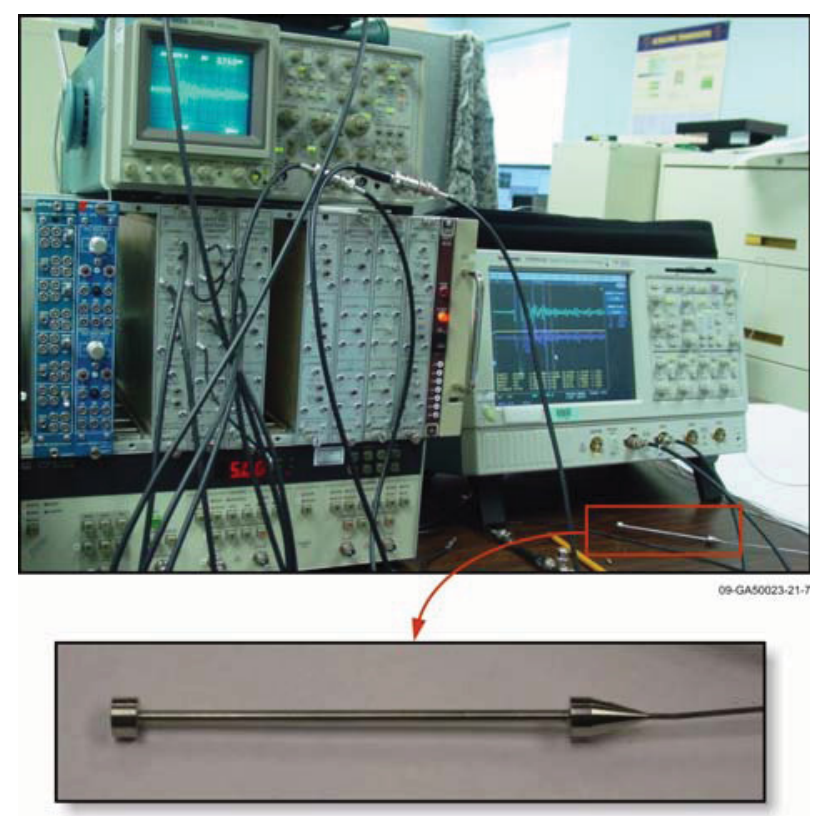

Figure 5-18. UT testing equipment evaluating specimen attached to acoustic horn and $30 \mathrm{ft}$ wave guide.

A tube furnace at INL's HTTL was used to perform preliminary time-of-flight (TOF) measurements on two stainless steel creep specimens at $525^{\circ} \mathrm{F}\left(302^{\circ} \mathrm{C}\right)$. Figure 5-19 compares the recorded waveforms from the 4 inch and 6 inch long specimens. The data indicate a $58.46 \mu \mathrm{s}$ time-of-flight for the 4 inch gage length specimen and a $78.72 \mu$ s time-of-flight for the 6 inch gage length specimen. Thus, the ultrasonic velocity in the gage length of the specimen is approximately $5 \mathrm{~mm} / \mu \mathrm{s}$. This value is consistent with guided wave theory predictions for the cylindrical gage section at $525^{\circ} \mathrm{F}\left(302^{\circ} \mathrm{C}\right)$. In addition, as noted above, the data demonstrate that welding of the specimen to the waveguide allows sufficient transmission of the ultrasonic signal.

A design was developed for testing this setup in an autoclave in FY11. An autoclave system, as shown in Figures 5-20 and 5-21, was recently installed at INL's HTTL. The system accommodates simultaneous ultrasonic testing of two creep specimens inside a 12 in tall pressure vessel. A positive displacement pump capable of a maximum of $17 \mathrm{gal} / \mathrm{h}$, with an independent pulse dampener and a simple back pressure valve, is used to develop the system pressure. Over-pressure protection for the system is provided by a relief valve set at 2800 psi, with backup protection 

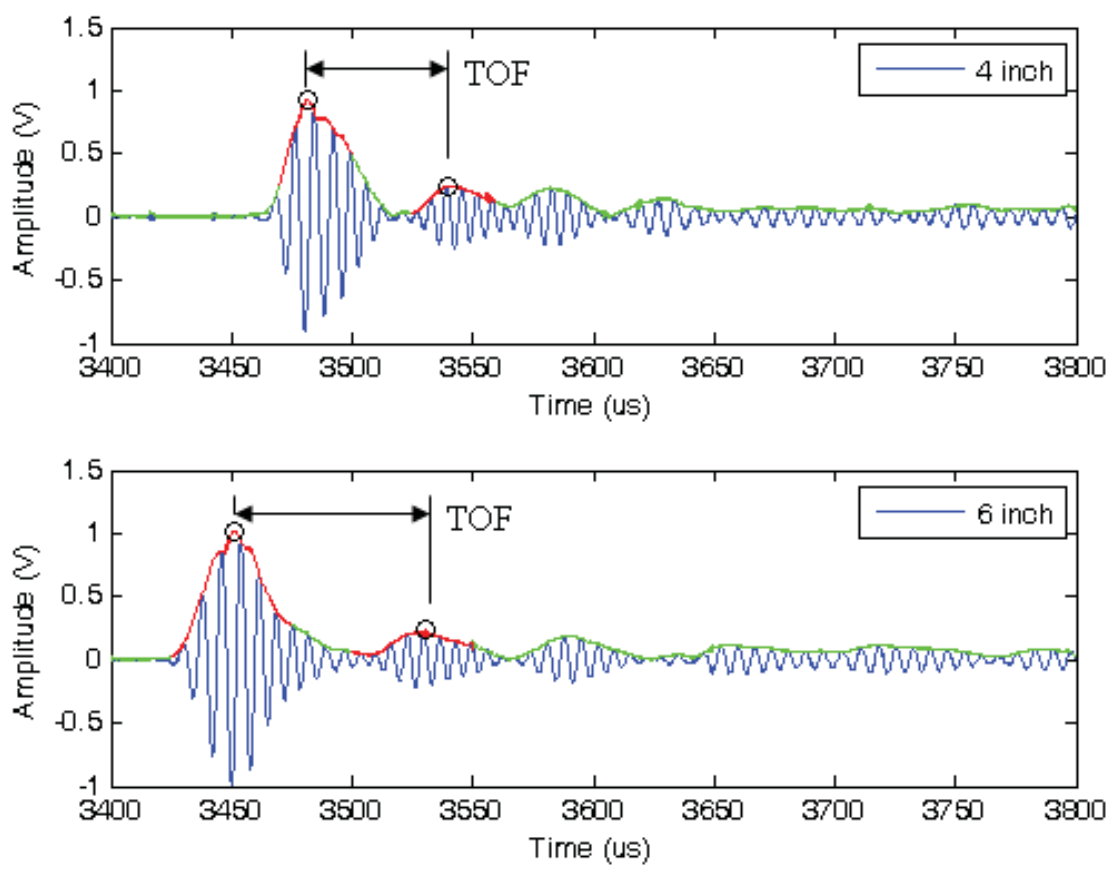

Figure 5-19. Comparison of waveforms from 4 and 6 inch specimens heated at $525^{\circ} \mathrm{F}\left(302^{\circ} \mathrm{C}\right)$.

provided by a 3000 psi rupture disc. Heaters inside the autoclave can be controlled to develop system temperatures as high as $350^{\circ} \mathrm{C}$.

The system pump, drawing suction from the makeup tank, provides flow to the autoclave. A recuperative heat exchanger, followed by a preheater, are installed in the pump-to-autoclave flow path. The recuperative heat exchanger and the preheater are important components that protect the autoclave from thermal shock. Water from the pump enters the recuperative heat exchanger at $\sim 30{ }^{\circ} \mathrm{C}$ and leaves at $\sim 280{ }^{\circ} \mathrm{C}$. Pump-to-autoclave flow then passes through a preheater, where it is heated to $\sim 330{ }^{\circ} \mathrm{C}$ just before entering the autoclave. Autoclave heaters, which are fitted with over-temperature control, can then be used to achieve temperatures as high as $350{ }^{\circ} \mathrm{C}$. Water leaving the autoclave passes through the recuperative heat exchanger and a house water cooler before returning to the makeup tank. A sample port is provided to allow sampling of the system water as appropriate.

Based on autoclave test results, alternate wave guide materials, such as molybdenum or Inconel, may be explored that have higher temperature and better repeatability characteristics. In addition, efforts to optimize the design of the acoustic horn for specimens of interest to ATR customers may be initiated. 


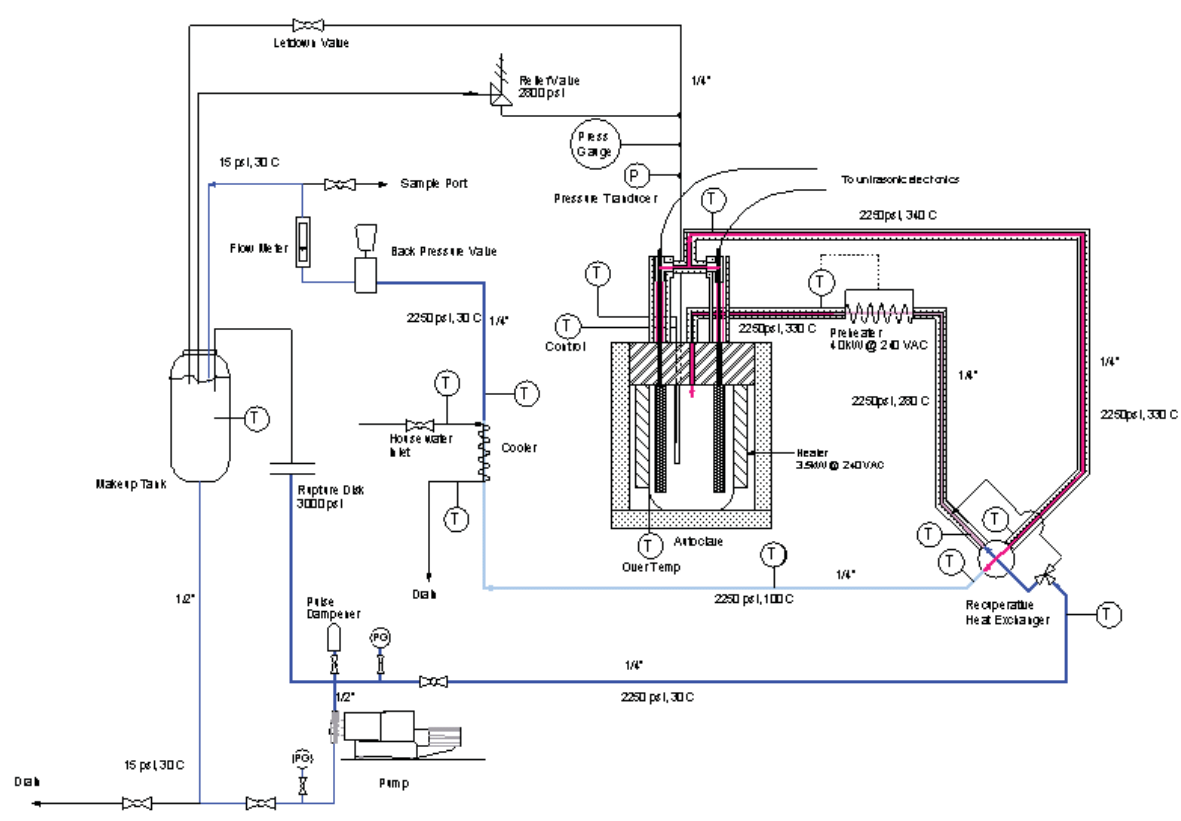

Figure 5-20. Diagram of autoclave setup for ultrasonic evaluations.
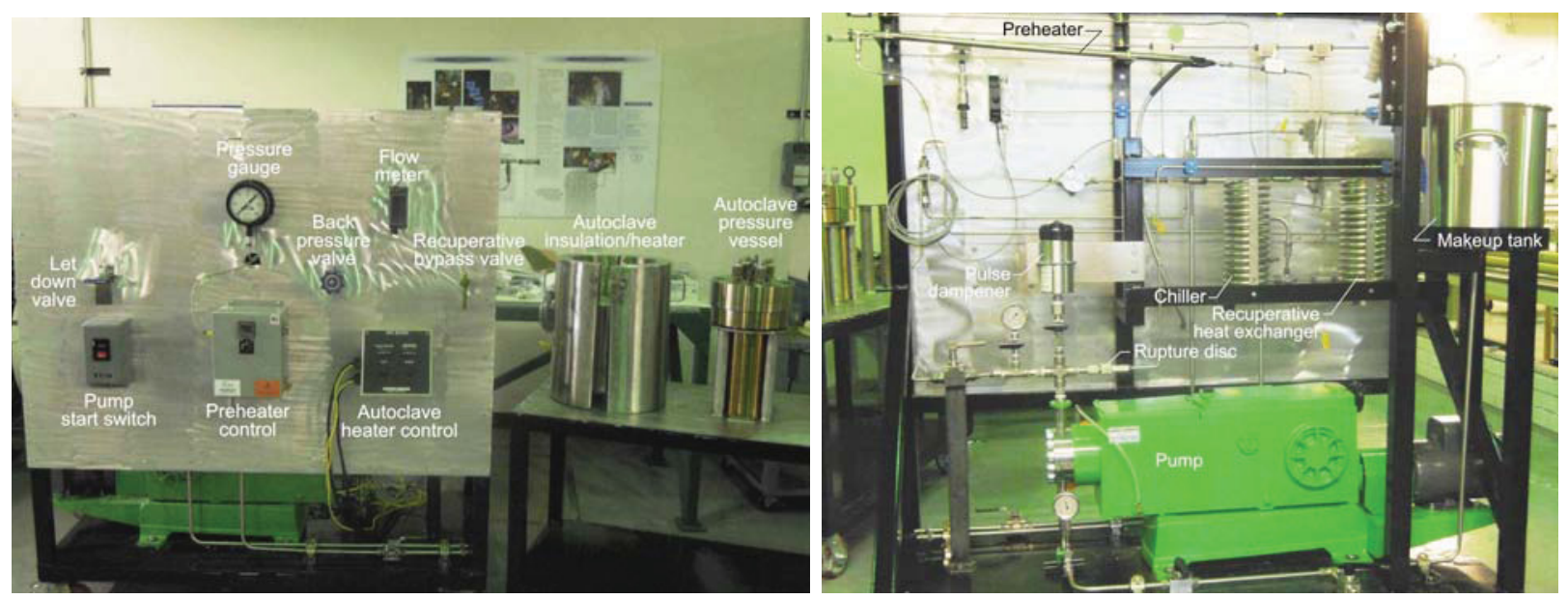

Figure 5-21. New autoclave system installed at HTTL for ultrasonics evaluations.

\subsection{Direct Current Potential Drop (DCPD)}

Crack initiation and growth of samples irradiated in instrumented lead and PWR loop tests in the ATR are evaluated out-of-pile. However, crack-growth rates in core structural component materials irradiated in the HBWR are monitored in-pile using miniaturized Compact Tension (CT) specimens and the "direct current potential drop (DCPD) method." The DCPD method (see Figure 5-22) is based on sending an electrical current through the specimen and measuring the 
potential (voltage) at several locations on the CT-specimen. The measured potentials depend on the propagation of the crack. Thus, the crack-length can be determined from the measured potential drops. IFE/HRP has applied this technology to detect the impact of coolant parameters ( $\mathrm{pH}$, impurities, boron concentration, etc.) on fuel cladding corrosion. In addition, IFE/HRP can perform such measurements on pre-irradiated fuel removed from commercial reactors.

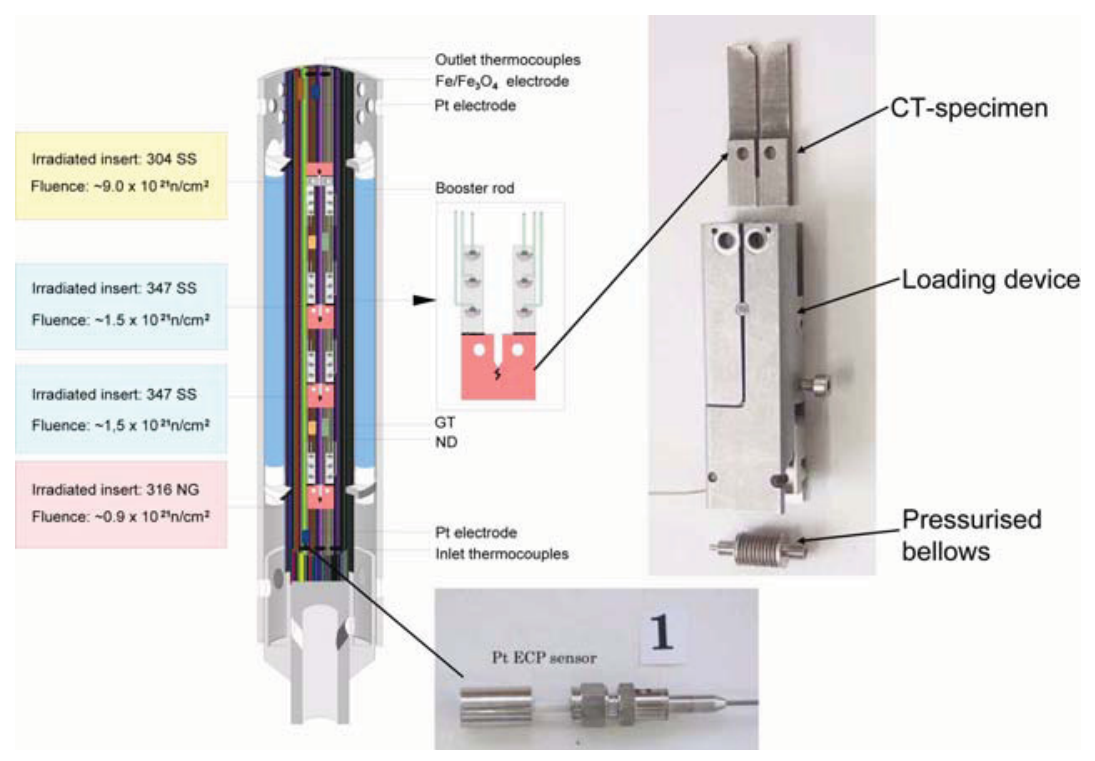

Figure 5-22. Crack growth test rig.

The major aspects of choosing a crack growth measurement technique are: specimen geometry, loading mode (active or passive) and crack length measurement technique. Crack length measurement by the DCPD technique is very well established and has become a de facto standard for in-core measurements. It is applicable to most specimen geometries, although specimen extensions are often used to provide adequate space to connect current leads and voltage probes. As discussed in Reference 115, this method has been applied in several research and test reactors. In addition, this technique has been applied in-core and in recirculation piping autoclaves of commercial BWRs. Some out-of-core measurements have used AC potential drop, but there do not appear to be significant advantages for this technique. Another method frequently applied in out-of-core tests is to measure "crack tip opening displacement" (COD) using a strain gauge. This is a very delicate procedure requiring elements that are not readily adaptable to incore environments. Thus, DCPD is proposed as the reference method for evaluation because of its prior in-core experience and its robust and reliable performance in appropriately designed and constructed systems.

As part of an ATR NSUF-funded effort, MIT developed a conceptual design crack growth test rig design that could be deployed in the ATR. As shown in Figure 5-23, this crack growth test rig contains two crack growth specimens and associated Electrochemical Potential (ECP) electrodes. This unit would be installed in one of the in-core PWR loops. Cables and thermocouples are not shown for clarity, but the design will allow passage of the instrumentation 
cables (e.g., the gas line for the lower specimen, the two ECP cables, and two thermocouples) past the upper specimen and ultimately, out of the test reactor.

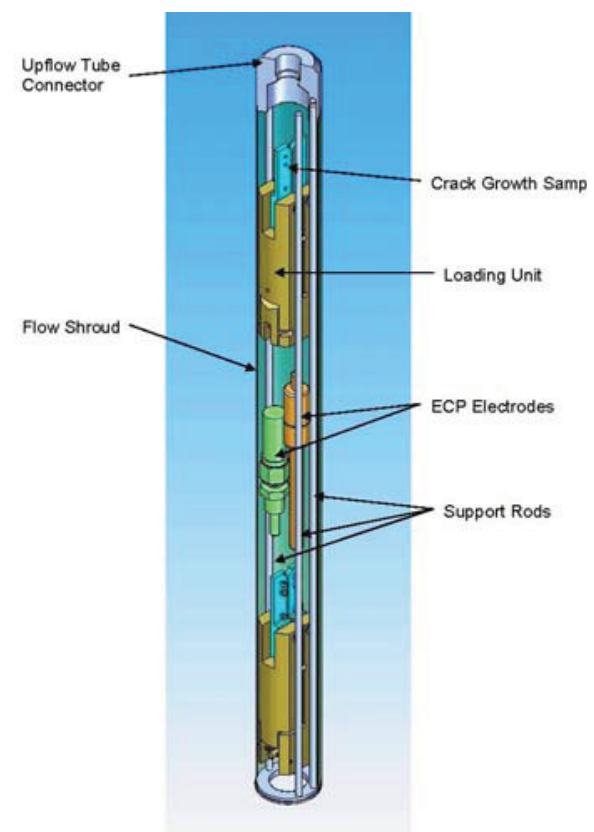

Figure 5-23. Cutaway 3-D rendering of an in-core contains two. Note that this design is for the MITR, but it is anticipated that a similar concept would easily fit within an ATR PWR loop.

For initial autoclave testing, only one crack growth specimen and associated auxiliary systems would be tested. An isometric drawing of the crack growth specimen is shown in Figure 5-23 with preliminary values for dimensions. The design of the specimen follows the requirements of ASTM E399-086 with the exception of the specimen thickness as discussed above. The posts shown are to facilitate connection of the mineral-insulated cable DCPD leads. Knife edges are provided to measure crack tip opening displacement during loading tests and fatigue pre-cracking (out of core). Figure 5-24 shows an isometric view of the proposed loading system with a specimen installed. Proposed dimensions for this system are also shown. The loading system incorporates a customized miniature bellows assembly.
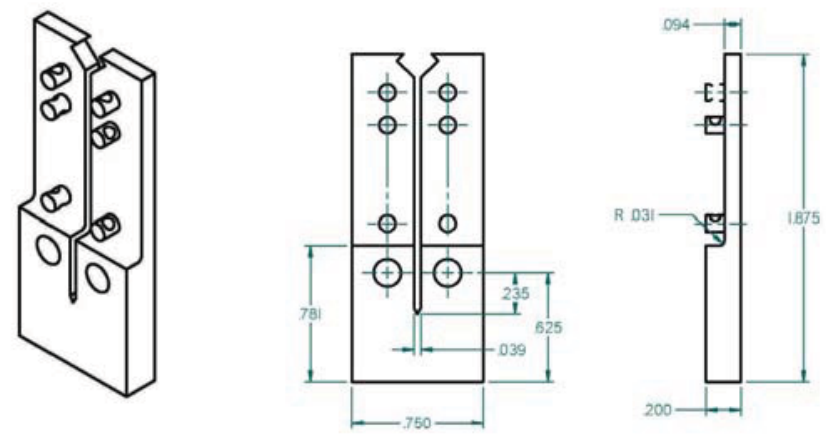

Figure 5-24. Isometric and dimensioned drawing of proposed crack growth specimen. 
A multi-year development program is needed to finalize the MIT-proposed design, complete laboratory tests in an autoclave, and demonstrate in-pile capabilities by completing irradiation testing at the MITR. Results from this three year effort will then be used to finalize a design for ATR testing. Unfortunately, FY10 funding limitations precluded building and testing of a prototype of this test rig in an autoclave at the HTTL. If funding is available in FY11, this effort will be resumed.

\subsection{Flux and Fluence}

Typically, ATR tests use flux wires and post-irradiation evaluations to detect the total fluence to which the fuel or sample was exposed. However, as noted in Section 3, MTRs in Norway, France, the Netherlands, Japan, Belgian, and the Republic of Korea routinely incorporate self-powered neutron detectors (SPNDs) during irradiation tests to gain real-time knowledge of the fission reaction rate. In recent years, French and Belgium test reactors have also incorporated specialized fission chambers to provide users real-time data related to neutron flux (see Section 3).

A joint Idaho State University (ISU)/ INL ATR NSUF project was initiated in FY10 to evaluate new real-time state-of-the-art in-pile flux detection sensors. Initially, the project is comparing the accuracy, response time, and long duration performance of several activation sensors (see Figure 5-25) and real-time flux sensors (see Figures 5-26), including French Atomic Energy Commission (CEA)-developed miniature fission chambers, specialized self-powered neutron detectors (SPNDs) developed by the Argentinean National Energy Commission (CNEA), specially developed commercial SPNDs, and back-to-back fission (BTB) chambers ${ }^{\mathrm{a}}$ developed by Argonne National Laboratory (ANL) for the Zero Power Physics Reactor (ZPPR) programs. During FY 2010, specialized fixturing was designed, fabricated, and installed for evaluating realtime flux detectors in six of the N-16 positions in the ATRC and integral fluence detectors in the NorthWest Large In-Pile Tube (NW LIPT) flux trap (the largest irradiation facility in the ATRC). Flux detector testing started in October 2010. Foils were irradiated in the NW LIPT and real-time flux detectors (e.g., SPNDs and fission chambers) were tested. During this time, researchers from CEA and ISU were present to assist in evaluations. An unplanned shutdown during the initial evaluations prematurely halted ATRC testing. Testing is anticipated to resume in March 2011. Additional fixturing will be also be developed in FY11 that will allow simultaneous evaluations of two or more sensors in the NW LIPT.

This section highlights some aspects of this effort are summarized below. Additional details may be found in Reference 117.

a. BTB fission chambers are often called $2 \pi$ fission chambers because they are designed to count almost all fission fragments emitting from a thin deposit in a $2 \pi$ solid angle. 

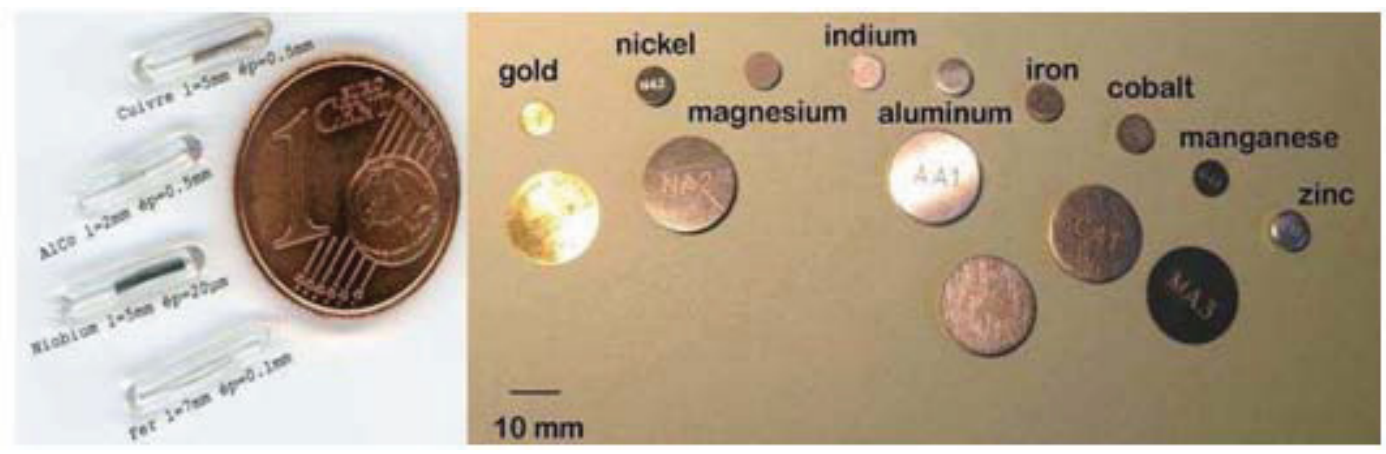

Figure 5-25. Representative activation foils and wires.
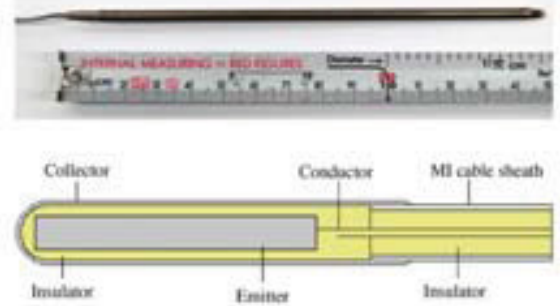

a) SPNDs

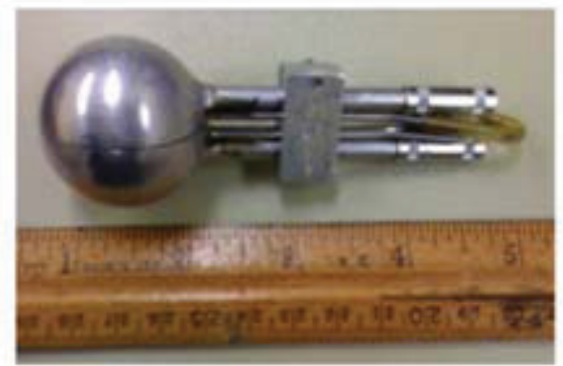

c) BTB Fission Chambers

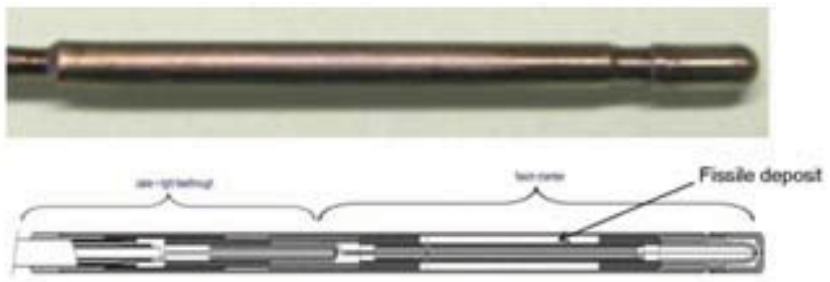

b) CEA Fission Chambers

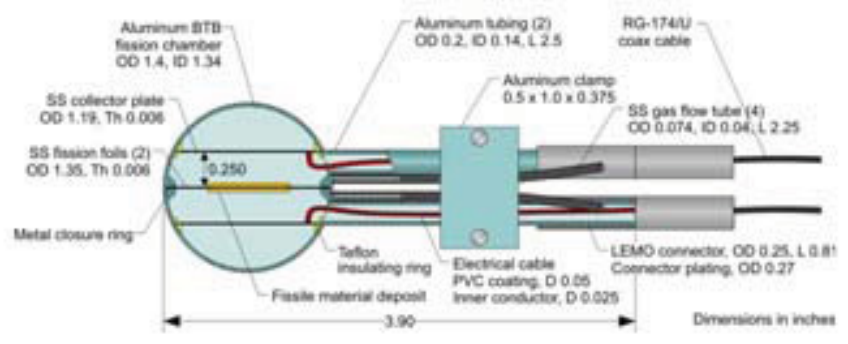

Figure 5-26. Representative real-time flux sensors evaluated at ATRC.

\subsubsection{Activation Foils}

Because the sensitivity of different foil materials to neutron energies varies, a selection of foil materials are included in these evaluations. As shown in Figure 5-27, some foils are placed inside standard 40-mil (1 mm) cadmium foil covers or boron-10 spectral modification shields to enhance their response in the epithermal and fast neutron ranges. These foils are from a very well-characterized inventory of foils used at the INL over a period of many years. 
The foils are activated in the ATRC NW LIPT. As shown in Figure 5-27 (Case 1), the foils used for thermal and epithermal neutron measurements are placed in covered aluminum strips that fit into a square holder, which in turn, fits into the square cavity in the cylindrical LIPT insert. A second fitting (Case 2 of Figure 5-27) that goes directly into the square cavity of the cylindrical insert is used to hold the boron sphere, which will contain the foils used for the fastneutron spectral range. The insert fittings shown in Figure 5-27 have O-rings around their cavities to keep the contents out of contact with the reactor water.

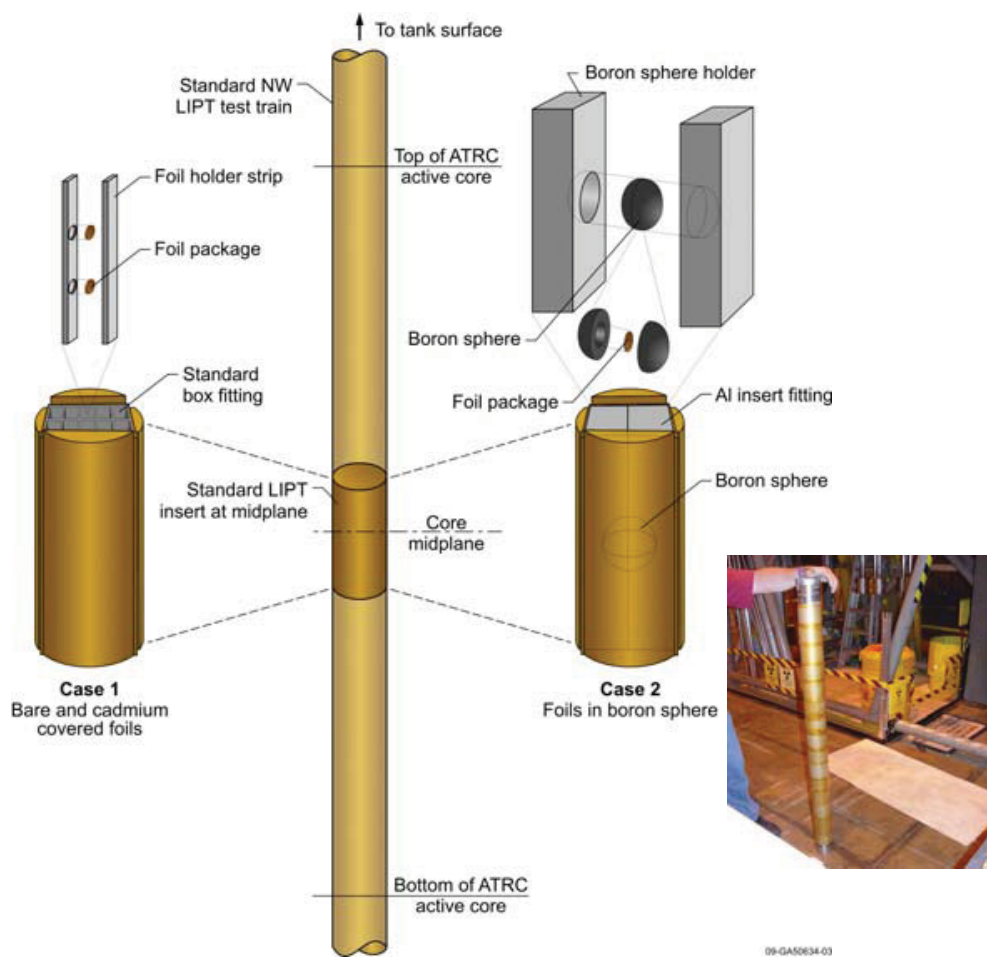

Figure 5-27. Positioning of activation detector apparatus in the ATRC NW IPT Test Train (the inset photo shows the entire test train assembly).

The typical NW LIPT experimental arrangement, referred to as a Test Train, consists of several standard anodized aluminum sample holders that are assembled together and then put inside of an aluminum shroud that fits inside of the NW LIPT. The Test Train rests on the bottom of the LIPT at an axial height of -28 inches from core mid-plane. The height of the test train is adjusted with a nosepiece that is adjustable from 2-4 inches. The test train runs the entire length of the core to provide a symmetric axial flux profile.

Co-normalization of flux from separate reactor runs is accomplished using measured activation of standard copper/gold (1.55\% Au by weight) flux wires at specific locations within the insert fittings as well as in the fuel elements. The $\mathrm{Cu} / \mathrm{Au}$ flux wires for these evaluations are also well-characterized by historical data. In addition, a set of activation measurements for the balanced outer shim critical configuration is made with standard ATRC uranium/aluminum flux wires mounted at the axial mid-plane of all odd-numbered $(1,3,5$, etc.) fuel elements using 
standard ATRC flux wands to determine the fission rate distribution throughout the ATRC core. The U/Al flux wires used in these measurements are typical for ATRC power measurements.

\subsubsection{Real-time Flux Sensors}

For testing, flux sensors are encased in tinted Lucite tubes to prevent any unwanted leakage of component materials (if they are not leak-tight) and to reduce unwanted noise from having sensor cabling in contact with metal surfaces. As shown in Figure 5-28, sensors are inserted into the ATRC N-16 positions using specially-designed Experimental Guide Tubes (EGTs). The EGTs are primarily fabricated from aluminum to minimize their weight. However, selected components, such as the guide tube shown in Figure 5-28, are made from stainless steel 304. As illustrated in Figure 5-28, the six EGTs mechanically position detectors at a specified vertical location in the four N-16 exterior positions and two Center Flux Trap N-16 positions. The position control and detector response are controlled and measured via LabView to allow all detectors to either individually or simultaneously move and measure the local neutron flux and provide a 3-dimensional measurement of the overall neutron flux. The EGTs are supported above the reactor by attaching to the reactor control bridge.

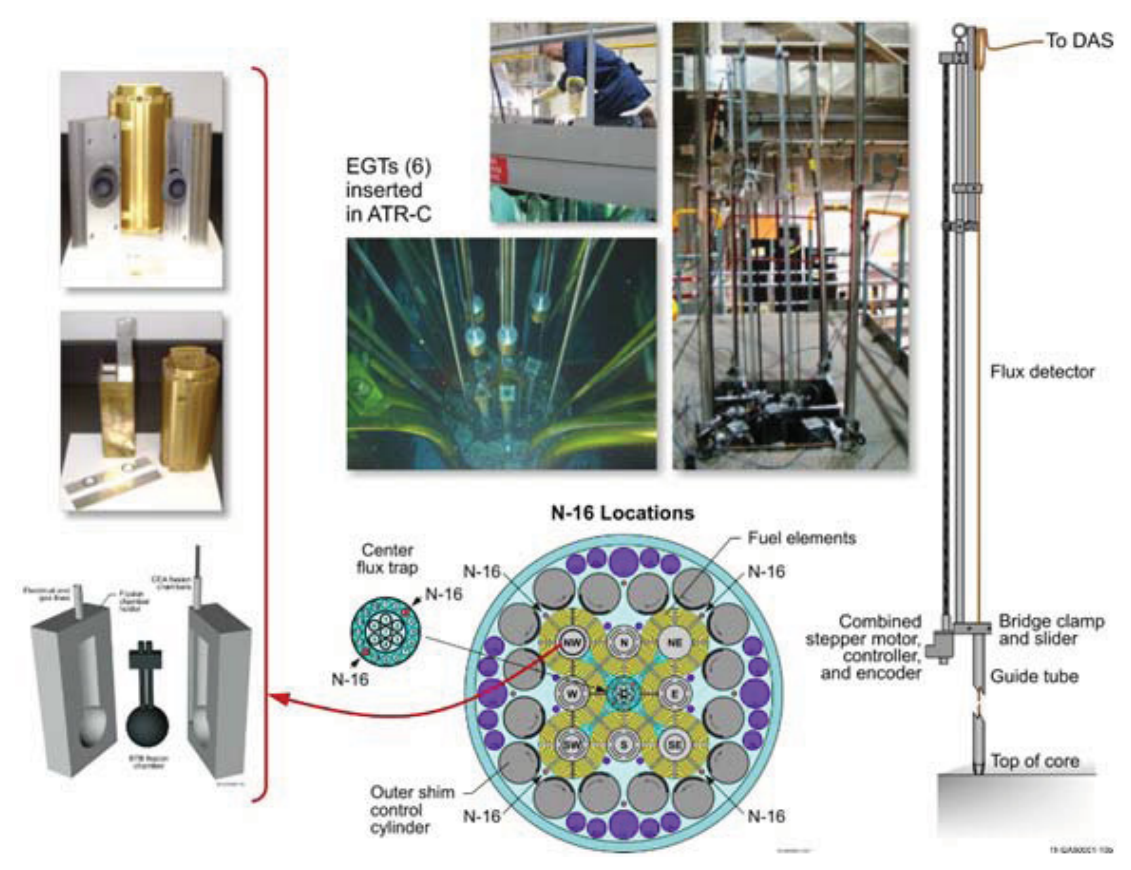

Figure 5-28. Specialized fixturing for flux detector evaluation in the NW LIPT (left) and EGTs for evaluations in six N-16 positions (right)

Tests are completed for three different critical configurations of the outer shim cylinders: balanced; tilted toward the NW flux trap; and tilted away from the NW flux trap. For each configuration, measurements are obtained for at least four intermediate power levels between 1 milliwatt and $600 \mathrm{~W}$. At $600 \mathrm{~W}$, axial flux measurements are obtained by varying detector 
positions using the EGTs. The response and accuracy of each type of flux detector is compared. In addition, data obtained from real-time flux sensors are compared to results from activation analysis.

The EGTs are designed so that they can be easily removed from the reactor control bridge so they will not be in the way for other experiment or fuel handling. When not in use, the EGTs will be stored on a rack located in the northwest end of the ATRC canal.

Ultimately, the results of this effort will be used to select the detector that can provide the best online regional ATRC power measurement. It is anticipated that this may offer the potential to increase the ATRC's current power limit and its ability to perform low-level irradiation experiments using the specialized fixturing and software developed in this project. In addition, the data should provide insights about the viability of using these detectors in the ATR. Hence, this effort complements current activities to improve ATR software tools, computational protocols and in-core instrumentation under the ATR Modeling, Simulation and V\&V Upgrade initiative, as well as the work to replace nuclear instrumentation under the ATR Life Extension Project (LEP) and provide support to the ATR NSUF.

In addition to real-time flux detectors needed for ATR and ATRC testing, there is significant (e.g., up to $30 \%$ ) uncertainty associated with real-time flux detector data. Hence, tasks performed in this effort offer significant benefit to MTRs because of the new capability that will be available to 'calibrate' flux detectors for precise flux measurements.

\subsection{Summary}

As outlined in this section, INL has initiated efforts to develop and obtain new sensors for measuring key parameters (e.g., temperature, length, diameter, etc.) during irradiation testing at the ATR. As discussed in Section 4, initial efforts are focussing on sensors that can provide data needed for ATR NSUF users and on "lower risk" technologies that are already deployed at other MTRs. These initial efforts have led to three new or enhanced sensors becoming available to ATR users: the doped Mo/Nb HTIR-TCs (Section 5.1.3), silicon carbide temperature monitors (Section 5.1.2), and enhanced melt wire selection and encapsulation options (Section 5.1.1). During FY11, it is anticipated that efforts to evaluate a creep test rig in an autoclave at the HTTL will yield a fixture ready for deployment in an ATR PWR loop. In addition, laboratory evaluations of an in-pile technique for detecting changes in average thermal conductivity are continuing and an evaluation of conductivity probe performance in an MITR fuel irradiation will be completed. During FY11, efforts will also be initiated to evaluate the viability of using miniature fission chambers developed by CEA and other flux detection systems (e.g., SPNDs) at the ATRC. In addition, efforts to explore the use of ultrasonic transducers for in-pile detection of elongation and temperature will continue. If sufficient funding is available, efforts will be initiated to further develop and test the crack growth conceptual design described in Section 5. 
INL/EXT-11-21231 


\section{REFERENCES}

1. J. L. Rempe, et al., Instrumentation to Enhance Advanced Test Reactor Irradiations, INL/EXT-08 -13985, September 2009.

2. "FY2009 Advanced Test Reactor National Scientific User Facility User's Guide," INL/EXT-0713577, Idaho National Laboratory, 2008.

3. S. B. Grover, "Irradiation Facilities at the Advanced Test Reactor," Transactions of the 11th International Topical meeting on Research Reactor Fuel Management and Meeting of the International Group on Reactor Research, March 2007, Lyon, France.

4. R. V. Furstenau and S. Blaine Grover, "The Advanced Test Reactor Irradiation Facilities and Capabilities," Proceedings of the Americas Nuclear Energy Symposium 2002 (ANES 2002), October 2002.

5. F. M. Marshall, "Advanced Test Reactor Capabilities and Future Operating Plans," presented at Test Research and training Reactors (TRTR) Annual Meeting, September 2005, Gaithersburg, MD.

6. C. J. Stanley and F. M. Marshall, "Advanced Test Reactor - A National Scientific User Facility," proceedings ICONE2008-48426, May 11-15, 2008, Orlando, Florida, USA.

7. A. J. Palmer, G. L. McCormick, S. J. Corrigan, "Hydraulic Shuttle Irradiation System (HSIS) Recently Installed in the Advanced Test Reactor (ATR)," Proceedings of ICAPP '10, Paper 10354, San Diego, CA, USA, June 13-17, 2010

8. International Atomic Energy Agency, "Nuclear Research Reactors in the World," www.iaea.or.at/worldatom/rrdb/, accessed January 10, 2008.

9. G. Bignan and J-P Chauvin, "JHR Project - A New High Performance Test Reactor in Europe Status June 2008," presentation at the Idaho National Laboratory, Idaho Falls, ID, June 2008.

10. H. Thoresen and S. Solstad, An overview of nuclear fuels and materials research at the OECD Halden Reactor Project, seminar presented at the Idaho National Laboratory, Idaho Falls, ID, July 15, 2008 .

11. J. Guidez, D. Iracane, and P. Ledermann, "Research Reactor Needs, Nuclear Engineering International, December 2007, p. 12.

12. J. Ahlf, “The High Flux Reactor Petten - Present Status and Prospects," Conf. 9002100, p 43.

13. J.F. Villard, "Innovative in-pile instrumentation developments for irradiation experiments in MTRs,” IGORR 10, Gaithersburg, Sept. 2005.

14. J. F. Villard, "INSNU Project - Instrumentation for Irradiation Experiments in Research Reactors," presentation at the Idaho National Laboratory, Idaho Falls, ID, June 2008.

15. J. F. Villard, "INSNU Project - Instrumentation for Irradiation Experiments in Research Reactors," presentation at CEA-Cadarache, Cadarche, France, October 2008. 
16. J-F Villard and M. Schyns, "Advanced In-Pile Measurements of Fast Flux, Dimensions, and Fission Gas Release," Proceedings of the ANS NPIC HMIT 2009 Topical Meeting on Nuclear Plant Instrumentation, Controls, and Human Machine Interface Technology, Knoxville, TN, April 2009.

17. D. Iracane, G. Bignan, Ph. Guimbal, and J-F. Villard, "Advanced Instrumentation for Irradiation Experiments in Material Testing Reactors (MTRs)," Proceedings of the First International Conference on Advancements in Nuclear Instrumentation, Measurement Methods and their Applications (ANIMMA), Marseille, France, June 2009.

18. C. Blandin, S. Breaud, JM. Laurens, L. Oriol, L. Vermeeren, M. Weber "In-pile CFUZ53 sub-miniature fission chambers qualification in BR2 under PWR conditions - 10th International Group on Research Reactors (IGORR) meeting, Gaithersburg (USA), September 2005.

19. S. Fourrez, G. Bailleul, M. Kollen, JF. Villard, "Characterisation of a thermocouple for high temperature measurement under irradiation - Definition and properties of the Molybdenum Niobium thermocouple, 12thInternational Metrology Congress, Lyon (France), June 2005.

20. J. F. Villard, S. Fourrez, "High temperature measurement needs for irradiation experiments in Material Testing Reactors - Development of a new type of thermocouple and interest of high temperature fixed points for its characterisation and in-pile qualification," Physikalisch-Technische Bundesanstalt Seminar on High-temperature fixed-points for industrial and scientific applications, Berlin (Germany), April 2005.

21. G. Cheymol, H. Long, J-F. Villard, and B. Brichard, "High Level Gamma and Neutron Irradiation of Silica Optical Fibers in CEA OSIRIS Nuclear Reactor," IEEE Transactions on Nuclear Science, Vol. 55, No. 4, August 2008, pp 2252-2258.

22. G. Cheymol, B. Brichard, J.F. Villard, "Fiber optics for metrology in nuclear research reactors applications to dimensional measurements," ANIMMA International Conference, Marseille, 7-10 June 2009.

23. M. F. Narbey, D. Baron, G Despaux, JM Saurel, "Determination of the composition of a gas mixture in a nuclear fuel rod by an acoustic method," Journal of the British Institute of Non-Destructive Testing (INSIGHT), 42, 603-605 (2000).

24. J.Y. Ferrandis, G. Leveque, F. Augereau, E. Rosenkrantz, D. Baron, J-F. Villard, "An ultrasonic sensor for pressure and fission-gas release measurements in fuel rods for pressurised water reactors, 9th International conference on CANDU fuel, Belleville (Canada), September 2005.

25. F. Augereau, J.-Y. Ferrandis, J.-F. Villard, D. Fourmentel, M. Dierckx, and J. Wagemans, "Effect of intense neutron dose irradiation on piezoceramics," Transactions from Acoustics '08, June 29July 4, 2008, Paris, France.

26. F. Algaber, JY. Ferrandis, F. Augereau, J-F. Villard, "PZT Materials under Gamma irradiation," 4th European Workshop on Piezoelectric Materials, Montpellier (France), July 2004. 
27. Moilanen, P., Tahtinen, S., Singh, B.N.; and Jacquet, P., "In-Situ Investigation of the Mechanical Performance and Life Time of Copper - Final report on design, construction, and calibration of test module for in-reactor tensile tests in BR-2 reactor," VTT Report BTUO 76-031127, October 27, 2004.

28. B. Aarset, "In-reactor Instrumentation for Fuel Behavior Studies at the OECD Halden Reactor Project," Proceedings from the Conference on Fast, Thermal, and Fusion Reactor Experiments, $\mathrm{p}$ 1-85 through 1-96, April 12-15, 1982, Salt Lake City, Utah.

29. O. Aarrestad and H. Thoresen, "Fuel Rod Performance Measurements and Re-Instrumentation Capabilities at the Halden Project," In-core instrumentation and core assessment: proceedings of a Specialists' Meeting, Mito-shi, Japan, 14-17 October, 1996.

30. C. Vitanza, "On-line fuel rod performance measurements and fuel inspection applications," Kerntechnik, 56, 1991, pp 124-130.

31. S. Solstad, HRP, email to J. Rempe, INL, February 6, 2008.

32. W. Wiesenack, "Experimental Techniques and Results Related to High Burn-up Investigations at the OECD Halden Reactor Project, Proceedings of a Technical Committee Meeting held in Pembroke, Ontario, Canada, April 28 - May 1, 1992, IAEA-TECDOC-697, p. 118.

33. P. Bennett, "In-core Measurements of Fuel-Clad Interactions at the Halden Reactor," IAEA Technical Meeting on Fuel Rod Instrumentation and In-Pile Measurement Techniques, Halden, Norway, 3-5 September 2007.

34. P. Bennett and T. Karlsen, "In-core Corrosion Monitoring in the Halden Test Reactor," Energy Materials: Materials Science and Engineering for Energy Systems, 3, 2, June 2008, pp. 81-90.

35. S. Solstad and R. Van Nieuwenhove, "Instrument Capabilities and Developments at the Halden Reactor Project," Proceedings of the ANS NPIC HMIT 2009 Topical Meeting on Nuclear Plant Instrumentation, Controls, and Human Machine Interface Technology, Knoxville, TN, April 2009.

36. K. Tsuchiya, "Irradiation Technology Development in JMTR" and "New JMTR," presentation and handouts provided to J. Rempe at JAEA meeting, September 29, 2009, Oarai, Japan.

37. M. Narui, T. Shikama, M. Yamasaki, and H. Matsui, "Development of High-Temperature Irradiation Techniques Utilizing the Japan Materials Testing Reactor," Basic Studies in the Field of High Temperature Engineering, Second Information Exchange Meeting, Paris, France, 10-12 October, 2001, pp. 145-152.

38. T. Shibata, T. Kikuchi, S. Miyamoto, K. Ogura, and Y. Ishigaki, "Development of the I-I TYpe Irradiation Equipment for the HTTR," Basic Studies in the Field of High Temperature Engineering, Second Information Exchange Meeting, Paris, France, 10-12 October, 2001, pp. 191-199.

39. T. Shikama, M. Narui, T. Kakuta, M. Ishitsuka, K. Hayashi, T. Sagawa, and T. Hoshiya, "Application of Optical Diagnostics in High-Temperature Gas-Cooled Systems," Basic Studies in the Field of High Temperature Engineering, Second Information Exchange Meeting, Paris, France, 10-12 October, 2001, pp. 153-160. 
40. C. Mori, A. Uritanit, T. Kakuta, M. Katagiri, T. Shikama, M. Naikazawa, T. Iguchi, J. Kawarabayashi, I. Kimura, H. Kobayashi, and S. Hayashi, "Measurement Method of In-core Neutron and Gamma-Ray Distributions with Scintillator Optical Fibre Detector and Self -Powered Detector," Basic Studies in the Field of High Temperature Engineering, Second Information Exchange Meeting, Paris, France, 10-12 October, 2001, pp. 161-196.

41. J. Markgraf, D. Perry, and J. Oudaert, "LWR Fuel Rod Testing Facilities in High Flux Reactor (HFR) Petten for Investigation of Power Cycling and Ramping Behavior," Res Mechanica, 13, 1985, 187-210.

42. Email from K. Bakker, NRG, to J. Rempe, INL, dated December 11, 2007.

43. K. Bakker, NRG, discussions with J. Rempe, INL, at Petten, Netherlands, October 2008.

44. P. Blanchard, P. May, and H. Scheurer, "A Machine for the Fatigue Testing of CT type samples in the HFR," Fusion Technology 1982, Proceedings of the 12th Symposium, 2, pp 749-752, 1983.

45. M. A. Fütterer, et al., "Next generation fuel irradiation capability in the High Flux Reactor Petten," Journal of Nuclear Materials,” 392, 2009, pp 184-191.

46. B. G. Kim, et al., "Status and Perspective of Material Irradiation Tests in the HANARO, paper and presentation from the 1st International Symposium on Materials Testing Reactors, JAEA-Oarai, Japan, July 2008.

47. B. G. Kim, K-N Choo, J. M. Sohn, S. J. Park, K.Kim and Y. J. Kim, "Instrumentations for Materials Irradiation Tests in HANARO," Proceedings of the ANS NPIC HMIT 2009 Topical Meeting on Nuclear Plant Instrumentation, Controls, and Human Machine Interface Technology, Knoxville, TN, April 2009.

48. W. Strydom, NESCA, "In-Pile Instrumentation," personal communication to J. Rempe, INL, email, dated February 5, 2008.

49. G. Proctor, "In-Reactor Pressure Vessel Measurements for the PBMR DPP," 3rd International Topical Meeting on High Temperature Reactor Technology (HTR2006), Johannesburg, South Africa, October 1-4, 2006.

50. Standard Guide for Use of Melt Wire Temperature Monitors for Reactor Vessel Surveillance, E706 (IIE), ASTM E 1214-06, dated February 13, 2006.

51. N. F. Pravdyuk, V. A. Nikolaenko, V. I. Kapuchin, V.N. Kusnetsov, in: Ed. D. J. Littler, Proceedings of the Properties of Reactor Materials and the Effects of Radiation Damage, Butterworths, 1962, p. 57.

52. L L. Snead, A. M. Williams, and A. L. Qualls, "Revisiting the use of SiC as a Post Irradiation Temperature Monitor," Effects of Radiation on Materials, ASTM STP 1447, M L. Grossbeck, Ed, ASTM International, West Conshohocken, PA, 2003.

53. L. Snead, ORNL, email to J. Rempe, INL, dated July 31, 2008.

54. L. Snead, ORNL, email to J. Rempe, INL, dated October 15, 2009. 
55. J. L. Rempe, K. G. Condie, D. L. Knudson, and L. L. Snead, "Comparison Measurements of Silicon Carbide Temperature Monitors," IEEE Transactions on Nuclear Science, 57, No. 3, June 2010 .

56. J. Rempe, D. Knudson, K. Condie, J. Daw, H. Ban, B. Fox, G. E. Kohse, S. C. Wilkins, "New Sensors for In-Pile Testing at the ATR NSUF," Proceedings of the First International Conference on Advancements in Nuclear Instrumentation, Measurement Methods and their Applications (ANIMMA), Marseille, France, June 2009.

57. J. Rempe and M. Meyer, "ATR NSUF Instrumentation Enhancement Efforts," Proceedings of the ANS NPIC HMIT 2009 Topical Meeting on Nuclear Plant Instrumentation, Controls, and Human Machine Interface Technology, Knoxville, TN, April 2009.

58. J. L. Rempe, D. L. Knudson, K. G. Condie, and S. C. Wilkins, "Thermocouples for High-Temperature In-Pile Testing,” Nuclear Technology, 156, No. 3, December 2006, pp 320-331.

59. J. L. Rempe, D. L. Knudson, K. G. Condie, and S. C. Wilkins, "High Temperature Thermocouple Design and Fabrication," US patent filed by Battelle Energy Alliance (IDR \#BA-142) on behalf of DOE (Serial Number 11/678,901), published by US PTO as No. 2008/0205483 and issued January 18, 2011, Patent 7871198.

60. J. L. Rempe, D. L. Knudson, K. G. Condie, and S. C. Wilkins, "Long Duration Performance of High Temperature Irradiation Resistant Thermocouples," Proceedings of the 2007 International Congress on Advances in Nuclear Power Plants (ICAPP'07), Nice, France, May 13-18, 2007.

61. J. Rempe, D. Knudson, K. Condie, J. Daw, and S. C. Wilkins, "New Sensors for In-Pile Temperature Detection at the ATR NSUF," Proceedings of the 13th International Topical Meeting on Nuclear Reactor Thermal-Hydraulics (NURETH13), Kanazawa, Japan, October 2009.

62. D. L. Knudson, J. L. Rempe, K. G. Condie, S. C. Wilkins, J. E. Daw, and J. C. Crepeau, "High Temperature Irradiation Resistant Thermocouples - A Low Cost Sensor for In-Pile Testing at High Temperatures," Paper 8222, Proceeding of the 2008 International Congress on Advances in Nuclear Power Plants (ICAPP '08), Anaheim, CA, June 8-12, 2008.

63. J. L. Rempe, D. L. Knudson, K. G. Condie, and S. C. Wilkins, "Thermocouples for High-Temperature In-Pile Testing,” Nuclear Technology, 156, No. 3, December 2006, pp 320-331.

64. J. L. Rempe, D. L. Knudson, K. G. Condie, S. C. Wilkins, J. C. Crepeau, and J. E. Daw, “Options Extending the Applicability of High Temperature Irradiation Resistant Thermocouples," invited paper for NURETH12 Special Edition, Nuclear Technology, 167, July 2009, pp 169-177.

65. J. E. Daw, J. L. Rempe, D. L. Knudson, S. C. Wilkins, and J. C. Crepeau, "High Temperature Irradiation-Resistant Thermocouple Performance Improvements," ANS NPIC HMIT 2009 Topical Meeting on Nuclear Plant Instrumentation, Controls, and Human Machine Interface Technology, Knoxville, TN, April 2009.

66. J. Daw, J. Rempe, and S. C. Wilkins, "Ultrasonic Thermometry for In-Pile Temperature Detection," 7th International Topical Meeting on Nuclear Plant Instrumentation, Control, and Human Machine Interface Technologies (NPIC\&HMIT 2010), Las Vegas, NV, November 7-11, 2010. 
67. M. Laurie, D. Magallon, J. Rempe, S. Wilkins, J. Pierre, C. Marquié, S. Eymery, and R. Morice, "Ultrasonic High Temperature Sensors: Past Experiments and Prospective for Future Use," Joint International Symposium on Temperature, Humidity, and Moisture and Thermal Measurements in Industry and Science, Portorož, Slovenia, May 31 - June 4, 2010.

68. J. K. Partin and G. D. Lancaster, "Radiation Resistant Fiberoptic Inspection Probes," INEELLDRD D043 final report, 1998

69. A.N. Gurzhiev, L.K. Turchanovich, V. G. Vasil'chenko, V. A. Bogatyrjov and V. M. Mashinsky, "Radiation damage in optical fibers," Nuclear Instruments and Methods in Physics Research A, 391 (1997) 417-422.

70. A. N. Paolantonio, "Fiber Optic Half-Life," Electro-Optical Systems Design, August 1982, pp. 3341 (1982).

71. A. I. Gusarov, F. Berghmans, O. Deparis, A. F. Fernandez, Y. Defosse, P. Megret, M. Decreton and M. Blondel, "High Total Dose Radiation Effects on Temperature Sensing Fiber Bragg Gratings," Phot. Technol. Lett., 11, 9, pp. 1159-1161 (1999).

72. H. Liu, D. W. Miller and J. W. Talnagi, "Gamma Radiation Resistant Fabry-Perot Fiber Optic Sensors," Rev. of Sci. Instrum., 73, 8, pp. 3112-3118 (2002).

73. H. Liu, D. W. Miller and J. W. Talnagi, "Neutron Radiation Effects on Fabry-Perot Fiber Optic Sensors," Nuclear Instrum. and Meth. in Phys. Res. A, 507, pp. 691-702 (2003).

74. V. Hagopian, "Radiation Damage of Quartz Fibers," Nuclear Physics B (Proc. Suppl.), 78 (1999) 635-638.

75. T. Shikama, T. Kakuta, M. Narui, T. Sagwa and H. Kayano, "Optical properties in fibers during irradiation in a fission reactor," J. Nuclear Materials 225 (1995) 324-327.

76. T. Shikama, T. Kakuta, N. Shamoto, M. Naruiand T. Sagwa, "Behavior of developed radiationresistant silica-core optical fibers under fission reactor irradiation," Fusion Engineering and Design 51-52, (2000) 179-183.

77. G. Cheymol, H. Long, J.F. Villard, B. Brichard, "High Level Gamma and Neutron Irradiation of Silica Optical Fibers in CEA OSIRIS Nuclear Reactor," IEEE Trans. Nuc. Science, 55 (2008) 2252-2258.

78. R. S. Fielder, K. Klemer, K.L. Stinson-Bagby, "High Neutron Fluence Survivability Testing of Advanced Fiber Bragg Grating Sensors,” Volume 699, pp. 650-657 (2004).

79. Bob Fielder, Luna Innovations, Director Optical Systems Group, Development of High-Temperature, Radiation Resistant Fiber Optic Sensors, presentation at Idaho National Laboratory, Idaho Falls, ID, July 25, 2008. 
80. Bryan D. Dickerson, Matthew A. Davis, Matthew E. Palmer, and Robert S. Fielder, "Temperature Compensated Fiber Optic Pressure Sensor under Combined High Temperature and High Fluence," ANS NPIC HMIT 2009 Topical Meeting on Nuclear Plant Instrumentation, Controls, and Human Machine Interface Technology, Knoxville, TN, April 2009.

81. M. Palmer, Assistant Director, Optical Systems Group, Luna Innovations, email to J. Rempe, INL, May 12, 2008.

82. K. L. Telschow, D.L. Cottle and R. S. Schley, INL Letter Report on LDRD, completed 2005.

83. B. Fox, H. Ban, J. Rempe, D. Knudson, and J. Daw, "Development of an In-pile Technique for Fuel Thermal Conductivity Measurement," Proceedings of the ANS NPIC HMIT 2009 Topical Meeting on Nuclear Plant Instrumentation, Controls, and Human Machine Interface Technology, Knoxville, TN, April 2009.

84. B. Fox, H. Ban, J. Rempe, J. Daw, K. Condie, D. Knudson, "In-Pile Thermal Conductivity Measurement Method for Nuclear Fuels," Thermal Conductivity 30/Thermal Expansion 18, Daniela S. Gaal and Peter S. Gaal (Editor), DEStech Publications Inc., p 886, October 2010.

85. B. Fox, H. Ban, J. Daw, K. Condie, D.Knudson, and J. Rempe, Evaluation of Candidate In-Pile Thermal Conductivity Techniques, INL/EXT-09-16039, May 2009.

86. B. Fox, H. Ban, J. Rempe, J. Daw, K. Condie, and D. Knudson, "In-Pile Thermal Conductivity Measurement Method for Nuclear Fuels," 30th International Thermal Conductivity Conference and 18th International Thermal Expansion Symposium, Pittsburgh, PA, August 29-September 2, 2009.

87. J. Daw, J. Rempe, K. Condie, D. Knudson, S. C. Wilkins, B. Fox, and H. Ban, "Hot Wire Needle Probe for In-Pile Thermal Conductivity Detection," 7th International Topical Meeting on Nuclear Plant Instrumentation, Control, and Human Machine Interface Technologies (NPIC\&HMIT 2010), Las Vegas, NV, November 7-11, 2010.

88. M. Laurie and M. Fütterer, EU JRC, email discussions with J. Rempe, INL, July through August 2009.

89. I. Cohen, B. Lustman, and J. D. Eichenberg, "Measurement of the Thermal Conductivity of MetalClad URanium Oxide Rods during Irradiation," Journal of Nuclear Materials, 3, No 3 (1961), pp 331-353.

90. W.N. Beck and R. J. Fousek, "Fission Gas Release and Thermal Conductivity Measurements on U-5 wt\% F Irradiated in CP-5," Trans. American Nuclear Society, 30, 528, 1978.

91. P. R. Betten, "In-Core Measurements of Uranium-5 wt\% Fissium Alloy Thermal Conductivity," Transactions of the American Nuclear Society, 50, pp. 239-240, November 1985.

92. A. L. E. F. Schleirmacher, Vher die Warmeleitungder gase, Weidemann Ann. Phys. 34, p. 625, 1988. 
93. Standard Test Method for Determination of Thermal Conductivity of Soil and Soft Rock by Thermal Needle Probe Procedure, ASTM D 5334-05, May 27, 2008.

94. M. S. Baghe-Khandan, Y. Choi, and M. R. Okos, "Improved Line Heat Source Thermal Conductivity Probe,” Journal of Food Science, 45, p 1430-1432, 1981.

95. J.J. Healy, J. J. de Groot, and J. Kestin, "The Theory of the Transient Hot-Wire Method for Measuring Thermal Conductivity," Physica, 82C, pp 392-408, 1976.

96. X-G Liang, "The Boundary Induced Error on the Measurement of Thermal Conductivity by Transient Hot Wire Method," Measurement Science Technology, 6, pp 467-471, 1995.

97. P. Prelovsek and B. Uran, "Generalized Hot Wire Method for Thermal Conductivity Measurements,” J. Phs. E: Sci. Instrum., 17, 1984.

98. K. Manohar, D. W. Yarbrough, and J. R. Booth, "Measurement of Apparent Thermal Conductivity by the Thermal Probe Method," Journal of Testing and Evaluation, September 2000.

99. M. Ichikawa, M. Uchida, K Yanagisawa, J. Nakamura and T. Nakajima, "Irradiation Studies of JAERI's Fuel at Halden Reactor,” Journal of Nuclear Science and Technology, 25 [8], pp.609-614, August 1988.

100. M. Ichikawa, T. Fujishiro and S. Kawasaki, "LWR Fuel Safety Research with Particular Emphasis on RIA/LOCA and Other Conditions," Journal of Nuclear Science and Technology, 26(1), pp. 118 125 (January 1989).

101. B. G. Kim, J. Rempe, D. Knudson, K. Condie, and B. Sencer, "An In-situ Creep Testing Capability for the Advanced Test Reactor," submitted to Nuclear Technology, MS 10-58, April 2010.

102. B. G. Kim, J. L. Rempe, D. L. Knudson, K. G. Condie, and B. H. Sencer, "Development of an Insitu Creep Testing Capability for the Advanced Test Reactor," 7th International Topical Meeting on Nuclear Plant Instrumentation, Control, and Human Machine Interface Technologies (NPIC\&HMIT 2010), Las Vegas, NV, November 7-11, 2010.

103. Anter Corporation, see www.anter.com

104. D. L. Knudson and J. L. Rempe, "LVDT Evaluations for ATR Irradiations," Proceedings of the ANS NPIC HMIT 2009 Topical Meeting on Nuclear Plant Instrumentation, Controls, and Human Machine Interface Technology, Knoxville, TN, April 2009.

105. D. Knudson and J. Rempe, "Recommendations for use of LVDTs in ATR High Temperature Irradiation Testing," 7th International Topical Meeting on Nuclear Plant Instrumentation, Control, and Human Machine Interface Technologies (NPIC\&HMIT 2010), Las Vegas, NV, November 711, 2010.

106. D. L. Knudson, J. L. Rempe, and J. E. Daw, Evaluation of Candidate Linear Variable Displacement Transducers for High Temperature Irradiations in the Advanced Test Reactor, INL/EXT09-16972, Rev. 1, to be released.

107. to://www.americanpiezo.com/ 
108. Toacsan, M. I., Ioachim, A., Nedelcu, L. and Alexandru, H. V., "Accelerated ageing of PZT-type ceramics," Progress in Solid State Chemistry 35, 531-537 (2007).

109. Broomfield, G. H., "The effect of low-fluence neutron irradiation on sliver-electroded lead-zirconate-titanante piezoelectric ceramics," J of Nuclear Materials 91, 23-34 (1980).

110. Guers, M. J. and Tittmann, B. R., "Finite element analysis of ultrasonic methods for in-situ monitoring of an ASTM creep specimen" Review of Progress in Quantitative Nondestructive Evaluation, 28, 1394-1401 (2009).

111. Guers, M. J. and Tittmann, B. R., "Influence of temperature on in-situ guided wave inspection and health monitoring of a rectangular bar specimen," Proc. of SPIE 7295, 72950N (2009).

112. R. Bratton, “AGC-1 Irradiation Experiment Test Plan,” INL/EXT-06-11102, May 2006.

113. FUEL MATERIAL TECHNOLOGY REPORT, Volume 1 Prepared by Brian Cox, Friedrich Garzarolli, Ron Adamson, Peter Rudling, Alfred Strasser, Advanced Nuclear Technology International, Krongjutarvägen 2C SE-730 50 Skultuna Sweden, October 2006.

114. V. G. Kritsky, Water chemistry and corrosion of nuclear power plant structural materials, ANS, La Grange Park, Illinois USA, 1991.

115. Gordon Kohse and Yakov Ostrovsky, "Report on Development of In-core Crack Growth Monitors for Use in MITR and ATR,” MIT-NRL 2009-1, July 2009.

116. Standard Test Method for Measuring Neutron Fluence Rates by Radioactivation of Cobalt and Silver, ASTM E481-03, February 2003.

117. Troy Unruh, Joy Rempe, David Nigg, Paul Hart, George Imel, Jason Harris, and Eric Bonebrake, "Flux Sensor Evaluations at the ATR Critical Facility," 7th International Topical Meeting on Nuclear Plant Instrumentation, Control, and Human Machine Interface Technologies (NPIC\&HMIT 2010), Las Vegas, NV, November 7-11, 2010. 
INL/EXT-11-21231

6-10 